\title{
THE STATE OF NETWORK ORGANIZATION: A SURVEY IN THREE FRAMEWORKS
}

\author{
Please forward comments to: \\ Marshall Van Alstyne \\ MIT Sloan School \\ 50 Memorial Drive E53-308 \\ Cambridge, MA 02139 \\ marshall@mit.edu \\ (617) 253-2970
}

Forthcoming in Journal of Organizational Computing (1997), 7(3) 


\begin{abstract}
This article reviews the literature on network organizations and interprets explanations for its behaviors in terms of established analytical principles. Tools from computer science, economics, and sociology give three markedly different interpretations of its core attributes but they also settle on a handful of common themes. The proposed benefits are a clarification of what it means for an organization to be network structured, a few insights into its origins, and a suggestion of where the boundaries to some of its different forms might lie.
\end{abstract}

\title{
ACKNOWLEDGMENTS
}

A helpful network of outstanding reviewers is responsible for many of the ideas appearing in this article. People who deserve special thanks for assistance on various drafts include Yaneer Bar-Yam, Erik Brynjolfsson, David Croson, Liz Davidson, Steve Freeman, Sharon Gillett, Tom Malone, Wanda Orlikowski, Omar Toulon, Chris Tucci, George Wyner, three anonymous reviewers and the guest editor Chee Ching. Any remaining errors are faults of the central processor. The MIT Center for Coordination Science and the MIT Industrial Performance Center provided generous financial support. 


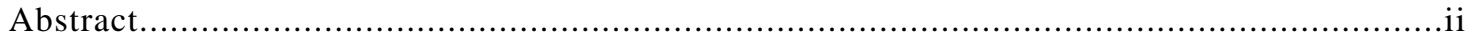

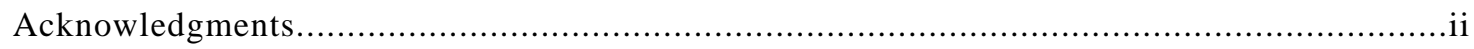

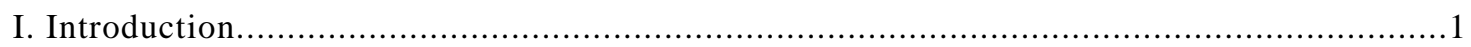

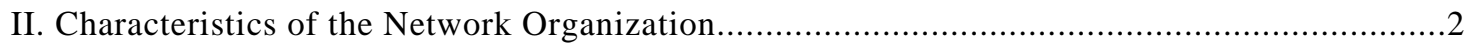

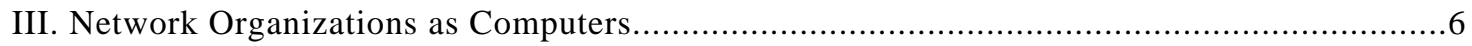

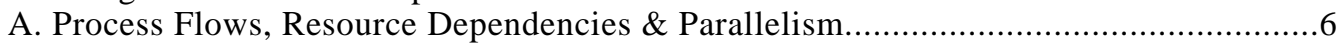

B. Processor Specialization versus Generalization...................................................

C. Vulnerability \& Tolerance to Processor Failure....................................................... 8

D. Communication Channels \& Coordination Costs.................................................

E. Distributed Knowledge, Sensing \& Coherence......................................................11

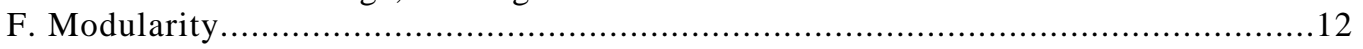

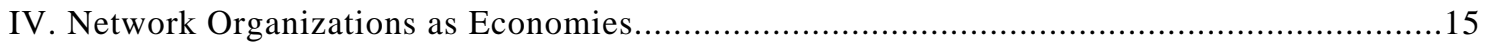

A. Risk \& Information Asymmetry ................................................................. 16

B. Teams, Games \& Self Interest versus Public Good.........................................................17

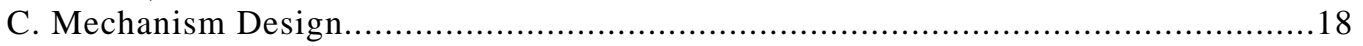

D. Vertical Integration \& Transaction Cost Economics.................................................18

E. Resources \& Property Rights..................................................................... 19

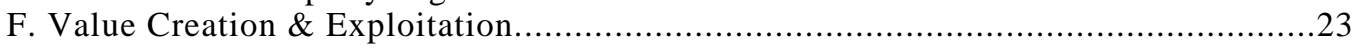

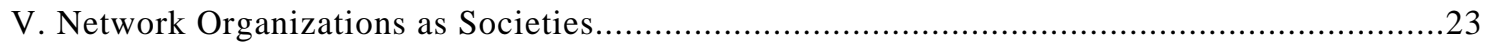

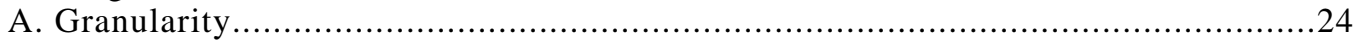

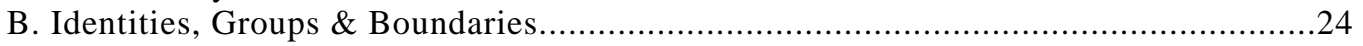

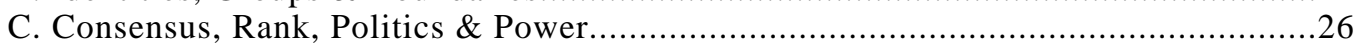

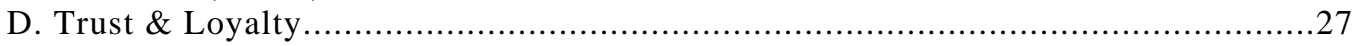

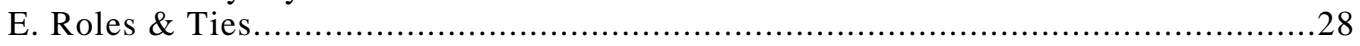

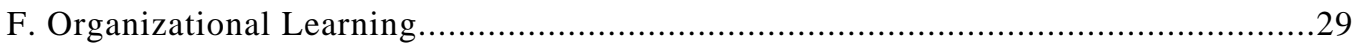

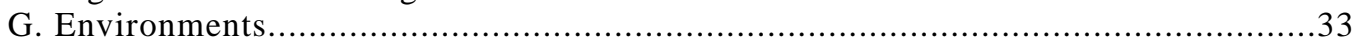

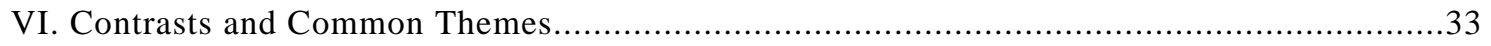

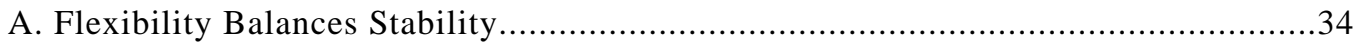

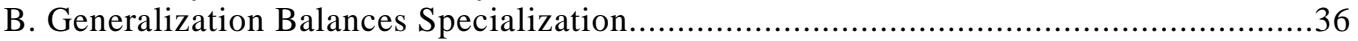

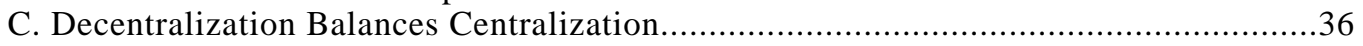

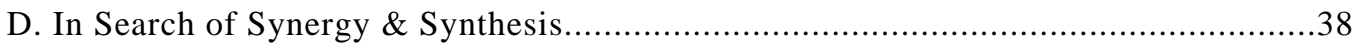

E. Supporting Role of Information and Information Technology ......................................39

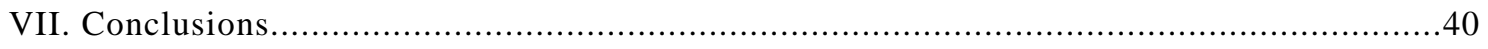

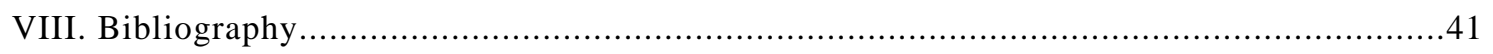

Appendix A -- Illustration of a Solution to the Public Goods Problem..........................................47 


\section{INTRODUCTION}

Novel environments can lead to new structures. Practices that once conferred a competitive advantage can trip, delay, and handicap organizations that continue to employ them. GM faced this problem, for example, when attempting to battle Japanese companies using a legacy of innovations Alfred Sloan had used successfully against Ford [31]. But when environments change, how should organizations be restructured? How should control over resources and people be reformed and by whom? Does reform alter morale? What should be the architecture of the firm?

This article explores the costs, benefits, and design variables of one alternative a "network" organization. This structure exhibits a high degree of flexibility and the first objective is to review the literature on how it moves quickly, manages economically, and responds socially in changing environments. A review helps expose the remarkable diversity of ideas and nomenclature $^{1}$ on networks and also brings different methodologies to bear when interpreting their features. Network organization literature spans empirical case studies and interviews ${ }^{2}$, microworlds and experiments ${ }^{3}$, survey research ${ }^{4}$, formal axiomatic models ${ }^{5}$, general theory ${ }^{6}$, and intra-disciplinary review ${ }^{7}$. With different twists and points of emphasis, the reference disciplines include economics, management, political science, organizational behavior, computer science, artificial intelligence, and law.

\footnotetext{
${ }^{1}$ In addition to "Network Organization" [10, 13, 71, $104,106,120]$, the concept of an association of distinct business units operating in tandem has also been called "Adhocracy" [88, 114], "Alliance Capitalism" [47], "Agile Enterprise" [101], "Cluster Organization" [6, 97], "Interorganizational Relation" [138], "Joint Venture" [58, 76, 118], "MetaCorporation" [121], "Modular Corporation" [131], "Moebius-strip organization" [121], "Organic Organization" [79], " Small Firm Network" [107], "Value-Adding Partnership" [72], and "Virtual Corporation" [20, 28].

2 [10, 37, 66, 79]

3 [80, 124]

${ }^{4}[46,100,132]$

$5[4,11,77,116,122]$

${ }^{6}[13,44,49,67,70,90,107,108,111,117,121$, $137,143]$

${ }^{7}[24,32,38,45,68,76,138]$
}

The second objective of this article is to synthesize results and contrast the explanatory power of competing theories. Structural models, for example, speak to issues of power and influence yet gloss over issues of etiology and efficiency in networks [104]. Efficiency models dictate whether transactions ought to occur inside or outside the firm yet overlook confounding issues of authority and maneuverability. Tools from different disciplines can better triangulate a network's most salient characteristics.

To mark conceptual boundaries, network organization is cast into three metaphorical molds -- the network as computer, economy, and society. These three metaphors draw on established principles of decision processes, of rational agency, and of organizational behavior to help judge different architectural forms. Different theories then provide insights into the appropriateness of network structures for efficient, rational, and social tasks.

Briefly, the computer metaphor models the firm as a decision process dependent on manager capabilities, communication paths, utilization rates, and decision errors while minimizing the costs of decision resources. Persons interested in decision efficiency can engage the computer metaphor, for example, to examine why shifting the locus of decisions alters throughput, errors, and communication costs. The rational agent metaphor augments this interpretation by adding self-interest and guile as factors in the firm's strategic behavior. Persons interested in rational decisions might consider economic tenets when exploring why changing the locus of decisions alters incentives and the ability to act on local information. Finally, the society metaphor marks the network firm as an organization composed of individual people whose actions are constrained by corporate culture and non-economic aspects of human nature. Persons interested in human behavior might invoke this perspective when considering how the same change in decision locus affects trust, power, and roles within the firm.

The abundant vocabulary sprouting from network literature has been likened to a "terminological jungle in which any newcomer may plant a tree" [104, p. 3 citing Barnes]. To avoid this problem, the term "network organization" will refer to homologous structures even when the original author used another term. Exceptions occur only when an author's unique phrasing illustrates novel ideas particularly well. A potential benefit of "network organization" is that it is widely used, relatively neutral, and sufficiently plastic to fit most applications. As its meaning can extend to that of non-eponymous synonyms, it might 
serve to acknowledge contributions from dissimilar fields.

An additional benefit is that "network" has the advantage of at least partly evoking the three disciplines used in this article. In computer science it represents the linked processor: "Networking computers" brings to mind issues of communications, errors, protocols, and control architecture. In economics, networks relate to coalitions and externalities: neither market nor hierarchy, they may still concern vertical integration, scale efficiency, firm boundaries, decentralized incentives, and non-cooperative gaming behavior among agents. And in sociology, the word network calls up connections -- lines of interpersonal affiliation and political influence: "networking" at a social function, for example, recognizes the importance of individual persuasion and noneconomic aspects of social pressure as the context for group activity. Although the complexity of these disparate concepts creates difficulties combining them, "network organization" is used here to do justice to as many concepts and authors as possible.

The next section lists several factors which help define network organizations and also contrasts them with other kinds of organization -- in particular, with markets and hierarchies. Through the proposed metaphors, each of these factors becomes the starting point for exploring theories of network behavior in the next three sections, one for each metaphor. The factors together with relevant analytical principles also appear in tables at the end of each section to summarize the findings from that perspective. Following the literature survey, a synthesis section remarks on the relative advantages of each metaphor and identifies common themes: As a response to volatile environments, network organizations struggle to balance stability against flexibility, specialization against generalization, and centralization against decentralization. They also attempt to make increasingly sophisticated use of information technology. The final section concludes with a summary integration of the principal findings.

\section{CHARACTERISTICS OF THE NETWORK ORGANIZATION}

What defines a network organization? A behavioral view is that a network is a pattern of social relations over a set of persons, positions, groups, or organizations [123]. This definition is useful because it emphasizes structure and different levels of analysis. A strategic view of networks considers them "long term purposeful arrangements among distinct but related for-profit organizations that allow those firms in them to gain or sustain competitive advantage [70 p. 32]," a perspective which duly recognizes goal-directed processes and economic competition. A third definition incorporates organic adaptation and flexibility, suggesting they are:

“.... adapted to unstable conditions, when problems and requirements for action arise which cannot be broken down and distributed among specialists' roles within a hierarchy. ... Jobs lose much of their formal definition ... Interaction runs laterally as much as vertically. Communication between people of different ranks tends to resemble lateral consultation rather than vertical command [and] omniscience can no longer be imputed to the head of the concern 8 ."

Network organizations are defined by elements of structure, process, and purpose. Structurally, a network organization combines co-specialized, possibly intangible, assets under shared control. Joint ownership is essential but it must also produce an integration of assets, communication, and command in an efficient and flexible manner. Procedurally, a network organization constrains participating agents' actions via their roles and positions within the organization while allowing agents' influence to emerge or fade with the development or dissolution of ties to others. As decision-making members, agents intervene and extend their influence through association; they alter the resource landscape for themselves, their networks, and their competitors and in the process can change the structure of the network itself. Then, a network as an organization presupposes a unifying purpose and thus the need for a sense of identity useful in bounding and marshaling the resources, agents, and actions necessary for concluding the strategy and goals of purpose. Without common purpose, agents cannot discern either the efficacy or desirability of association or know whether actions are directed towards cooperative gains. These three design elements -- co-specialized assets, joint control, and collective purpose -- distinguish network organizations from centralized organizations, inflexible hierarchies, casual associations, haphazard societies, and mass markets ${ }^{9}$.

$8[79$ p 188 citing Burns and Stalker].

${ }^{9}$ Various studies have considered representative structures in finance [37], real estate [10], asian economies [13, 47], biotechnology [113], chain stores and textiles [72], multinational corporations 
To place these elements in a survey context, subsequent exegesis will consider networks to exhibit most, if not all, of several features which the preceding description is intended to distill from the literature. Specifically, a network organization maintains permeable boundaries either internally among business units or externally with other firms $[6,32,71,105,120,128]$. Management is less hierarchical [37, 106, 109], deriving its authority more from expertise than from rank [71, 73, 74, 112]. This in turn stems from network output demanding a high degree of intangible, local, or specialized know-how [32, 46, 71, 112]. Communication is direct and point-to-point rather than "through channels" [79, 97, 120], while knowledge of emerging problems and opportunities may arrive via multiple loose associations or weak ties [19, 49]. Resources are specialized and customizable within a given product or service scope $[32,70,117]$ yet they are less vertically integrated than their hierarchical counterparts [72, 79, 109]. Purposeful agents within the network may establish ties to other agents and organizations to wrest control for themselves or thwart competitors' attempts to do the same [140]. Tasks are more project and less functionally driven [88, 106], leading to shorter runs of more differentiated products [72, 106]. Networks reintegrate staff conception and line execution [111, 121] such that local concerns are more locally addressed [73, 109, 121]. Local conception also implies a higher degree of local ownership and project incentives which are more performance driven [15, 74]. Given the possibility of opportunism, network membership also requires a high degree of trust or commitment between parties [70, 100, 107, 112, 117, 121]. This in turn enables partners to make riskier investments [58] and transfer unfinished goods knowing that disputes from unforeseen events will be handled amicably and equitably [117].

These design variables are summarized in Table 1 and contrasted with similar design variables for markets and hierarchies. It is worth noting here that one of the principal concerns of the network literature centers on whether networks represent an intermediate organizational form midway between markets and hierarchies [32, 112, 117]. Along the axes of vertical integration and product differentiation, networks fall squarely between them. Substantial evidence suggests, however, that markets and hierarchies do not bracket networks [13, 32, 107, 111, 112, 117]. The most compelling of these arguments focus on issues of affiliation, loyalty, and trust -- dimensions

[32], publishing [14], research [46, 113], automotive parts and supply $[11,100]$. along which markets resemble hierarchies more than either resemble networks. Hierarchies avoid problems with trust and risk due to hold-up and opportunism by vertically integrating assets they require. Markets involve few repeat transactions so talk is cheap, reputations not held dear, and strategic misrepresentation commonly assumed. In networks -- where intangibles and rapidly applied expertise provide key sources of value -- reputations, commitments, and trust become essential.

The position taken here is that a comprehensive and well-established literature on markets and hierarchies makes them useful backdrops to bring the otherwise blurry image of networks into sharper focus. A twodimensional table provides a useful yet simplifying abstraction. Still, to conceive of networks as falling exclusively between markets and hierarchies is to employ a false and misleading scale. The columns of the table merely suggest relationships for these three organizational forms which are in fact archetypes. A hierarchy with a profit sharing plan, for example, creates incentives but can leave intact rigid boundaries, centralized control, and vertical integration. Hybrid combinations can certainly exist. For the most part, aggregate features will be used to characterize a network organization as one or another feature varies on the margin to probe its definition.

Of the distinguishing characteristics in Table 1, vertical integration measures the degree to which ownership and property rights vest with a central office. In hierarchies, assets are tightly controlled; in markets assets are completely distributed [142]. Networks tend to involve multiple owners who exercise their stewardship over a specific subset of total assets. A leading cause of vertical integration is asset or resource specificity. More specific assets permit greater efficiency but when they are controlled outside the firm, one owner can hold-up another for the profits from efficiency by denying access [143]. The high cost of purchasing and owning such assets often means that cost reduction is achieved by mass production, using scale to amortize fixed costs. Concentrating ownership might therefore lead to minimal product differentiation and to homogeneous goods. Networks employ more flexible resources, such as knowledge [71, 112, 117], permitting greater niche seeking and customization.

Despite hold-up problems, substantial efficiency gains can motivate trading parties to cement a relationship. One possible solution to hold-up problems and strategic misrepresentation is to build trust. This may be achieved through shared values and social norms of loyalty [100, 117], as in the case of Japanese enterprise [13], or through transacting or trading frequently in order to establish points for 
COMPARISON OF NETWORKS WITH MARKETS AND HIERARCHIES

\begin{tabular}{|c|c|c|c|}
\hline FIRM ATTRIBUTE & HIERARCHIES & NETWORKS & MARKETS \\
\hline Purpose & $\begin{array}{l}\text { - Advance the Interests of a Central } \\
\text { Executive }\end{array}$ & $\begin{array}{l}\text { - } \text { Advance the Interests of a } \\
\text { Cooperative }\end{array}$ & - $\quad$ Provide a Forum for Transacting \\
\hline Vertical Integration & $\begin{array}{l}\text { High; Centralized Ownership of } \\
\text { Inputs to Production }\end{array}$ & $\begin{array}{l}\text { Variable (Moderate for Stable } \\
\text { Networks e.g. Keiretsu, Lower for } \\
\text { Dynamic Networks); Modularly } \\
\text { Decentralized Ownership } \\
\end{array}$ & $\begin{array}{l}\text { None; Completely Decentralized } \\
\text { Ownership of Inputs to Production }\end{array}$ \\
\hline Assets \& Resources & $\begin{array}{ll}- & \text { High Asset Specificity, Not Easily } \\
& \text { Traded } \\
\text { - } & \text { Slack Resources, Buffer Stock } \\
\text { - } & \text { Fixed, Largely Tangible Assets } \\
\end{array}$ & $\begin{array}{ll}- & \text { Moderate to High Asset } \\
& \text { Specificity } \\
\text { - } & \text { Few Slack Resources } \\
\text { - } & \text { Flexible, More Intangible Assets } \\
\end{array}$ & $\begin{array}{ll} & \text { Low Asset Specificity } \\
- & \text { Easily Traded }\end{array}$ \\
\hline Products & $\begin{array}{l}\text { Mass Produced, Large Scale } \\
\text { Economies }\end{array}$ & $\begin{array}{l}\text { More Customized, Scale / Scope } \\
\text { Economies }\end{array}$ & $\begin{array}{ll}\text { - } & \text { Spot Contracts Permit Enormous } \\
& \text { Variation }\end{array}$ \\
\hline Trust & $\cdot \quad$ Low & - $\quad$ Moderate to High & $\cdot \quad$ Low \\
\hline Transactions & $\begin{array}{ll}- & \text { Long Term Time Frame } \\
- & \text { High Likelihood of Repetition }\end{array}$ & $\begin{array}{ll}\text { - } & \text { Moderate to Long Term } \\
\text { Variable Repetition (Higher for } \\
\text { Stable Networks e.g. Keiretsu, } \\
\text { Lower for Virtual Networks) } \\
\end{array}$ & $\begin{array}{ll}- & \text { Short Term Time Frame } \\
- & \text { Low Likelihood of Repetition }\end{array}$ \\
\hline Property Rights Transfers & $\begin{array}{ll}- & \text { Wage Claims Incurred at Time of } \\
\text { Production } \\
\text { - Little/No Labor Claim to } \\
\text { Production Inputs or Future } \\
\text { Revenue Stream } \\
\end{array}$ & $\begin{array}{ll}\text { - } & \text { Episodic/Sustained Property } \\
\text { Rights Transfers Including WIP } \\
\text { and FG } \\
\text { Negotiated/Often Shared Claim to } \\
\text { Revenue Stream } \\
\end{array}$ & $\begin{array}{l}\text { - Claim to Wages or Revenues } \\
\text { Incurred at Time at Sale, Conferred } \\
\text { by Property Rights }\end{array}$ \\
\hline Conflict Resolution & $\begin{array}{ll} & \text { Detailed Contracts } \\
- & \text { Administrative Fiat } \\
\end{array}$ & $\begin{array}{l}\text { Relational/Recurrent Contracts, } \\
\text { Joint Negotiation, Reciprocity }\end{array}$ & $\begin{array}{ll}\cdot & \text { Market Norms } \\
- & \text { Courts, Legal System } \\
\end{array}$ \\
\hline Boundaries & $\begin{array}{ll}- & \text { Fixed, Rigid, In or Out } \\
\text { - } & \text { Strong, Typically Stable Ties or } \\
& \text { Associations }\end{array}$ & $\begin{array}{ll}\text { - } & \text { Flexible, Permeable, Relative, } \\
\text { Latent Linkages } \\
\text { Strong and Weak, Often Dynamic } \\
\text { Ties or Associations } \\
\end{array}$ & $\begin{array}{ll} & \text { Discrete, Entirely Atomic } \\
\text { Distant, Arms-Length, One-Time } \\
\text { Ties or Associations }\end{array}$ \\
\hline Communications & $\begin{array}{ll}\text { - } & \text { Persistent } \\
\text { - } & \text { Through Channels (Vertical) } \\
& \text { One-to-Many (or Many-to-One) } \\
\end{array}$ & $\begin{array}{ll}\cdot & \text { As Needed } \\
\cdot & \text { Direct } \\
& \text { Many-to-Many } \\
\end{array}$ & $\begin{array}{ll}\cdot & \text { Short Lived } \\
\cdot & \text { Direct } \\
\text { - } & \text { Many-to-Many } \\
\end{array}$ \\
\hline Task Basis & $\begin{array}{ll} & \text { Functional Orientation }\end{array}$ & - $\quad$ Project Orientation & $\begin{array}{ll} & \text { Unitary (one party completion } \\
\text { start to finish) }\end{array}$ \\
\hline Incentives & $\begin{array}{l}\text { Low, Process Steps and Output are } \\
\text { Pre-specified; Greater reliance on } \\
\text { fixed wages. } \\
\end{array}$ & $\begin{array}{l}\text { Higher, Performance Oriented; } \\
\text { Benefit from Multiple } \\
\text { Transactions. } \\
\end{array}$ & $\begin{array}{ll}\text { - High Powered, Sell Output or Exit } \\
\text { Market }\end{array}$ \\
\hline Decision Locus & $\begin{array}{ll} & \text { Top Down, Distant } \\
\end{array}$ & $\begin{array}{ll}\cdot & \text { Joint or Negotiated and Largely } \\
\text { Local }\end{array}$ & - Immediate / Complete Autonomy \\
\hline $\begin{array}{l}\text { Control / Authority / Mode of } \\
\text { Influence }\end{array}$ & $\begin{array}{ll} & \text { Status or Rule Based } \\
& \text { Command/Obedience } \\
& \text { Relationship }\end{array}$ & $\begin{array}{ll}- & \text { Expertise or Reputation Based; } \\
\text { More Persuasion } \\
\text { - Control also Effected via Tie } \\
\text { Formation } \\
\end{array}$ & $\begin{array}{l}\text { - Persuasion Achieved via Pricing } \\
\text { Mechanism }\end{array}$ \\
\hline
\end{tabular}

Table 1 -- Network design variables differ from markets and hierarchies across multiple dimensions. Each column represents an archetype.

Most entries are loosely based on [32, p. 155], [97, p. 173-174], [112, p. 300] or [117, p. 486]. 

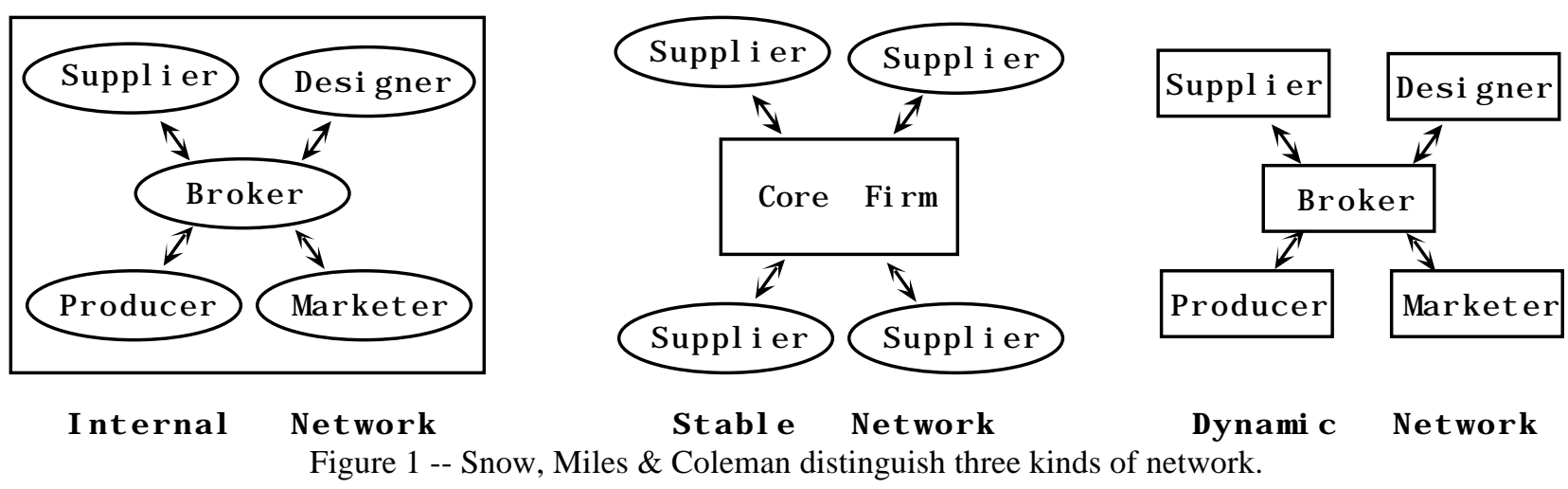

review and possible sanction. Property rights transfers can allow trading parties to periodically inspect intermediate goods and performance [117] and it can help align incentives [51, 61]. If performance is unsatisfactory, organizations may seek to resolve conflicts in different ways depending on governance structure. In networks, where trust is present, this may involve relational contracts which specify avenues for negotiation rather than damages. Hierarchies tend instead to use administrative fiat while markets resort to the courts for arbitration.

Another distinguishing characteristic is that lines of ownership and of group identity, i.e. boundaries, become ill-defined. This includes the edge between the network firm and its markets and even the edges of different functions within the firm. "The chief structural characteristic of network organization is the high degree of integration across formal boundaries" [10 p. 400]. In Sabel's evocative terminology, the "Moebius-strip organization" is one in which its inside is indistinguishable from its outside. The interpenetration of firms, formal functions, and markets is a consequence of several shifts in organizational design. Point-to-point communication between groups, often supported by information technology, integrates borders between them. "Networked firms are usually conceived of as communication rich environments, with information flows blurring traditional intra-company boundaries" [120 p. 191].

Cutting across boundaries also results from shifting the basis of tasks from rationalized functions to market-driven projects. Rather than passing projects from function to function, say from marketing to design, from design to manufacture, and then on to distribution, networks focus functions on a given project simultaneously. "Networks are webs of interrelationships organizations use to carry out the tasks of projects" [106 p. 4]. Shifting to a project orientation also means that incentives are more difficult to specify ex ante because routine behavior which could be specified under a functional orientation will not serve the unanticipated needs of each new project. For autonomous employees to make decisions favoring the organization, the employee's and the organization's goals must coincide. Networks resolve this problem by moving project ownership and the locus of decisions closer to the point of action within the network. This leads to a reintegration of conception and execution [121] or a collocation of decision rights and specific knowledge of a situation at hand. In describing "cluster organization," Mills writes that "a cluster is a group of people drawn from different disciplines... [It] develops its own expertise, ... pushes decision making toward the point of action, ... and accepts accountability for its business results [97 p. 29-30]. Local agents are not only better positioned to gather information on specific local conditions, but vested with decision authority and ownership of the result, they are also more likely to look for problems and opportunities.

This argument also draws attention to another useful property of network organizations, namely, that knowledge and expertise become important criteria for admission to project teams. Authority, or the ability to lead and direct others, no longer derives from traditional status or hierarchical rank but from knowledge. Organizations which reward performance and expertise are more successful in turbulent environments [36, 79].

The general network organization framework permits several gradations in type. Snow, Miles and Coleman [128], for example, distinguish between three kinds: internal, stable, and dynamic. Internal networks are loose associations of assets and business units contained within a single company and which subject themselves to market forces. Oil companies will trade internally at market transfer prices or secure outside spot contracts because they find it too expensive to misprice exploration, extraction, refining, or distribution. Stable networks consist of firms engaged in long term relationships with external suppliers who bring expertise into the parent 
company. Participants are typically organized around a single large firm as with Japanese auto manufacturing. Dynamic networks are more temporary alliances of firms with key skills usually organized around a lead or brokering firm. Each of the units tends to be independent and collaborates on a specific project or opportunity. In the fashion industry, manufacturers, designers, and retailers frequently use this model.

As these type gradations illustrate, tie strength varies between network members. Weick [137] and Powell [112] suggest that while network ties begin at the level of individual pairs, linkages exist at most levels of granularity. Ties tend to be stronger between pairs than between groups, and those between groups tend to be stronger than those between organizations, industries, and whole societies respectively. Analyses presented in different sections will consider networks at different levels of granularity under the general assumption that tie strength diminishes with increasing aggregation.

\section{NETWORK ORGANIZATIONS AS COMPUTERS}

"In ... post-industrial society, the central problem is ... how to organize to make decisions -- that is to process information" $\mathrm{H}$. Simon [125].

Viewing firms and organizations as information processors has a fairly well-established history [27, $44,45,77,85,88,116,122,126]$. In a distributed or decentralized system, the principal challenge is to exhibit coherence of purpose, that is to achieve global efficacy from local activity. The purpose, in this case, is coordinated problem solving in complex environments. A computational view draws attention to design variables parameters for tasks, processors (or managers), their arrangement and communications between them. Computational processes address questions of how to disassemble tasks, with whom to communicate, how to recover from error, and how to improve execution speed. By analogy to hierarchy and to markets, serial and parallel designs both influence the "architecture" of the firm. This section considers six dimensions of information processing:
(A) Process Flow, Resource Dependencies \& Parallelism
(B) Processor Specialization \& Generalization
(C) Vulnerability \& Tolerance to Processor Failure

\author{
(D) Communication Channels \& \\ Coordination Costs \\ (E) Distributed Knowledge, \\ Sensing \& Coherence \\ (F) Modularity
}

A summary of these design issues appears in Table 3 at the end of this section. The tools involved in analyzing network organizations draw from queuing theory, coordination theory, search theory, parallel design, complexity theory, modular design, and distributed artificial intelligence.

\section{A. Process Flows, Resource Dependencies \& Parallelism}

Coordinated problem solving deals with the critical need to break tasks into reasonable subtasks for distribution and processing [41, 77, 82, 85]. To assign tasks, organizations must first use a set of goals to measure their activities and the distance to desired targets. The act of organizing may then be defined as the establishment of appropriate goals, the segmenting of tasks for distribution, the communication of both assignments and completed results, and the reintegration of outputs which achieve goals [85]. Coordination among agents is then a plan for sharing scarce resources, completing subtasks, and sharing intermediate results. Adaptation is also possible by changing the way tasks are divided or the way agents exercise control.

This also draws attention to the complexity of information processing in different structures based on the ability to reconstitute process flows. Complexity is the amount of information necessary to describe the state space of behaviors exhibited by a system .[5]. This space is smallest for hierarchies which have the strongest but also the fewest interconnections among vertically fixed elements. Networks have both more numerous and more plastic links enabling them to cope with greater environmental complexity by rearranging process flows. Markets have few if any strong links but by far the most numerous latent links. Thus markets respond more slowly but have the largest state space and information processing capacity.

The completeness of available information also affects process flows. If agents have full and accurate information, they may complete their tasks with minimal contact [82] or they may delegate discrete subtasks in simple "master-slave" fashion. Only discrete tasks and discrete results need to be passed between agents. Ill-structured problems with incomplete data, on the other hand, may require greater coordination of multiple knowledge sources. This may involve iteration and communication of partial results. Agents then use a process like 
tatonnement to settle on their ultimate solution [35, 64].

In coordinating problem solvers, it is also useful to enumerate and catalogue kinds of agent and task dependency. With canonical representations, firms may adapt and use them to implement new business practices as though using a cookbook for organizational design [85]. Additionally, dependencies which highlight interdependence can generate economies of scale by suggesting ways to share resources. Examples include resource requirements, simultaneity constraints, subtask decompositions, and producer/consumer relations where output from one task is input to another [87]. Illustrating the value of a computer metaphor, evaluation criteria such as abstraction layering, modularity, and component reusability represent organizational design concepts which have direct counterparts in software engineering.

Enumerating task dependencies can also suggest opportunities for simultaneous execution. As with decentralization and centralization, parallel and serial designs can greatly affect processing times. Indirectly, this is the bottom-up insight Peters [109] espouses in the management literature in which hundreds perhaps even thousands of business units pursue separate agendas without necessarily taking direction from a central office -- a process which maps decision problems to computational structure. Networks tend to perform bottom-up breadth search where hierarchies tend to perform top-down depth search. Importantly, it may be possible to pursue both strategies by passing intermediate reports backand-forth. By working simultaneously from both directions, agents can sometimes achieve a combinatorial implosion on a search space that might appear intractable using a single strategy [77]. Other ways in which parallel processing differs from serial include pattern-selective broadcast (the degree to which communications are focused on individuals or broadcast to a community), fairness in resource competitions, ability to spawn new processes, synchronous versus asynchronous communication, and task backlogs [41]

Designing process flows becomes considerably more complex in the presence of input variability. Stabilizing variable inputs is often a best choice but if this is too difficult, organizations can add slack resources [44]. Underutilized agents, expanded timeframes, and quality margins can increase a network organization's effective capacity. As a second option, organizations may create additional processing capacity by adding lateral relationships [44] which can enhance their ability to cope with complexity. They can also borrow capacity as necessary and thereby create a "Virtual Corporation" [20, 28]. Network structured organizations gain virtual access through outsourcing, joint venturing, and relying more heavily on suppliers [28, 101, 109, 118]. By analogy to virtual memory, in which the central processor accesses off-chip resources, a virtual corporation accesses markets, capital, patents, or know-how that do not belong to the core resource pool or that may be under the control of other agents. Virtual resources may entail much higher variable costs but enjoy much lower total costs. A third option involves levels of specialization, which has much broader implications than variable input handling.

\section{B. Processor Specialization versus Generalization}

Variability of job types and variability of arrival rates both influence the desired level of processor specialization. Variability of job types increases the attractiveness of resource pooling -- an overlap in capabilities which helps prevent processors of one job type from idling while those of another type labor under heavy loads. The tradeoffs in throughput and utilization rates represent a useful application of queuing theory. Flexible processors may be more expensive or slower on average but the overall improvement in performance can make the tradeoff worthwhile [59]. Even with job types and average arrival rates held constant, variable arrival rates lead to congestion. If input is constant in type and arrival rate, however, specialized processors optimized for prescribed tasks will likely prove more cost effective.

Serious problems can also arise when processing delay exceeds arrival rate [116]. Queuing theory further suggests that, assuming Poisson task arrivals, doubling processor speed is not nearly as effective at reducing the number of jobs in the queue -- and hence waiting times -- as adding a second processor [30]. Thus two inexpensive agents may be more attractive than a single high capacity agent if input arrival rates vary widely on jobs of the same type.

In a processing sense, the degree of specialization is also a necessary consequence of the need to allocate decisions in the context of information overload [116]. Specialized or unique processors represent potential bottlenecks [29]. The efficiency of a special purpose hierarchy versus a general purpose network is an optimization which balances expensive processors against expensive delays. If processors are expensive then cost minimization favors more serial processing with high utilization rates but if delays are expensive then cost minimization favors a flatter, more parallel architecture with high throughput rates [116]. 
Specialization can become attractive when processors are unable to coordinate due to high communication or overhead costs associated with agent interdependence [45]. As in functional organizations, specializing in finance or manufacturing can permit agents to reduce their coordination with research and sales. Agents perform independent functions while receiving delayed or infrequent information on unrelated functions. Although this can avoid overhead locally, specialization generally creates overhead at interfaces where tasks must be reintegrated. Lower connectivity also implies a loss of complex processing. Specialization's advantage is that it permits different levels of management to focus on different problems assuming that coherence does not suffer greatly. Organizational solutions may be computed at the lowest level necessary to address them or be "kicked upstairs" only when some exception event occurs [44]. In fact, "management by exception is a powerful device for economizing on the use of information in an organization" [116 p. 1403]. As with operating systems, exception handling is an essential architectural design element affecting reliability and perceived resource transparency [30].

Increasing coordination tends to require more complex agents and these can only be bought at the cost of increased computation [45]. How, then, might managers in a network organization increase their capacity? Applegate, Cash and Mills [6] argue that managerial decision capacity improves as a result of increasing decision support. Access to knowledge bases and analytic tools might therefore reduce hierarchy as staff managers require less data processing by line managers within the firm. Malone, Yates, and Benjamin [90] also argue that information technology, in general, increases managers' capacity for coordination implying a move towards interdependence. These arguments represent two of the stronger explanations for the rise of network structured firms.

\section{Vulnerability \& Tolerance to Processor Failure}

Whether organizations degrade gracefully in the presence of local failure affects their performance [29, 45]. A centralized system with a special purpose hierarchy is thus particularly dependent on the judgment and non-failure of the senior processor [41]. Moreover, the complexity of problem solutions can be no greater than the complexity of decision processes which design them. Network organizations, with their larger state space of behaviors, are distinctly less vulnerable to large scale problem complexity than are hierarchies. This can imply, however, that knowledge of the complete organizational response is not given to the mind of any single individual [5]. Thus, decentralized networks can err more frequently (though generally on smaller problems) since individual agents might have less total information and they are less subject to hierarchical review.

Despite increased local vulnerability, a decentralized system is typically more robust. It can recover gracefully by reassigning responsibilities within the network. Another solution, often employed by hierarchies, is to use slack resources to buffer the organization from mistakes and delayed decisions by increasing the margin of error [44]. Vulnerability is an issue of balancing costs of safeguards, costs of recovery, and costs of non-recovery.

Sah and Stiglitz [122] introduce project error into a model of decisions in hierarchies and networks or "polyarchies." Firms must judge projects on their profit potential before committing resources. Projects are evaluated either in series by several processors, i.e. a hierarchy, or in parallel by the same number of processors, i.e. a polyarchy or network. Each layer of management in a hierarchy must evaluate a project favorably before it is passed on to the next layer and ultimately chosen for investment. A single manager in a network, however, is sufficient to move a project forward and commit resources. Sah and Stiglitz show that the parallel decision process of a network tends toward more profitable decisions when the costs of accepting bad projects are lower than the costs of rejecting good ones. In contrast, an abundance of bad projects or bad decisions favors the insurance provided by another layer of hierarchical managers.

\section{Communication Channels \& Coordination Costs}

Networks can be less efficient than hierarchies in terms of communication channel costs [106]. Assuming $\mathrm{N}$ nodes in an organization, vertical communications pathways require only $\mathrm{N}-1$ channels, one over each node in a hierarchical decision tree. Relationships are many-to-one as each node reports to his manager or one-to-many as strategy is disseminated in the other direction. In contrast, a network requires $\mathrm{N}(\mathrm{N}-1) / 2$ channels, one between each and every node giving $\mathrm{O}\left(\mathrm{N}^{2}\right)$ channels. Direct reporting relationships are many-to-many. The costs of networking employees together, which may be following the declining cost of information technology, may thus account for improved opportunities for networked firms even as it contributes to information overload.

Coordinating resources can also create a heavy demand for communication $[86,90]$. Networks tend to have 
lower coordination costs than markets and more flexibility than hierarchies. An example ${ }^{10}$ comparing relative governance structures illustrates. In this example, let $M$ be the number of firms required to produce a given level of output, let $\mathrm{N}$ represent the number of processing steps per product (the same across products), and let $\mathrm{X}$ be the number of processors per firm. The number of sequential steps is the same across organizations producing the same good but different structures exhibit different scale and coordination economies since they arrange steps differently.

Functional hierarchies $(F H)$ and product hierarchies $(\mathrm{PH})$ both possess high capacity specialized assets arranged vertically as in Figures 2.A and 2.B. Only one firm is necessary to produce the output and it owns all necessary processors. Thus $\mathrm{M}=1$ and $\mathrm{X} \geq$ $\mathrm{N}$. The key difference is that functional hierarchies gather homogeneous task types into departments run by functional managers whereas product hierarchies gather heterogeneous tasks under product managers. In the former research, sales, and manufacturing would be in separate departments; in the latter, they would be grouped into product lines. The senior executive in a functional hierarchy determines output levels by function from which functional managers set job tasks for each processor. As the focal point, the executive also ensures the movement of work in progress from function to function. In a product hierarchy, product managers determine processing task assignments so unfinished goods do not pass between departments. The general manager, however, can reallocate processors among product lines to achieve better global load balancing as in the case of a discontinued product.

Markets, as shown in Figures 2.C and 2.D are characterized by numerous small firms who coordinate to produce output. As before, production involves $\mathrm{N}$ steps per product but each firm only has one processor so $\mathrm{X}=1$ and $\mathrm{M} \geq \mathrm{N}$. In a centralized market $(C M)$, each small firm manages an individual processor while a broker or central planner handles coordination and distributes job assignments to the appropriate combinations of firms involved at each stage. In contrast, the small firms in a decentralized market $(D M)$ have no central planner so firms in stage $\mathrm{N}$ of production submit bid requests to firms in stage N-1. As many bids return from which the sender selects the best offer and awards a contract.

${ }^{10}$ This example is based on descriptions appearing in $[84,89,103]$. The network example is an extension and is closer to the coordination structure appearing in [21].
Network organizations $(N W)$, shown in Figure 2.E, generally fall between markets and hierarchies on communications and costs. Firms generally have more than one processor but not necessarily all that are necessary for production so $1 \leq \mathrm{X} \leq \mathrm{N}$ and the number of firms is $M \geq N / X$. By controlling multiple high capacity processors, individual firms may achieve greater scale economies than firms in markets. Still, they save on market coordination costs by communicating largely within the group of partners. These savings vanish, however, if a processing constraint binds in which case the network resorts to market bidding mechanisms to select a new partner.

These simple processor models are consistent with transaction cost descriptions of markets and hierarchies $^{11}$ [90, 142] while they also highlight possible information overload at processor bottlenecks [44]. Each processor arrangement offers advantages in different cost contexts and they can be ranked in order of attractiveness.

Coordination Costs: Hierarchies exhibit lower message passing and coordination costs than markets $[90,142]$ with networks falling roughly in between as they occasionally engage in market transactions. A single product manager, however, does not need to coordinate with other product managers since all processing steps are intra-departmental. In contrast functional managers must coordinate hand-offs of unfinished products across functions. With many fewer firms, networks require less coordination than markets. Then, due to a global planner, centralized markets enjoy a coordination cost advantage over decentralized markets. Consistent with [89], the approximate ordering for coordination costs is therefore $\mathrm{PH}<\mathrm{FH}<\mathrm{NW}<\mathrm{CM}<\mathrm{DM}$.

Unit Costs: Assuming that larger production runs can take advantage of economies of scale, hierarchies with highly specific assets can achieve the lowest unit production costs, followed by networks, and markets respectively. Since product hierarchies spread processors across departments, they might not achieve quite the scale economies of functional hierarchies. Also, since decentralized markets essentially use a lowest cost "greedy" algorithm, they can do no better at efficient task assignment than the global optimum designed by a central planner. The rough order for unit production costs might therefore be $\mathrm{FH}<\mathrm{PH}<$ $\mathrm{NW}<\mathrm{CM} \leq \mathrm{DM}$.

${ }^{11}$ Transaction Cost arguments are presented in the network organization as economy section. 

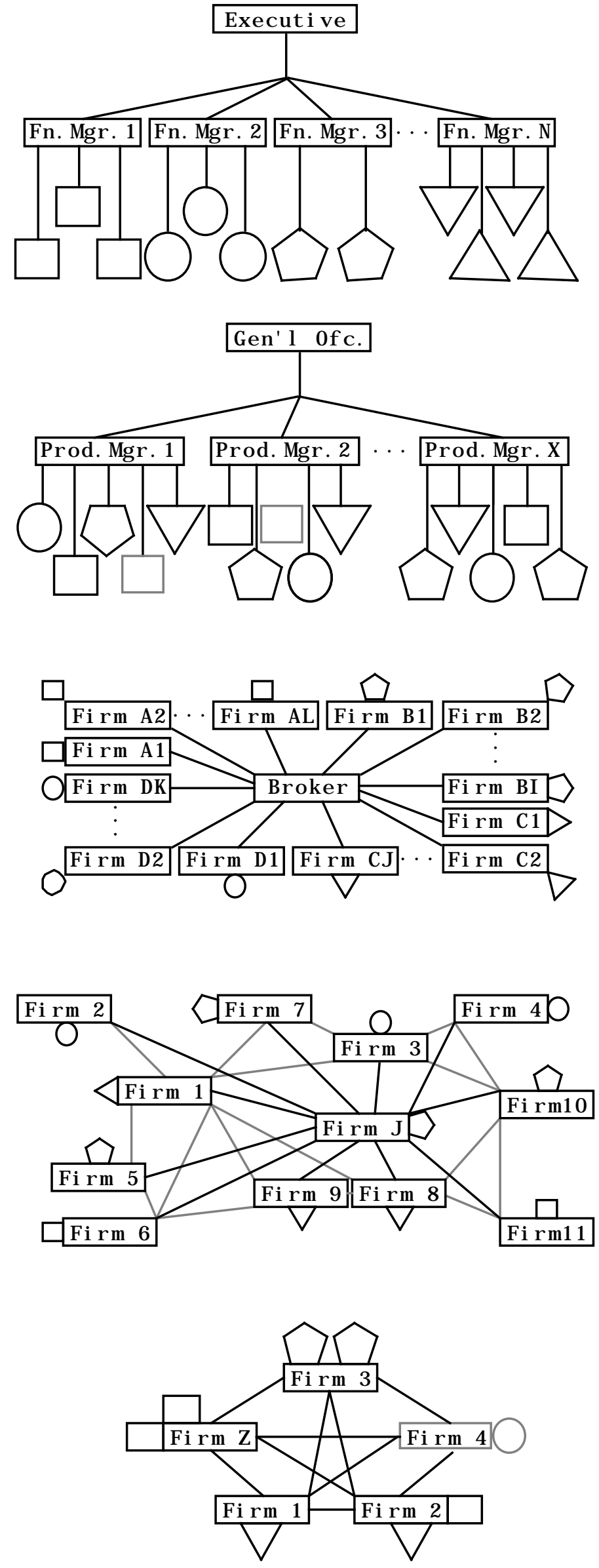

Figure 2.a - Functional Hierarchy - At least N high capacity processors, i.e. not less than one per production stage, are grouped by function in a single firm. Demand changes cause the executive to issue new optimal output targets and coordination schedules from which managers issue new task assignments. Control failures at any level can disrupt all product lines; processor failures can be handled by functional managers within their departments by reassigning tasks.

Figure 2.b - Product Hierarchy - At least N high capacity processors are grouped under each product line in a single firm. Small demand changes can be handled by a product manager but large changes require the general manager to rebalance loads by reallocating processors as suggested by the gray boxes. Control failures at the senior level can disrupt all products but control failure at the product level disrupt only one product; processor failures may require the general manager to rebalance loads.

Figure 2.c - Centralized Market - Numerous small firms with single processors receive their task and coordination assignments from a central planner who determines optimal output for each firm in all $\mathrm{N}$ stages of production. Demand changes cause numerous reassignments. Control failures seriously disrupt all production activities; processor failures are easily reassigned to one of the $\mathrm{M} / \mathrm{N}$ firms performing the required stage.

Figure 2.d - Decentralized Market - Each single processor firm at stage $\mathrm{N}$ requests bids from each of the possible $\mathrm{M} / \mathrm{N}$ firms at stage $\mathrm{N}-1$, a process which repeats up to the last stage (different products may use different sequences). Contracts are awarded to the lowest bidder. Failure of any processor reinitiates the bidding process. (Numerous possible cross connections omitted for clarity.)

Figure 2.e - Network Organization - Firms have X moderately specialized processors with $1 \leq \mathrm{X} \leq \mathrm{N}$. They coordinate demand changes among the $\mathrm{N} / \mathrm{X}$ firms in the network unless a capacity constraint binds or a processor fails. In this case, they use market-like bidding mechanisms to locate new partners as suggested by the grayed box for Firm 4 . 
Vulnerability Costs: These depend on different kinds of processor failure. Recovery from the failure of a central executive is likely to be more costly than recovery from a processing step failure [84] yet replacing a specialized high volume asset can also be expensive. Adaptation may also be conceived of as changing control structure and changing task assignment [45] suggesting two separate indices: one for control flexibility and one for processor flexibility. If the concentration of task allocation decisions is used as an index ${ }^{12}$ of control vulnerability or flexibility, then a decentralized market is the least vulnerable while a centralized market is the most vulnerable. Then, since functional hierarchies rely more heavily on a central executive for coordination, they are more vulnerable than product hierarchies who in turn are more vulnerable than networks since networks make decisions closer to the processor level. This gives rise to an ordering of control flexibility which has $\mathrm{DM}>\mathrm{NW}>\mathrm{PH}>\mathrm{FH}>\mathrm{CM}$. For processor flexibility these inequalities are reversed. A centralized market can easily reassign tasks to one of functional hierarchy which enjoys the lowest cost of production. If the environment is stable but coordination costs are high, a product hierarchy might emerge. In constantly churning environments with low coordination costs, decentralized markets appear most attractive since they have the most flexible control structures. If processors fail constantly, then a centralized market with many low cost easily interchangeable processors becomes more attractive. A network structure dominates when the environment favors a combination of flexible control and moderately low cost production -- a finding which is also consistent with "flexible specialization" [111, 121].

\section{E. Distributed Knowledge, Sensing \& Coherence}

The need to represent concrete programs has led to the design of fairly sophisticated distributed knowledge models, a distinct advantage of a computer metaphor. The key tension in designing cooperative knowledge structures is balancing flexibility and independence

\begin{tabular}{|c|c|c|c|c|}
\hline $\begin{array}{l}\text { Governance } \\
\text { Structure }\end{array}$ & $\begin{array}{l}\text { Coord. } \\
\text { cost }\end{array}$ & $\begin{array}{l}\text { Unit } \\
\operatorname{Cos} t\end{array}$ & $\begin{array}{c}\text { Control } \\
\text { Flex }\end{array}$ & $\begin{array}{l}\text { Proc. } \\
\text { FIex }\end{array}$ \\
\hline Functional Hierarchy & 2 & 1 & 4 & 2 \\
\hline Product Hierarchy & 1 & 2 & 3 & 3 \\
\hline Centralized Market & 4 & 4 & 5 & 1 \\
\hline Decentralized Market & 5 & 5 & 1 & 5 \\
\hline Network Organization & 3 & 3 & 2 & 4 \\
\hline
\end{tabular}

Table 2 -- Environmental factors will render different governance structures more attractive under different circumstances.

its many small processors while a decentralized market must reinitiate the bidding process. A functional hierarchy can recover by shifting tasks within departments while a product hierarchy must reallocate across products. The network can shift some tasks among partners, but if processing constraints bind, it may need to use market mechanisms to find new partners. Thus for processor flexibility $\mathrm{CM}>\mathrm{FH}>\mathrm{PH}>\mathrm{NW}>\mathrm{DM}$. These results, reported in order of attractiveness, are summarized in Table 2.

The pattern that emerges is one in which different structures dominate in different environments depending on the relative importance of any given column. In highly stable environments where flexibility is not a premium, conditions favor

${ }^{12}$ A Herfindahl index using sums of squared percentages would suffice to give a numeric index ranging from zero to one. This was originally used for measuring market share concentration. against coordination and coherence [29]. With greater flexibility and local decision authority comes the risk of losing coherence, a supra-regional property of efficiency and clarity in problem solving [45]. Distributed problem solvers need ways to model global behavior to match their performance to goals, recover from error, and reconfigure [45, 98]

Coherence may be achieved by devising a global plan centrally or by distributed incremental planning whereby local plans are disseminated and revised to eliminate conflicts [35]. Agents may also synchronize their activities by transferring local knowledge to a global database or "blackboard" visible to other agents [39, 64, 102]. Central processing heuristics ensure that information is consistent, shared, and ubiquitous even if agents themselves only focus on portions of the entire database.

In distributed artificial intelligence, agents can require knowledge not only of their own capabilities but also knowledge of other agents' plans [45]. Local 
projection of distant activities allows agents to model global patterns of system behavior. Agents' local decisions may then proceed without explicit interagent coordination. This avoids overhead and delay since communication tends to be slower than computation [29]. Internal agent models also aid the system's ability to dynamically self-configure relative to changed environments. Local adaptation may proceed with minimal communication if one agent can count on another to respond in predictable ways [35].

Agents need explicit representations of goals, interactions, resources, tasks, and success probabilities. Using the problem solving success of scientific communities as an example, Kornfeld and Hewitt [77] combine the programming concept of abstract data types (ADT) or objects with researcher collaboration to model coordinated problem solving. Agents or "sprites" with prescribed behaviors are "triggered" when task requirements match their capabilities, goals, and resources. With market-like bidding mechanisms for allocating resources, this model achieves coherence by shunting resources to more promising solutions. It can also achieve the combinatorial search implosion noted earlier.

Object representations have also been used to model contexts for cooperative problem solving [27]. Contexts are task domains spanning specialized operators or skill sets. A knowledge system is then represented as a collection of smaller knowledge subsystems with specific contexts. Manager agents divide and distribute tasks to worker agents or other managers based on the recipient's context knowledge as in Figure 3.

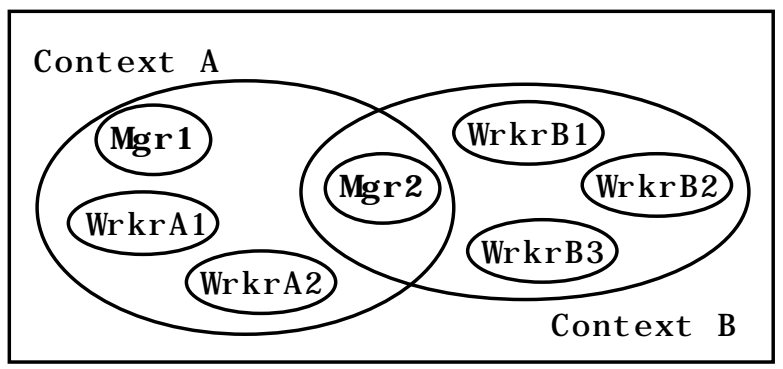

Figure 3 -- Manager 1, in context A, allocates subtasks to other managers or to workers depending on his context knowledge of their skills. Manager 2 may then partition tasks in context B.

Contexts can be carried to arbitrarily deep levels of abstraction. The system solves problems by managerial migration of successively smaller tasks from context to context until subtasks are finished or alternatives are exhausted. Reintegration of output occurs at the lowest appropriately placed vertical node. Hierarchy follows naturally from centralized control and progressive dilution of top level awareness of bottom level activity; networks follow from decentralized control and fewer layers of dilution. The relevance of such systems for organizational design is that increasing worker contexts, analogous to generalizing their skills, increases their complexity and their workload but reduces hierarchy and the dilution of awareness.

One important feature of network organizations, their sensitivity to market conditions [128], falls under the rubric of benefits from distributed sensing. In cooperative problem solving, data from disparate sources must be collected, analyzed, and fused into a plan of action [45]. Recall that in networks, communications channels grow as $\mathrm{O}\left(\mathrm{N}^{2}\right)$. Mathematically, this also implies that reducing the communications distance between all pairs of agents by the same amount exponentially reduces sum total distance between all agents. Thus each agent is closer to multiple original sources. When data gathering proceeds in parallel at multiple sites, it provides earlier and more complete detail allowing an organization to respond opportunistically to its environment [64]; it also encourages "pluralism" or the ability to entertain multiple, possibly incompatible hypotheses [77]. Pluralism generally proves superior in solving ill-structured problems [41]. Conflicting hypotheses incur reconciliation costs but, as in a scientific community, they support a whole system in the difficult task of generating alternatives. The group can then explore more promising solutions, defer apparently barren paths, and not jeopardize the community by eliminating all but one option.

As a rule, managing information in distributed systems confronts issues of incompleteness, inconsistency, and incompatibility. These occur when one agent has information unavailable to another, when agents have contradictory information, and when true and complete information is represented in irreconcilable forms respectively [45, 65].

\section{F. Modularity}

Modular designs facilitate coordination and reduce the potential for harmful interaction. Given a large volume of messages, for example, organizations can reduce their coordination requirements by creating self-contained tasks that lessen their dependence on interdepartmental communication [44]. Referring to work by Glassman, Weick [136] suggests that the degree of coupling, or conversely of self-containment, can be measured on the basis of activity or variable sharing -- the greater the commonality among variables, the greater the degree of coupling. "Encapsulation," a key property of the objects used to 


\section{NETWORK ORGANIZATIONS AS COMPUTERS}

\begin{tabular}{|c|c|c|c|c|c|}
\hline \multicolumn{2}{|r|}{$\begin{array}{c}\text { View of Network } \\
\text { Organization Feature }\end{array}$} & $\begin{array}{l}\text { Potential } \\
\text { Benefits }\end{array}$ & $\begin{array}{l}\text { Potential } \\
\text { Concerns }\end{array}$ & $\begin{array}{l}\text { Useful Analytical } \\
\text { Perspectives }\end{array}$ & $\begin{array}{c}\text { Useful } \\
\text { References }\end{array}$ \\
\hline 兽 & Coordinated Problem Solving & $\begin{array}{ll}\text { - } & \text { Multiple agents can solve more } \\
\text { - } & \text { Momplex problems. } \\
\text { - } & \text { Reduces bottlenecks. } \\
\text { - } & \text { Better sensing / adaptation. }\end{array}$ & $\begin{array}{l}\text { - Task decomposition / reassembly, } \\
\text { coordination costs, delays. } \\
\text { Danger of loss of coherence. } \\
\text { - Possibly local not global } \\
\text { optimization. }\end{array}$ & $\begin{array}{l}\text { - } \quad \text { Distributed Artificial Intelligence. } \\
\text { - } \quad \text { Coordination Theory. } \\
\text { - } \quad \text { Complexing Theory. } \\
\end{array}$ & $\begin{array}{c}{[41,44,45} \\
77,82,85 \\
88,122,125 \\
126]\end{array}$ \\
\hline 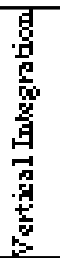 & $\begin{array}{l}\text { Process Flows, Resource } \\
\text { Dependencies \& Parallelism }\end{array}$ & $\begin{array}{ll} & \text { Decentralization reduces } \\
\text { bottlenecks. } \\
\text { Decentralization minimizes } \\
\text { delays. } \\
\text { Lateral links increase } \\
\text { computational ability. }\end{array}$ & $\begin{array}{l}\text { Centralization facilitates plan } \\
\text { coherence. } \\
\text { Centralization minimizes } \\
\text { processor costs. } \\
\text { Decentralization increases } \\
\text { coordination costs and message } \\
\text { passing. }\end{array}$ & $\begin{array}{ll}\text { - } & \text { Queuing Theory. } \\
\text { - } & \text { Coordination Theory. } \\
\text { - } & \text { Comptributed Artificial Intelligence. } \\
& \text { Complexity Theory. }\end{array}$ & $\begin{array}{c}{[37,54,55} \\
84,85,88 \\
101,103 \\
105,106 \\
109,116 \\
142]\end{array}$ \\
\hline$\frac{2}{\stackrel{2}{*}}$ & $\begin{array}{l}\text { Process Flows, Resource } \\
\text { Dependencies \& Parallelism }\end{array}$ & $\begin{array}{ll}- & \text { Virtual resources relax capacity } \\
\text { constraints / more flexible. } \\
\text { - } \\
\text { - } \quad \text { Exwer fixed costs when unused. } \\
\text { needed. }\end{array}$ & $\begin{array}{l}\text { Higher variable costs for virtual } \\
\text { resources. }\end{array}$ & $\begin{array}{l}\text { - } \quad \text { Cost/Benefit Analysis. } \\
\text { Basic Optimization. }\end{array}$ & $\begin{array}{c}{[20,28,44} \\
45,88,103 \\
105,106 \\
109,116]\end{array}$ \\
\hline 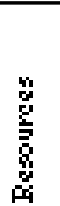 & $\begin{array}{l}\text { Processor Specialization vs. } \\
\text { Generalization }\end{array}$ & $\begin{array}{ll}\text { - } & \text { Specialized processors handle } \\
\text { same tasks faster. } \\
\text { Generalized / multiple processors } \\
\text { handle more variable inputs. }\end{array}$ & $\begin{array}{l}\text { - Specialization obsoleted faster in } \\
\text { volatile environments. } \\
\text { General purpose processors more } \\
\text { complex. }\end{array}$ & $\begin{array}{l}\text { Queuing theory to consider trading } \\
\text { slow throughput of flexible } \\
\text { resources for faster throughput of } \\
\text { specialized resources. } \\
\text { - } \quad \text { Principles of exception handling. }\end{array}$ & $\begin{array}{c}6,29,41 \\
44,45,59 \\
109,111 \\
116,121]\end{array}$ \\
\hline 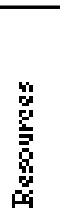 & Modularity & $\begin{array}{l}\text { - Local sensing mechanism. } \\
\text { Local adaptation, coexistent } \\
\text { mutation, self determinism, no } \\
\text { need to change whole or- } \\
\text { ganization. } \\
\text { - Failures isolated. }\end{array}$ & $\begin{array}{ll} & \text { Large scale change is difficult. } \\
\text { - } & \text { Assistance remote or delayed. } \\
\text { Independence may interfere with } \\
\text { coordination between groups. }\end{array}$ & $\begin{array}{l}\text { - Theories of loosely coupled } \\
\text { systems. } \\
\text { Principles of encapsulation and } \\
\text { inheritance. } \\
\text { - Complexity Theory. }\end{array}$ & $\begin{array}{l}{[45,86,87} \\
126,136- \\
138]\end{array}$ \\
\hline 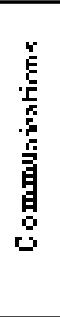 & $\begin{array}{c}\text { Communication Channels \& } \\
\text { Coordination Costs }\end{array}$ & 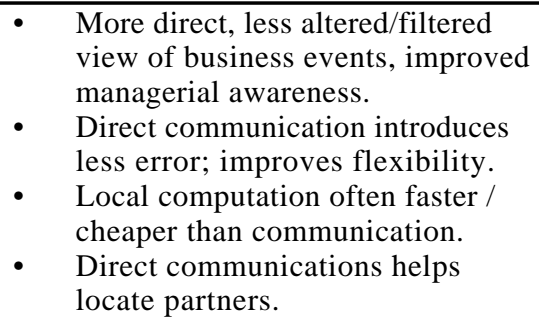 & $\begin{array}{ll} & \text { Information input overload. } \\
& \text { Requires high cross connectivity. }\end{array}$ & $\begin{array}{l}\text { - Intelligent filtering to reduce } \\
\text { unnecessary communication. } \\
\text { - Coordination Theory. } \\
\text { Principles of information } \\
\text { transmission across noisy } \\
\text { channels. } \\
\text { Queuing theory to measure } \\
\text { backlog. }\end{array}$ & $\begin{array}{c}{[21,24,28} \\
41,45,55 \\
67,79,84 \\
85,88,90 \\
97,103,105 \\
106,109 \\
120]\end{array}$ \\
\hline
\end{tabular}




\begin{tabular}{|c|c|c|c|c|c|}
\hline 骨 & $\begin{array}{l}\text { Process Flows, Resource } \\
\text { Dependencies \& Parallelism }\end{array}$ & $\begin{array}{l}\text { - } \quad \text { Task assignment based on } \\
\text { workload and processor expertise. } \\
\text { Task partitioning reduces problem } \\
\text { scope. } \\
\text { - } \quad \text { Increased Flexibility. } \\
\text { - } \quad \text { Parallelism can increase speed. }\end{array}$ & $\begin{array}{l}\text { - } \quad \text { Task decomposition and } \\
\text { reassembly is difficult and requires } \\
\text { significant coordination. } \\
\text { Possible information overload at } \\
\text { point of reassembly. }\end{array}$ & $\begin{array}{l}\text { - } \quad \text { Coordination Theory. } \\
\text { Principles of partitioning, task } \\
\text { decomposition. } \\
\text { Principles of serial versus parallel } \\
\text { flow of control. }\end{array}$ & $\begin{array}{c}{[28,45,82} \\
85,86,88, \\
97,101,105 \\
106,109]\end{array}$ \\
\hline 幽 & Modularity & 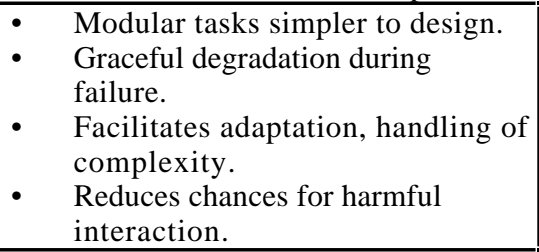 & $\begin{array}{l}\text { - Harder to coordinate synchronized } \\
\text { coherent direction. } \\
\text { Less standardization across } \\
\text { modules. } \\
\text { Information partitioning reduces } \\
\text { overload. }\end{array}$ & $\begin{array}{l}\text { Layering of abstraction levels, } \\
\text { encapsulation. } \\
\text { - } \quad \text { Principles of standardization. } \\
\text { Parallelism and non-determinism. }\end{array}$ & $\begin{array}{l}{[24,44,45,} \\
87,126,136- \\
138]\end{array}$ \\
\hline 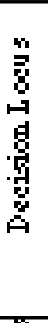 & $\begin{array}{l}\text { Process Flows, Resource } \\
\text { Dependencies \& Parallelism }\end{array}$ & $\begin{array}{l}\text { - } \\
\text { Parallelism permits simultaneous } \\
\text { exploration of multiple } \\
\text { alternatives. } \\
\text { - } \\
\text { Asynchronous processing. } \\
\text { More projects likely to be } \\
\text { undertaken. } \\
\text { Decentralization useful for } \\
\text { solving ill-structured problems } \\
\text { and encouraging "Pluralism." } \\
\end{array}$ & $\begin{array}{ll}- & \text { Costly duplication of efforts. } \\
\text { - } & \text { Local suboptimization. } \\
& \text { Complexity of responses can be } \\
\text { no greater than complexity of } \\
\text { decision processes. }\end{array}$ & $\begin{array}{l}\text { - Weigh costs of poor projects } \\
\text { against opportunity cost of too } \\
\text { few projects. } \\
\text { - Search theory for quickly locating } \\
\text { best choices. } \\
\text { - } \quad \text { Parallelism and non-determinism. } \\
\text { - } \quad \text { Distributed artificial intelligence. } \\
\text { - } \quad \text { Principles of exception handling. }\end{array}$ & $\begin{array}{c}{[28,29,35} \\
39,64,77 \\
98,102,106 \\
109,122]\end{array}$ \\
\hline 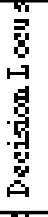 & $\begin{array}{l}\text { Vulnerability \& Tolerance to } \\
\text { Processor Failure }\end{array}$ & $\begin{array}{l}\text { Graceful degradation, easier and } \\
\text { more robust error recovery. } \\
\text { Integrated processors and } \\
\text { controllers. } \\
\text { - } \\
\text { Lateral links reduce vulnerability. }\end{array}$ & $\begin{array}{ll}- & \text { Decentralized decisions increase } \\
\text { chances of inconsistency. } \\
\text { More prone to errors; Less } \\
\text { hierarchical review or protection. } \\
\text { Exceptions may require special } \\
\text { handling. }\end{array}$ & $\begin{array}{ll} & \text { Distributed artificial intelligence. } \\
\text { - } & \text { Principles of database systems. } \\
\text { Principles of decentralized } \\
\text { systems. } \\
\text { - Complexity Theory. }\end{array}$ & $\begin{array}{c}{[29,41,44} \\
45,84,89 \\
116,122]\end{array}$ \\
\hline 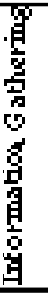 & $\begin{array}{l}\text { Distributed Knowledge, Sensing \& } \\
\quad \text { Coherence }\end{array}$ & $\begin{array}{ll}\text { - } & \text { Better global picture, increased } \\
\text { information gathering from } \\
\text { bottom up versus top town } \\
\text { processing. } \\
\text { - } \quad \text { Facilitates self-configuration. } \\
\text { - Encourages "Pluralism" } \\
\text { Encourages opportunistic } \\
\text { response to the environment. }\end{array}$ & $\begin{array}{l}\text { Incomplete, inconsistent, or } \\
\text { incompatible information. } \\
\text { Disintegrated perspectives can } \\
\text { lack coherence. }\end{array}$ & $\begin{array}{l}\text { - } \quad \text { Distributed Artificial Intelligence. } \\
\text { Complexity Theory. }\end{array}$ & $\begin{array}{c}{[29,35,39} \\
41,45,64 \\
65,72,77 \\
97,98,102 \\
109,128]\end{array}$ \\
\hline
\end{tabular}

Table 3 -- Viewing the network organization in computational terms provides several efficiency, modularity, and coherence measures across process architecture.

Note references may relate to theory or network organization attributes and may appear in multiple frameworks. 
represent coordinated problem solvers, is a means of hiding internal complexity from external processes. Encapsulation guarantees that responding internally to change leaves external processes unaffected since internal workings are essentially unavailable for external use. Optimizing encapsulated processes can proceed without disrupting parallel processes so long as output is reliable. Similarly, "inheritance" is a way to avoid redefining old attributes and behaviors in new contexts. Using inherited templates economizes on resources and design effort.

Loose coupling distinguishes separate conceptual building blocks which can be grafted onto or severed from an ongoing enterprise with minimal disruption to its activities [136 p. 3]. Simon [126] suggests that a system is "nearly decomposable" if the interactions between the systems are weak while the interactions within the systems are strong. In a nearly decomposable system, the short run behavior of each subsystem is approximately independent of the short run behavior of other components but a subsystem's long run behavior depends on the aggregate behavior of other components [126]. Near decomposability and loose coupling both lead to graceful degradation of the system should one part of the organization cease to function $[44,86,98,126$, $137,138]$.

To illustrate the benefits of modularity in complex environments, Simon [126] tells the story of Tempus and Hora, two celebrated watchmakers whose 1000 part watches were much in demand. Tempus carefully crafted his watches from the many pieces but when interrupted by a customer, would need to start over and could lose almost 1000 steps. Hora, on the other hand, crafted his watches from 10 assemblies of 10 subassemblies of 10 components each. Customer interruptions cost him at most 10 steps. The ability to compartmentalize tasks and distribute them in lieu of directing all tasks centrally allows firms to handle greater complexity, to more easily modify tasks, to reuse building blocks, and to isolate components for troubleshooting.

As Table 3 suggests, the benefit of the computer processing metaphor concerns multiple design variables for the network organization. Computer metaphors provide precise notions of modularity and loose coupling, reusability, efficiency, skill sets, task division, allocation and reassembly, processor control and coordination, and complexity among others. In the network organization as computer metaphor, the purpose is to coordinate problem solvers. Structural elements address such issues as which processors to choose and which arrangement limits vulnerability while procedural elements address such issues as how to compose and decompose tasks, how to coordinate distributed agents, and how to adapt.

\section{NETWORK ORGANIZATIONS AS ECONOMIES}

“... [a man] will be more likely to prevail if he can interest [his brethren's] self-love in his favour and show them that it is for their own advantage to do for him what he requires of them... It is not from the benevolence of the butcher, the brewer, or the baker that we can expect our dinner, but from their regard to their own interest ${ }^{13}$." Adam Smith (1776)

Use of an economic or rational agent metaphor for network firms leads to the question of motivating self-interested parties to achieve mutually satisfactory Pareto efficient outcomes. Efficiency, in this sense, is maximized when redistributing a trade surplus leaves everyone at least as well off as before. One or another party may exercise guile and deception yet they are at all times assumed to behave rationally and purposefully with respect to their own welfare. The purpose of collaboration is to produce a surplus at least as great as the sum of agents' gains working independently. Structural variables concern, for example, risk, information asymmetry, transaction costs, and complementary assets. Processes typically seek to align incentives in decentralized systems, to create and capture consumer surplus, and to establish mechanisms through which agents truthfully reveal their hidden information. The principal topics addressed in the economics of network organization span:
(A) Risk \& Information Asymmetry
(B) Teams, Games \& Self Interest versus Public Good
(C) Mechanisms Design
(D) Vertical Integration \& Transaction Cost Economics
(E) Resources \& Property Rights
(F) Value Creation \& Exploitation

Among the tools used to probe network organizations, the economy metaphor uses principalagency, game theory, contract theory, transaction cost economics, utility theory, and principles of product

${ }^{13}$ Reprinted as [127, p. 18]. 
bundling and price discrimination. Table 3 , at the end of this section, summarizes these points.

\section{A. Risk \& Information Asymmetry}

Among the critical aspects of negotiated relationships, principal-agent theory models risk, information asymmetry, and incentives $[38,116]$. In principal-agency theory, the main issue is whether or not, and under what conditions, the principal or owner of a project can successfully contract with an executor, the agent, to undertake work on his behalf $[38,60]$. Problems clearly arise when transferring the principal's agenda to any self-interested, rational and potentially guileful agent, partly due to inherent inefficiencies in motivating risk averse individuals. Moreover when an agent has private or asymmetric information, he can misrepresent the true state of affairs to secure more favorable terms or relative advantage. In the worst cases, for example, would-be partners intend to enter into a joint venture in order to appropriate technology and know-how [53]. In general, reduced surplus appears in the relationship as costs of insuring risk averse agents, as information rents extracted by agents with private knowledge, or as deadweight loss from non-value adding activities such as monitoring.

Strategic misrepresentation provides a primary reason for networks to collocate decision rights and local information. It may be more advantageous to "sell the project" to someone with local knowledge because their incentives are better aligned if they own the result they produce. Either at the outset or through the course of executing his duties a local agent may acquire private knowledge of his capabilities or the true difficulty associated with carrying out his tasks. This asymmetry of information works to his advantage insofar as he can misrepresent both problems and his intended efforts in order to increase his compensation. Misleading an associate in advance of a contract is "adverse selection" -- the partner or principal could have chosen a less guileful agent -- while underperforming after a contract is "moral hazard" -- an agent reneges on his commitment of effort shirking his "moral" responsibility to fulfill its terms $[38,116]$. In the context of network organization, partners must be at the same time credible and reliable or they must own the results of their actions. One semiconductor manufacturer lost significant market share due to the delivery failure of one of its two suppliers [20]. Over-optimistic representation of capability is a pitfall of asymmetric information.

Risk aversion may also cause firms to form "strategic alliances" or "joint ventures" [53, 76, 118]. Risk is roughly defined as the need to make decisions in the face of uncertainty. Beyond financial risk, it is variously defined as commercial risk (the chances of falling behind or finding a market niche), technology risk (the chances of investing in unproven technology or bringing it to market), and strategic risk (misapprehension of strategic concepts or venturing into unfamiliar markets) $[117,120]$. A network both helps to reduce the degree of uncertainty by bringing a greater abundance of more specialized resources to bear on a problem and it reduces possible loss through burden sharing.

One measure of network organization is the degree of risk sharing between a buyer and supplier in a subcontracting relationship [70]. If all risk is assumed by the subcontractor, then their association is through a fixed price contract and not a network. If, on the other hand, the buyer assumes all risk then the contract is cost plus, again there is no burden sharing and it is not a network. In either case, one party is fully insured. Jarillo cites an unpublished mimeograph by Kawasaki and McMillan in which the subcontractor bore approximately $30 \%$ of the risk in a large sample of Japanese network relationships. This finding is consistent with the general assumption of the principal-agent model in which the less risk averse and presumably wealthier principal bears more of the burden of uncertainty, in this case $70 \%$, than the more risk averse agent. In networked partnerships, it is relatively more efficient for the less risk averse, typically wealthier, partners to bear more risk. This supports joint control as one of the defining elements of network organizations.

Competition and speed requirements are forcing an ever higher degree of local, regional, and niche market responsiveness [109]. But, rapid decision speed limits firms to on-site supervision as the volume of information flows outstrips their capacity to move local knowledge to central planners. As noted earlier, centralized governance structures are potential bottlenecks. Although generalized knowledge and enduring summary statistics can be conveyed to a central planner, this is not true of specific knowledge of time and place [63]. The need to use unorganized, ephemeral, or specific local knowledge favors the distributed decision making of network organizations. Even if it were possible to communicate voluminous detail, central planners could not control events in each of their markets with the alacrity of managers on the spot. Collocating decision authority with knowledge of local conditions is one advantage networks have over hierarchies. Rather than transferring local data to corporate staff, networks transfer decision rights to line management [6, 97]. Piore [111] and Sabel [121] refer to this as the reintegration of conception and execution. Handy [56] strengthens this argument, calling it the principle of "subsidarity." According to this view, 
redistributing decision rights is not a transfer but a restoration of authority usurped by rising corporate hierarchy. Decisions ought to remain in the hands of those most familiar with the issues. This division leaves decisions requiring general knowledge of goals and structure with senior management and decisions requiring specific knowledge of local conditions with line management [105].

\section{B. Teams, Games \& Self Interest versus Public Good}

Decentralized decision rights create numerous opportunities for misaligned incentives and, as a result, network partnerships are no strangers to strife $[37,120]$. Corporate staffs often perform the difficult task of balancing conflicting goals among operating units, and subcontractors may legitimately fear closer relations with an overbearing partner [121]. Indeed, "interdependencies result in a substantial potential for conflict because they often involve tradeoffs among the goals of [network partners]" [37 p. 185]. To resolve such conflicts in cooperative partnerships, Johnston and Lawrence make an explicit appeal to Axelrod's [9] tit-for-tat game theoretic principles:

(1) Individually, each partner should avoid being the first to game the system in order to build trust.

(2) Reciprocate both cooperation and competitive maneuvering quickly.

(3) Do not be too clever attempting to outsmart one's partners.

More generally, game theory concerns the strategy spaces, rules of play, and actual decisions of selfinterested players in a game. In this case, each party seeks to maximize his own interests subject to the maximization plans of the other self-interested players. For networks, the most relevant aspects concern establishing coalitions and predicting agents' strategic behaviors when there are multiple rounds of competition.

For the tit-for-tat type of strategy to work, relationships must either be sufficiently long in duration or frequent in contact to permit assessment and review. Network members face a "prisoner's dilemma" in which they may find reneging on prior arrangements privately advantageous even though the joint profit maximizing strategy is for everyone to play as agreed. When one party cheats other parties suffer. Over time, however, agreements become enforceable because fellow partners can punish opportunism [72, 116]. Moreover, individuals and firms develop a reputation for fairness or unscrupulousness that qualifies them for participation in future deals. Through repeated transactions, relationships can become symbiotic [106] and trustworthy 14 [72, 107]. "Potential collaborators rightly assume that each will forbear from exploiting each other's vulnerabilities" [121 p. 32]. Network firms may even wish to commit their best resources in order to attract future partners [20]. The ability to form alliances for mutual gain greatly raises one's reputation as a desirable partner [21].

At low industry concentrations, networks can foster cooperation and responsiveness but at higher levels, when firms collectively control an industry, the same forces can tend towards collusion [138]. Through cartels, they can engage in monopolistic pricing and they can limit innovation choosing instead to reinforce the status quo. As before, cartels can be difficult to sustain whenever cheating appears more privately advantageous than collaborating.

Sustaining a partnership can also be difficult to sustain if one network member coasts on the relationship. Firms may need to be increasingly vigilant at maintaining their core competencies lest they become unattractive partners $[53,72]$. Shifts in tastes and technologies can obsolete a skill base or critical complementary asset. Forces which drove a network to take on a partner can also cause it to look elsewhere when tastes or technologies change. Indeed, many firms have outsourced portions of their value chain only to find that they have "hollowed" out their core competencies and are later abandonedby their partners [20].

Network partnerships rely on synergy; together, collaborators earn more by pooling resources than they would earn acting independently [112]. Cooperation works when there are excess returns to share, for example during periods of market growth. Applying game theory to networks, repeating the prisoner's dilemma can improve upon the one period solution because there are excess gains to share [72, 116]. If a market sours, however, collaboration may turn to competition. Interest in increased mutual gain may become self-interest in laying claim to shrinking pools of residual assets. Networks are difficult to sustain if the repeated prisoner's dilemma is reduced to a one-shot deal. Long term contracts have been found easier to enforce than spot contracts [116] and a survey of joint venture literature reports that changes in industry structure can lead to joint venture dissolution [76].

\footnotetext{
${ }^{14}$ Although "trust" in this instance is based on long term self-interest, a loyalty based interpretation is presented in the network as society section.
} 
It is possible, however, that in the absence of trust or any potential for reward from successor projects, firms can maintain short term contracts through "mutual hostage taking" [76]. Joint commitment devices include the pledging of resources, bonding, and the taking of joint stock positions among collaborators.

As teams of self-interested agents, networks broadly suffer from incentive problems with respect to surplus or "public goods" jointly created but individually consumed. Teams confront an organizational version of the "tragedy of the commons." Members have an incentive to overstate their private preferences when a good is provided from common resources but to understate their private preferences when asked to ante up their share of costs. Networks are particularly susceptible to this problem as network members have an incentive to minimize their own efforts while free riding on the efforts of others [118].

\section{Mechanism Design}

One possible solution to the public goods problem is a Groves-Clarke mechanism, a type of contract which encourages "truth telling" with respect to agents' private information. This incentive system compensates members through side payments which are proportional to the value members create for each other. It works by making each individual decision pivotal in determining the final outcome so that no one member has an incentive to misrepresent his or her private valuation.

Although not noted as such, Eccles and Crane [37] describe what appears to be the natural evolution of a Groves-Clarke mechanism in a network environment ${ }^{15}$. Individual investment bankers work in dynamic teams that form to bid on client projects. These teams have the unusual property that everyone gets to claim the full value of a project for his or her department if the bank wins a contract in competition with other banks. They also share direct costs equiproportionally which fixes total returns and limits haggling over burden and benefit sharing.

The problem with such an arrangement is that on any given project, the mechanism is clearly not budget balancing. Eccles and Crane take pains to emphasize this point, "Although revenues are measured, little effort is made to ... arrive at profitability figures, whether on a customer or a product basis, except at fairly aggregate levels" [37 p. 187]. Only upon

${ }^{15}$ This example is formally presented in Appendix A. annual review is there an effort to reconcile and assess the profitability of a given account. Only a very loose coupling ties effort to profit on specific projects and, on a cash basis, this system is clearly not sustainable in the long run. In practical terms, much of the shared benefits must come in the form of knowledge and political capital. Bankers do, in fact, keep an informal tally of political debits and credits, and chronic debtors are quickly denied access to subsequent deals.

\section{Vertical Integration \& Transaction Cost Economics}

Transaction cost economics sets the boundaries of the firm at the point where the marginal cost savings from conducting operations within the firm equal the marginal costs of errors and rigidity [60]. Transacting outside the firm entails costs for locating vendors, product screening, transportation, and delay. These market activities typically involve arms-length trading of relatively non-specific goods. This in turn, leads to inefficiencies when adapting unspecialized inputs to specialized use. A further concern lies in small numbers bargaining. If supply is limited, then buyers and suppliers are "inclined to expel considerable resources bargaining over the price at which the exchange is to take place" [142 p. 28]. Hierarchies solve these problems by vertical integration and owning the assets they use. Networks typically solve them by granting multi-party residual claims to the output from co-specialized production in order to align incentives.

Sharing control almost always involves investment inefficiencies [51] and overhead in governance structures, but it may be that agents cannot be separated from their assets i. e. they are indispensable to asset deployment. This occurs, for example, in the case of consulting know-how but it also implies that organizations cannot simply purchase such assets and vertically integrate them. If combining complementary assets creates more value than sharing control with indispensable agents, network organizations might emerge in preference to hierarchy.

At the other extreme, markets tend to be more flexible than hierarchies but they lack coordination mechanisms. From a strategic perspective, the market exposure provided by a network structure may improve on hierarchies by improving flexibility and environmental scanning. It may also foster innovation due to increased survival pressure [97, 109, 118, 128]. Agents can create more discriminating information by pooling their observations especially when data may be noisy [93]. Atomistic vendors in the marketplace are extremely aware of market conditions and highly sensitive to 
competition [72]. Moreover, internal transfer prices within networks tend to reflect market conditions leading to greater efficiency. Forcing corporate divisions to sell both internally and externally subjects otherwise inefficient operations to the conditioning tonic of the market [36]. As competition intensifies, firms will subject their internal assets to market tests to justify ownership [128 p. 12].

An economic justification for market pricing transfers draws support both from transactions cost theory and from the principle of comparative advantage. A firm will integrate activities if the sum of external prices and transaction costs is greater than the cost of internal production [142]. Internal production dominates low cost external production if transaction costs are too high. A network firm is one which is more efficient at minimizing transaction costs and therefore more capable of market transactions [70]. Additionally, this allows a firm or business unit to deconstruct the value chain and to assemble a coalition of partners, each with a comparative advantage in some phase of production. Teams generate more surplus when members co-specialize [93, 127]. A network "allows a firm to specialize in those activities of the value chain that are essential to its competitive advantage, reaping all the benefits of specialization, focus, and possible size" [70 p. 35]. Echoing this sentiment, "for collaboration to succeed, each party must contribute something distinctive" [53 p. 135]. By constructing a network of firms individually characterized by distinct comparative advantages, a single firm can trade for goods it produces less efficiently, generate economies of scale through sales to a larger external market, create economies of scope through product complements, and enjoy the advantages of reduced fixed costs having replaced them with highly efficient variable costs through its partners.

\section{E. Resources \& Property Rights}

A resource based view of the firm explains competitive advantage as a rational search for the best application of assets in the presence of asset heterogeneity, ex post limits to competition, ex ante limits to competition, and imperfect asset mobility [108]. Heterogeneity ensures that one collection of resources is intrinsically more efficient than another thus creating a competitive advantage. Resource differences may derive from scarcity, property rights, irreversible commitments, scale, first mover advantages, reputation, buyer search costs, buyer switching costs, information asymmetry, and channel crowding among others. Ex post limits to competition guarantee that rents are not dissipated or competed away once a market is established. Likewise, ex ante limits to competition preserve economic rents by preventing firms from prespending expected profits merely to secure favored access to resources. Imperfect mobility, as might be observed for intangible resources or co-specialized resources, imply that assets are not traded on an open market and therefore accumulate within the firm where they remain concentrated on a specific task. These four factors combine to guarantee above average payoffs.

One particularly interesting resource differential is information asymmetry in the form of "causal ambiguity," an ability to foster uncertainty regarding the causes of efficiency that prevents potential imitators from copying strategy [108]. Analysis of data regarding one's own customers and operations -to the extent that competitors cannot duplicate such data -- provide a substantial source of differential efficiency [71]. It is possible that sharing information among a partnership can also create new information [68] by focusing diverse expertise on identifiable problems and opportunities, thus creating more asymmetric information resources vis-a-vis competitors. A theory model of information sharing illustrates the possibility of creating a sustaining resource advantage [3] while a study of US, Japanese, and European joint ventures suggests that sharing can strengthen a partnership against competitors even as it weakens partners relative to one another [53]. Information asymmetry and causal ambiguity therefore highlight the importance of capturing as much information from network relationships as possible.

The innovation $[46,134]$ and management $[32,71$, $112,115]$ literature emphasize in particular the importance of know-how as a resource in network structured organization. Variations include specialized skills, technology, and unique information or patents. As companies seek complementary skill sets to exploit market opportunities, they partner with other firms having unique knowledge of a given market, product, technology or strategic resource. These arguments generally fall within the framework of incomplete contracts theory.

Under an incomplete contracts or property rights theory, agents make smaller up-front investments in assets whose use they have contracted for than those they own [51,61]. The basis for this argument is that under any unforeseen circumstance or incompletely specified contract, the owner has the last word on the disposition of any asset in question. This increases the owner's possible share of the reward ex post at the expense of the lessor. Thus any incomplete contract increases lessor risk and reduces their investment incentives. Accordingly, different ownership structures or property rights are more or 
NETWORK ORGANIZATIONS AS ECONOMIES

\begin{tabular}{|c|c|c|c|c|c|}
\hline \multicolumn{2}{|r|}{$\begin{array}{c}\text { View of Network } \\
\text { Organization Feature }\end{array}$} & $\begin{array}{c}\text { Potential } \\
\text { Benefits }\end{array}$ & $\begin{array}{l}\text { Potential } \\
\text { Concerns }\end{array}$ & $\begin{array}{l}\text { Useful Analytical } \\
\text { Perspectives }\end{array}$ & $\begin{array}{c}\text { Useful } \\
\text { References }\end{array}$ \\
\hline 产 & $\begin{array}{l}\text { Create a collective surplus in } \\
\text { excess of those created } \\
\text { individually. }\end{array}$ & $\begin{array}{ll}\text { - } & \text { Increased total gains. } \\
\text { - } & \text { Scope / scale economies. } \\
\text { - } & \text { Flexible access to resources. } \\
\text { - } & \text { Moderate specialization increases } \\
& \text { efficiency. }\end{array}$ & $\begin{array}{ll}\text { - } & \text { Difficult to divide surplus. } \\
\text { Difficult to measure team } \\
\text { contributions. } \\
\text { Tragedy of the commons, public } \\
\text { goods problem. } \\
\text { - Free rider problem. }\end{array}$ & $\begin{array}{ll} & \text { Principal-agency theory. } \\
\text { - } & \text { Transaction cost economics. } \\
\text { - } & \text { Game theory. } \\
\text { Property rights and incomplete } \\
\text { contracts theories. } \\
\text { - Utility Theory. }\end{array}$ & $\begin{array}{l}{[32,58,70} \\
72,76,105 \\
112,118 \\
138]\end{array}$ \\
\hline 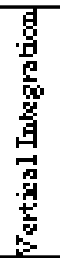 & $\begin{array}{l}\text { Vertical Integration \& Transaction } \\
\text { Cost Economics }\end{array}$ & $\begin{array}{l}\text { - } \quad \text { Closer to market transfer prices. } \\
\text { - } \quad \text { Lower fixed costs than hierarchy. } \\
\text { flexibility over hierarchies. }\end{array}$ & $\begin{array}{l}\text { - Higher variable costs than } \\
\text { markets. } \\
\text { - } \quad \text { Less flexible than markets. } \\
\text { Opportunism risk of non-owned } \\
\text { assets. }\end{array}$ & $\begin{array}{ll}\text { - } & \text { Transaction cost economics. } \\
\text { - } & \text { Scope/Scale efficiency principles. } \\
\text { Property rights and contract } \\
\text { theory. }\end{array}$ & $\begin{array}{l}1,22,37 \\
60,72,79 \\
105,109 \\
114,116 \\
142,143]\end{array}$ \\
\hline 焉 & $\begin{array}{l}\text { Vertical Integration \& Transaction } \\
\text { Cost Economics }\end{array}$ & $\begin{array}{ll} & \text { Specialization improves } \\
\text { - } & \text { Inficiency. } \\
\text { aternal resources generally traded } \\
\text { at efficient market levels. } \\
\text { Asset complements and scope } \\
\text { economies improve efficiency } \\
\text { over markets. }\end{array}$ & $\begin{array}{l}\text { Danger of shifts in relative } \\
\text { competency without continued } \\
\text { investment; hollowing. } \\
\text { Specialization increases } \\
\text { opportunism risk. } \\
\text { Bilateral monopoly. }\end{array}$ & $\begin{array}{l}-\quad \text { Transaction cost economics. } \\
\text { - } \quad \text { Rule of comparative advantage. } \\
\text { Value chain analysis. }\end{array}$ & $\begin{array}{l}{[22,32,36} \\
53,58,70 \\
76,96,101 \\
128,142 \\
143]\end{array}$ \\
\hline 产 & Resources \& Property Rights & $\begin{array}{l}\text { Heterogeneity provides } \\
\text { competitive advantage. } \\
\text { Intangible resources harder to } \\
\text { duplicate; help create "causal } \\
\text { ambiguity" for competitors. } \\
\text { Indispensable agents together } \\
\text { with highly complementary assets } \\
\text { helps explain network firms. }\end{array}$ & $\begin{array}{ll} & \text { Requires mobility barriers. } \\
\text { - } & \text { Intangible resources hard to } \\
\text { transfer. } \\
\text { Coordinating owners of } \\
\text { intangible assets incurs } \\
\text { governance costs. }\end{array}$ & $\begin{array}{ll} & \text { Resource based view. } \\
& \text { Property rights theory. }\end{array}$ & $\begin{array}{l}{[4,11,33} \\
51,61,97 \\
108,112]\end{array}$ \\
\hline$\frac{2}{3}$ & Value Creation \& Exploitation & $\begin{array}{l}\text { - } \\
\text { miche markets with higher } \\
\text { margins and lower competition. } \\
\text { - Smaller aftermarkets. } \\
\text { Scope / scale economies and } \\
\text { product complements. } \\
\text { Possible network externalities. }\end{array}$ & $\begin{array}{ll} & \text { Need to know consumer } \\
\text { preferences. } \\
\text { - } & \text { Customization harder to achieve. } \\
\text { Hard for producer to capture } \\
\text { network externality benefits. } \\
\text { Possible collusion, cartels limit } \\
\text { innovation. }\end{array}$ & $\begin{array}{ll}- & \text { Principles of price discrimination } \\
\text { and bundling. } \\
\text { - Principles of product } \\
\text { differentiation. } \\
\text { - Utility theory. } \\
\text { - Scope/Scale efficiency principles. } \\
\quad \begin{array}{l}\text { Principles of standards, network } \\
\text { externalities. }\end{array}\end{array}$ & $\begin{array}{l}{[28,32,37} \\
40,58,72 \\
75,97,101 \\
105,106 \\
109]\end{array}$ \\
\hline$\stackrel{\hbar}{\stackrel{\hbar}{g}}$ & $\begin{array}{l}\text { Teams, Games \& Self Interest vs. } \\
\text { Public Good }\end{array}$ & $\begin{array}{ll} & \text { Repeated transactions build } \\
\text { reputation and trust. } \\
\text { - } & \text { Shared risk. } \\
\text { Increased economies of } \\
\text { collaboration / synergy. }\end{array}$ & $\begin{array}{l}\text { Self-interested agents with guile } \\
\text { may practice deception; } \\
\text { opportunism } \\
\text { More enlightened self-interest } \\
\text { than loyalty. } \\
\text { - Cooperation ends if game appears } \\
\text { near end. } \\
\text { Cheating on relationship not } \\
\text { uncommon. }\end{array}$ & $\begin{array}{l}\text { Game theory as a model of } \\
\text { cooperation. }\end{array}$ & $\begin{array}{l}9,37,53 \\
70,72,76 \\
112,116 \\
117,120 \\
121]\end{array}$ \\
\hline
\end{tabular}




\begin{tabular}{|c|c|c|c|c|c|}
\hline मूँّ & $\begin{array}{l}\text { Teams, Games \& Self Interest vs. } \\
\text { Public Good }\end{array}$ & $\begin{array}{ll} & \text { Long term interaction or } \\
\text { repetition encourages sustained } \\
\text { cooperation over cheating. } \\
\text { Repeated transactions build } \\
\text { reputation and trust. }\end{array}$ & $\begin{array}{l}\text { May require mutual hostage } \\
\text { taking. } \\
\text { Long term lock-in incurs } \\
\text { inflexibility costs similar to } \\
\text { hierarchy. }\end{array}$ & $\begin{array}{l}-\quad \text { Game Theory. } \\
\text { - } \quad \text { Transaction cost economics. }\end{array}$ & $\begin{array}{c}{[9,21,70,72,} \\
76,105,116, \\
142,143]\end{array}$ \\
\hline 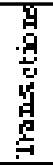 & $\begin{array}{l}\text { Vertical Integration \& Transaction } \\
\text { Cost Economics }\end{array}$ & $\begin{array}{l}\text { Transactions costs generally } \\
\text { lower than for markets. }\end{array}$ & $\begin{array}{l}\text { Transactions costs generally } \\
\text { higher than for hierarchies. }\end{array}$ & - $\quad$ Transaction cost economics. & $\begin{array}{l}{[36,60,70,} \\
90,105,142, \\
143]\end{array}$ \\
\hline 留 & Resources \& Property Rights & $\begin{array}{l}\text { Increased investment efficiency } \\
\text { by changing ownership structure. }\end{array}$ & $\begin{array}{l}\text { - Joint control incurs governance } \\
\text { costs. }\end{array}$ & $\begin{array}{l}\text { Property rights and incomplete } \\
\text { contracts theories. }\end{array}$ & $\begin{array}{c}{[51,60,61} \\
117]\end{array}$ \\
\hline 䒿 & Resources \& Property Rights & 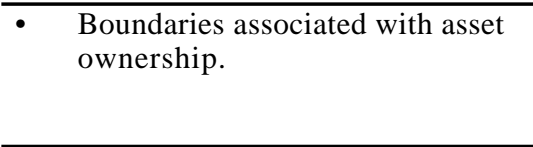 & $\begin{array}{l}\text { - Joint control incurs governance } \\
\text { costs. }\end{array}$ & $\begin{array}{ll} & \text { Property rights theory. } \\
& \text { Transaction cost economics. }\end{array}$ & $\begin{array}{l}{[51,60,61,} \\
70,128,143]\end{array}$ \\
\hline 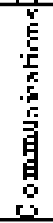 & Risk \& Information Asymmetry & $\begin{array}{l}\text { More direct communications help } \\
\text { reduce information asymmetry. } \\
\text { Increased network communication } \\
\text { can increase information } \\
\text { asymmetry relative to } \\
\text { competitors. }\end{array}$ & $\begin{array}{l}\text { - Transmitting voluminous specific } \\
\text { local detail may be infeasible. } \\
\text { More communication of no help if } \\
\text { asymmetry due to guile. }\end{array}$ & $\begin{array}{l}\text { Collocation of specific knowledge } \\
\text { of local conditions and decision } \\
\text { rights or authority to act. } \\
\text { Principal-agency theory. }\end{array}$ & {$[63,95,105]$} \\
\hline 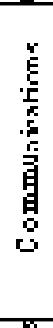 & Resources \& Property Rights & $\begin{array}{l}\text { Information sharing can provide } \\
\text { resources to help partners make } \\
\text { better decisions. } \\
\text { Communicating information can } \\
\text { lead to new combinations of } \\
\text { expertise and created value. } \\
\text { Information asymmetry creates a } \\
\text { "causal ambiguity" resource } \\
\text { relative to competitors. }\end{array}$ & $\begin{array}{l}\text { - Competitive environments } \\
\text { discourage sharing. } \\
\text { Shared information can be } \\
\text { damaging with opportunistic } \\
\text { partners. }\end{array}$ & $\begin{array}{l}\text { - } \quad \text { Resource theories of the firm. } \\
\text { Theories of communication in } \\
\text { networks. } \\
\text { Theories of information systems } \\
\text { and learning. }\end{array}$ & $\begin{array}{c}{[3,53,68,} \\
108]\end{array}$ \\
\hline 幽 & $\begin{array}{l}\text { Vertical Integration \& Transaction } \\
\text { Cost Economics }\end{array}$ & $\begin{array}{l}\text { Partners trade on the basis of core } \\
\text { competencies. } \\
\text { Avoid opportunity costs of } \\
\text { performing tasks at which firm is } \\
\text { second rate. }\end{array}$ & $\begin{array}{l}\text { Danger of "hollowing" of skill } \\
\text { base through outsourcing. }\end{array}$ & $\begin{array}{l}\text { - } \quad \text { Principle of comparative } \\
\text { advantage. }\end{array}$ & $\begin{array}{r}{[20,32,53,} \\
70,72,76]\end{array}$ \\
\hline 悬 & Risk \& Information Asymmetry & $\begin{array}{ll} & \text { Burden sharing reduces risk. } \\
\text { Decentralization increases } \\
\text { incentives. }\end{array}$ & $\begin{array}{ll}\text { Employees often risk averse } \\
\text { compared to firms. } \\
\text { Performance rewards can be } \\
\text { costly; Incentives may skew } \\
\text { desired behaviors } \\
\text { Moral hazard and adverse } \\
\text { selection. } \\
\text { Information asymmetry leads to } \\
\text { insurance, information rents, and } \\
\text { deadweight loss. }\end{array}$ & $\begin{array}{l}\text { Principal-agency theory. } \\
\text { - Utility theory. }\end{array}$ & $\begin{array}{c}{[38,53,70} \\
76,93,116 \\
117,120]\end{array}$ \\
\hline
\end{tabular}




\begin{tabular}{|c|c|c|c|c|c|}
\hline 窎 & Mechanism Design & - $\quad$ Can be truth telling. & - $\quad$ Not always budget balancing. & $\begin{array}{l}\text { Revelation mechanisms (e.g. } \\
\text { Groves-Clarke). }\end{array}$ & {$[37,133]$} \\
\hline 害 & Resources \& Property Rights & $\begin{array}{l}\text { Ownership improves investment } \\
\text { incentives. }\end{array}$ & $\begin{array}{l}\text { Joint control incurs governance } \\
\text { costs. }\end{array}$ & $\begin{array}{l}\text { Property rights and incomplete } \\
\text { contracts theories. }\end{array}$ & $\begin{array}{l}{[4,11,16} \\
22,51,61]\end{array}$ \\
\hline 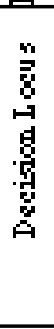 & Risk \& Information Asymmetry & $\begin{array}{l}\text { Decentralization provides risk } \\
\text { sharing among stakeholders. } \\
\text { "Selling the Project" reduces } \\
\text { inefficiencies of information } \\
\text { asymmetry. } \\
\text { Decentralization increases effort } \\
\text { and innovation. }\end{array}$ & $\begin{array}{ll}\text { - } & \text { Not all decision rights can be } \\
\text { - } & \text { easily transferred. } \\
\text { Information asymmetry leads to } \\
\text { insurance costs, information } \\
\text { rents, and deadweight loss. } \\
\text { - } \quad \text { Hard to monitor effort. } \\
\text { Hard to allocate individual / firm } \\
\text { contributions. } \\
\text { - Subject to hold-up. } \\
\end{array}$ & $\begin{array}{l}\text { Principal-agency theory. } \\
\text { Collocation of specific knowledge } \\
\text { of local conditions and decision } \\
\text { rights or authority to act. }\end{array}$ & $\begin{array}{c}{[6,38,56} \\
63,76,93 \\
97,105,116]\end{array}$ \\
\hline 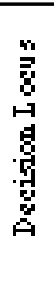 & $\begin{array}{l}\text { Teams, Games \& Self Interest vs. } \\
\text { Public Good }\end{array}$ & $\begin{array}{l}\text { Decentralized decisions improve } \\
\text { speed and accuracy in local } \\
\text { markets. }\end{array}$ & $\begin{array}{l}\text { Local suboptimization, } \\
\text { decentralized decisions misalign } \\
\text { group / individual incentives. } \\
\text { - } \quad \text { Free rider problem. } \\
\text { Tragedy of the commons, public } \\
\text { goods problem. } \\
\text { Cooperation can lead to } \\
\text { cartelization. }\end{array}$ & $\begin{array}{ll} & \text { Game theory. } \\
- & \text { Principal-agency theory. } \\
\text { Collocation of specific knowledge } \\
\text { of local conditions and decision } \\
\text { rights or authority to act. }\end{array}$ & $\begin{array}{c}{[72,93,97} \\
105,128 \\
138]\end{array}$ \\
\hline 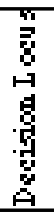 & Resources \& Property Rights & $\begin{array}{l}\text { - Secure cooperative gains by } \\
\text { involving indispensable agents } \\
\text { with cospecialized assets. }\end{array}$ & $\begin{array}{l}\text { Inefficiency from shared } \\
\text { governance. }\end{array}$ & $\begin{array}{l}\text { Property rights theory and } \\
\text { incomplete contracts. }\end{array}$ & $\begin{array}{l}{[4,16,51,} \\
61]\end{array}$ \\
\hline 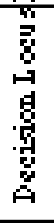 & $\begin{array}{l}\text { Vertical Integration \& Transaction } \\
\text { Cost Economics }\end{array}$ & $\begin{array}{l}\text { Combining conception with } \\
\text { execution for faster turnaround, } \\
\text { better incentives, and innovation. }\end{array}$ & $\begin{array}{ll} & \text { Reduced scope of attention. }\end{array}$ & $\begin{array}{l}\text { Principal-agency theory. } \\
\text { Collocation of specific knowledge } \\
\text { of local conditions and decision } \\
\text { rights or authority to act. } \\
\text { Property rights theory and } \\
\text { incomplete contracts. }\end{array}$ & $\begin{array}{c}{[56,63,74} \\
97,105,109 \\
111,121]\end{array}$ \\
\hline 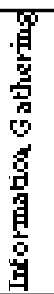 & $\begin{array}{l}\text { Vertical Integration \& Transaction } \\
\text { Cost Economics }\end{array}$ & $\begin{array}{l}\text { Networks more like markets in } \\
\text { information gathering. }\end{array}$ & $\begin{array}{l}\text { Need to integrate decentralized } \\
\text { information. }\end{array}$ & $\begin{array}{l}\text { Tradeoffs in transferring decision } \\
\text { rights versus transferring local } \\
\text { information. }\end{array}$ & $\begin{array}{c}63,71,72 \\
93,97,105 \\
109,128]\end{array}$ \\
\hline
\end{tabular}

Table 4-- Viewing the network organization as an economy yields insights on products and pricing, on risk and efficiency, on strategic gaming behavior, and on mechanism design. Note references may relate to theory or network organization attributes and may appear in multiple frameworks. 
less efficient depending on the efficiency of the ex ante investments they induce.

Why might a vertically integrated firm not acquire an entrepreneurial firm once a niche had been discovered and made profitable [107]? To the extent that knowhow represents an intangible or uncontractible good, it cannot easily be written into a complete contract $[4,16]$. Intangibility makes know-how difficult to purchase or even to gauge whether its owner has fully deployed it leading to severe problems of moral hazard. With asymmetric information, a principal can best ensure an agent's contributed know-how by transferring or sharing project ownership. If both parties have unique knowledge, then skill complements prevent full transfer of ownership to either party because both are indispensable. Network organization might therefore emerge as a compromise in which all parties are residual claimants and all parties contribute non-contractible complementary know-how at a level which ensures that the surplus from strategic complements exceeds the overhead and efficiency costs of joint control. In the etiology of network organizations, this offers a third possible explanation for their emergence together with reductions in coordination costs and improvements in decision support tools.

\section{F. Value Creation \& Exploitation}

At a consumer level, a network's flexibility allows it to provide more customized goods [28, 37, 72, 90, 97, 106, 109]. Italian textile mill networks have proven very responsive to fashion [72] and investment bankers successfully tailor each deal to specific clients [37]. The economic justification for custom tailoring and product differentiation is the ability to enter niche markets $[90,109]$ where firms are no longer in direct competition and they can charge full price to the consumer. Such prices and their higher margins capture consumer surplus for the producer or firm. Customization also reduces the secondary markets for products because there are fewer consumers with identical demand profiles. Cooperation between product firms also enables them to take advantage of economies of scope. Strategic complements are products which sell better together than apart. The practice of bundling strategic complements further assists companies with price discrimination, allowing them to capture more consumer surplus.

"Network externalities" also constitute a second form of product complements $[40,75]$. The difficulty for firms is in finding ways to capture surplus from value created external to their production functions. Buyers create network externalities by purchasing products whose consumption benefits not only themselves but also the collection or "network" of users who also own it. Acquiring a telephone service, for example, allows a buyer to reach others while affording others a low cost avenue to the buyer. Other examples include computer operating systems and QWERTY keyboards. Standards which create network externalities can benefit users and producers by allowing the purchase or manufacture of compatible components rather than entire systems. Corporations attempt to create these standards, to the exclusion of competing standards, by banding together in coalitions or networks -- a phenomenon which describes certain emerging markets particularly in computers and telecommunications [105, 109]. Firms may also collectively experience the advantages of cooperation as when their industry sector or region benefits from shared information or infrastructure [107]. Northern Italian textile manufacturers benefit from such regional cooperation.

Table 4 summarizes the key contributions of the network organization as economy metaphor and captures key structural variables concerning, for example, risk, transactions, incentives, property rights, resource heterogeneity, and contracts. Processes often involve ways to align incentives through repeated interaction or transferring property rights. The goal of team collaboration is largely to create surplus by specialization and by combining complementary assets.

\section{NETWORK ORGANIZATIONS AS SOCIETIES}

\begin{abstract}
"Organizations are and always will be run by people. They are infused with purpose and meaning only through the imagination and will of people..." Lawrence and Lorsch
\end{abstract} (1967)

Many sociological and psychological factors have not yielded to mainstream computational or economic models of human behavior [116]. Sociologists argue that social patterns of human interaction transcend reductionist economic agendas: "The pursuit of economic goals is typically accompanied by [such] non-economic [goals] as sociability, approval, status, and power... Economic action is socially situated and cannot be explained by reference to individual motives alone" [50 p. 25]. Expressing a similar sentiment, Biggart and Hamilton propose that "Homo economicus is a generic individual distinguished not by sex, ethnicity, religion, age, or any other social characteristic" [13 p. 480]. Market pricing models appear to be simplifying mechanisms which fail to capture the intricacies and richness of responsive human interaction [112]. 
Accordingly, the society metaphor augments the computer and economy metaphors by focusing on human context. It concerns human response to contextual cues such as horizontal, vertical, and geographic boundaries [10], cultural or structural behavior constraints, and communications manner as well as content. A sociological approach recognizes what an efficiency approach might not insofar as opinions and perceptions are influenced by desires for power and recognition, fear of shame, and avoidance of demeaning work among others. Concepts employed by sociologists may include sameness of participants, alienation, in-group bias, peer pressure, desire, loyalty, status, and symbolism. As Table 5 at the end of this section suggests, these issues affect network design variables respecting:
(A) Granularity
(B) Identities, Groups \& Boundaries
(C) Consensus, Rank, Politics \& Power
(D) Trust \& Loyalty
(E) Roles \& Ties
(F) Organizational Learning
(G) Environment

Sociological findings tend to interpret behavior and its consequences calling upon, for example, general systems theory, contingency theory, group theory, structuration theory, process theory, political influence and power theories, and population ecology.

\section{A. Granularity}

An advantage of the network organization as society metaphor is its greater appreciation of granularity and the differences in interpretation resulting from different levels of analysis. Reflecting Weick's [137] observation that the level of coupling varies with the level of analysis, Markus and Robey [92] point out that entities of interest range from individuals to groups, to organizations, and to whole societies. Each entity is embedded within a different layer of social context implying that a compartmentalized, discrete, or context independent analysis may omit critical factors which determine the actions of any entity in question. This section considers how individuals perform within groups. The next section considers groups within organizations; and the final section considers organizations within environments.

Network organizations can evolve out of personal or small group ties: "Many of the arrangements ... commonly found in the publishing, fashion, computer software, construction, and entertainment businesses, are among individuals, independent production teams, or very small business units" [112 p. 330]. Among the more systematic inquiries into group behavior, one series of experiments identified efficiency versus sociability tradeoffs in teams of five people [80]. Teams had to solve certain well identified problems in which experiments differed according to communication channels and the abstractness of the tasks. The two configurations closest to hierarchical and network structures ${ }^{16}$ are depicted in Figure 4.
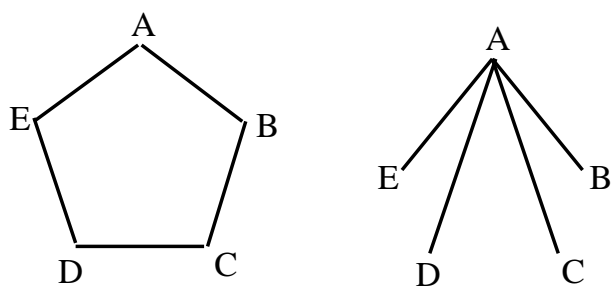

Figure 4 -- A five person network structured team is depicted on the left and a centralized team on the right.

Two basic results emerged concerning organizational structure. First, according to efficiency criteria such as speed, message count, and frugal use of resources, the centralized structure outperformed the network structure on almost all tasks. The network lacked a central coordinating mechanism and spent more time negotiating procedures. On average, however, persons in the network structure were apt to value their participation more and be much happier with their experience. The one exception was the central person in the hierarchy who was generally quite happy with their experience. Second, for the more abstract tasks the network tended to generate more novel ideas which were also adopted more frequently. New ideas generated in the centralized configuration were more likely to be discarded on the grounds that the central person was too busy, that the innovation was too bothersome to implement, or that current practices required no improvement. In a sense, networks of small groups or individuals prove to be more innovative, a finding supported by other articles [72, 109].

\section{B. Identities, Groups \& Boundaries}

Identities help shape organizations by helping members conceive of boundaries for actions, resources, and purpose. Organizations in general are purposive social systems for directing collective action toward common goals [2]. Yet within network literature this emphasis is especially great as agents forge identities for themselves within groups and for groups within organizations. Members experience a

${ }^{16}$ Two of three structures appearing in [80]. 
"dual citizenship" of affiliation with project teams and with companies [56]. They have both in-group and out-group ties yet work to achieve a larger social integration [10]. Network members need "shared goals" [120], a "common background" [112], and a collective "vision" [97, 101, 109].

Identities facilitate boundary construction by addressing the confusion arising from integration and permeability. As loosely coupled systems, group cooperatives respond to one another but preserve independent identities and some evidence of "physical or logical separateness" [136, p. 3]. An identity is any source of action or effort at control not rooted in biological or physical phenomena and to which an observer can attribute meaning, for example employers, communities, and crowds [139]. Actors perceive identities as continuous and create associations which are self-similar. By perception or construction, the organization to which an individual belongs may be understood to mean that entity with which they identify most strongly or that institution they believe themselves to represent. Allegiances of identity might therefore shift more fluidly than discrete changes in contracts or asset ownership. When an employee of one organization works on-site and on behalf of another [74], jointly held beliefs may determine an agent's true affiliation along with whatever publicly declared boundaries separate one group from another.

Although network organizations attempt to integrate across formal boundaries, group differentiation and boundary setting can lead to in-group bias and reduced integration. This may result from social psychology and affinity for like types -- or for economizing on time and effort -- since investments in out-group contacts require resources [10]. As the total number within a group increases, the number of contacts per person grows until damped by time and effort constraints. Thus, as group size increases, the number of out-group ties decreases, suggesting that integration is difficult to sustain as organizations grow larger [10]. The need for boundary spanning communication intensifies with more ambiguous roles and objectives [37].

A group theory of social behavior suggests that groups -- associations of two or more people influencing one another through direct communication over time -- benefit individuals by "providing information resources, emotional resources, and identity support" [42 p. 42]. Groups then benefit organizations through coordinating joint activities, promoting specialization, and facilitating organizational learning. Aside from collective productivity, however, groups concern themselves with identity maintenance where recognition, fear of shame, and peer pressure play a role. Members tend to judge actions for consistency with identity, using peer pressure to sanction behaviors apposite of group norms: the nail that sticks up is the one hammered down. Japanese companies pursue extra-curricular group activities to socialize employees and establish group identity [42]. These same forces help explain decreased employee morale during layoffs. When group integrity and identity are destroyed, the organization as society suffers.

Informal cultural constraints can also appear above the group in a larger social context. Western traditions regarding personal and religious freedom have led to laws promoting individual rights. The establishment of individual opportunity, for example, extends to legal proscriptions on nepotistic hiring. In Asian economies, on the other hand, traditions regarding the importance of family and societal obligation have given rise to different expectations regarding loyalty and employment [13]. Despite their size, Korean chaebol are essentially family-run businesses. In Japan, keiretsu are descended from family owned zaibatsu which were forcibly decontrolled after World War II. The same phenomenon holds in Taiwan where jituanqiye or family owned conglomerates play a central role in the economy. With the subordination of individual identity, powerful group-centered organizations emerge.

A structuration view can be helpful interpreting the constraints and enablements of social norms, particularly as it complements other theories. Psychological theories of social groups tend to project people's behaviors onto social wholes as magnified versions of individual phenomena. The direction of influence runs from individuals to societies. Holistic theories, in contrast, consider the direction of influence to be reversed. According to this view, societies exhibit emergent properties and have autonomous needs, goals, and interests such that they mold the behaviors of constituent members [52]. Without appealing to emergent, sui generis, properties of wholes exceeding their aggregate parts, structuration theory allows that there remain useful referent constructs for both individuals and collectives and that causality can run both ways. Social systems are ongoing and reciprocal patterns of relationships, structures, generative rules, and resources [48, 52]. Action, in structuration theory, is recursive and selfreproducing in that it creates social scaffolding or structure. Awareness of structure enables certain actions even as it inhibits others. Social norms guide individual actions and individual actions can reinforce, reinterpret, or remake social norms. This sheds light on the behavior of people in groups. 
Within network organizations, identification with group and social norms can guide action even as actions can influence norms. Social structure may be "a common law, language, and currency -- a uniform way of doing business" [56]. Having interviewed American managers in a Japanese bank, Ouchi ${ }^{17}$ relates a story indicating how culture determines business practice. The U.S. managers voiced a concern that the Japanese executives never understood objectives and never provided specific targets for sales volume or profitability but rather spoke in broad generalities. Without objective targets, management by objectives was impossible. Japanese executives, in turn, voiced a concern that the U.S. managers did not understand objectives. If the managers could only understand the Japanese "philosophy of banking" -how they should relate to their customers, competitors, employees, and community -- then they could determine for themselves the appropriate targets regardless of how unusual the situation might appear. "In essence, [social norms] become a substitute for formal controls" [10 p. 426] even as behaviors establish appropriate norms. In this case, identity, norms, and actions define an informal boundary between their organizations.

\section{Consensus, Rank, Politics \& Power}

Shared control in network organizations leads to more consensus management which tends to increase "buyin" among employees affected by new decisions. "Research suggests that hierarchical design dampens employee motivation because individuals are likely to be more committed when they have participated in a decision, and much less enthusiastic when they have been ordered by superiors to undertake a particular task" [112 p. 319]. Participatory involvement of committees and line management in the process of setting strategy increases group member acceptance of and responsibility for final recommendations [66, 109]. Asian companies may appeal explicitly to group decision processes in order to promote harmony [13]. Differences in individual reactions to the same task when assigned by fiat and when assigned by joint agreement are difficult to explain except in terms of respect for workers as persons not substitutable forms of homogeneous labor.

Decentralizing authority reduces the number of hierarchical ranks and increases responsibility among those who were not previously decision makers. With better decision support, the rank of a person required to make a decision becomes less important [6]. Joint control tends to accompany

\footnotetext{
${ }^{17}$ Cited in [99].
}

"empowerment," meaning that individuals receive information about their own and the organization's performance, they are rewarded for performance, they possess the skills required to perform, and they are granted decision authority [71]. Not surprisingly, this can win autonomy by losing unanimity and purchase participatory buy-in at the cost of political bail-outs.

A prime hazard of team organization is that individual team members tend to overvalue their own contribution relative to other members [124]. Many refuse to subordinate their interests to the interests of the community and the distribution of authority in networks affords them the ability to act on their own behalf. At times of resource scarcity, individuals will also tend to hoard resources making them unavailable for more desirable purposes.

Consensus management has been cited as a prime cause of failure to conduct organizational change [12]. In effect, no one party wishes to have their own "ox gored" to improve the whole organization. Particularly in times of crisis, participatory management can misallocate resources since it often leads to proportional burden sharing rather than complete restructuring. Continuous and strong senior management support is necessary to effect radical change [12]. Increased political influence costs balance, to a limited extent, the benefits of an option to replace non-performing network members.

Consensus management and empowerment can change organizational behavior, as individuals, once given authority, grapple to extend it. Networks, more than hierarchies, tend to fall victim to corporate politics and local turf battles [128]. When titular authority yields to expertise, task delegation which was formerly a matter of fiat becomes a matter of persuasion and negotiation [73]. In short, shifting between networks and hierarchies has social ramifications with respect to modes of influence. Interpersonal skills come to the fore and persons are free to challenge the authority on which demands are based. As noted in Rockart and Short [120], "network structures ... are flexible, flat, complex and rife with conflict"18 and "recurring conflict is inevitable"19.

Movement to flatter organization changes power structures within the firm $[28,74,88,109,120$, 144]. Structural leveling may conflict with both the self interest of entrenched management and with the expectations of persons lower in the hierarchy.

\footnotetext{
${ }^{18}$ Ibid. Quoting Eccles \& Crane.

${ }^{19}$ Ibid. Quoting Lawrence \& Lorsch.
} 
People vary to the extent that they seek power but rarely do they voluntarily relinquish it [91]. This can make it extremely difficult to move towards network structures even if employee compensation were to increase. Kanter [73] points out that corporations have reason to proliferate management tiers since power and status within a multi-tiered system are a few of the non-financial perquisites of success. Flattening structure reduces incentives by cutting chances for promotion and it clashes with employee expectations of status as a reward for performance. Greater responsibility, increased demand for skills, and lower opportunity for advancement tend to raise worker demands for income [6].

Theories of power help to explain network organizational behaviors on the basis of using networks to effect control [14, 43, 140]. Power may be considered as a measure of dependence in relationships [94] where one agent's dependence shows another's control over resources that are in demand or that have a high motivational effect. Power may also be an index of an agent's ability to bring about desired results [110]. Increasing one's independence and others' dependence increases one's power. Decreasing one's motivational interest in outcomes -- for example, by finding satisfactory alternatives -- increases independence while securing control over resources increases others' dependence. Based on resources, small firms may have little political or market power unless they form networks [107]. In network organizations, power can also be measured by indices of "centrality" [43]. "Degree" counts the number of links to other agents and thus the number of alternative channels to potential resources. "Closeness" sums the shortest paths to others and measures efficiency of reach. "Betweenness" counts the instances of an agent interposing themselves or appearing along the only path between other agents so that their position allows them to mediate communications and access. Empirically, these measures appear to correlate with perceptions of influence and control in publishing [14]. They also accord well with levels of processor control as depicted in Figures 2.A-E as well as the index of control concentration described in that section. Gaining and maintaining control in various environments can be achieved by managing networks of ties [140].

\section{Trust \& Loyalty}

An organizational behavior perspective also holds that trust as well as economic risk determine governance structures [112, 121]. Based on loyalty, network organizations routinely violate the assumption that price is the primary factor in purchasing decisions, preferring instead to favor suppliers with whom they have established relations [13]. With trust, new governance structures emerge which permit "cooperative pursuit of common goals" at the same time there is "vigilant monitoring to ensure that the costs and benefits of achieving those goals are fairly shared" [121 p. 33 citing Dore]. Ring and Van de Ven [117] use trust and risk to elaborate four different governance structures. Trust corresponds to predictability of expectations and reasonable confidence in a partner's goodwill while risk corresponds to its use in the network organization as economy. Combining these concepts leads to a prediction of the governance structures ${ }^{20}$ in Figure 5.

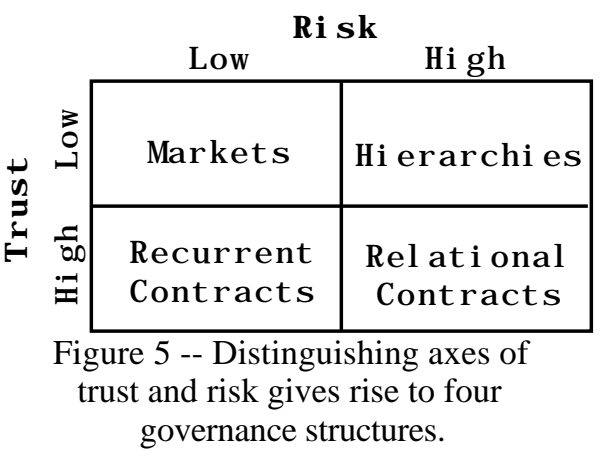

Here, markets and hierarchies do not differ substantially from their transactions cost interpretations; efficiency is the central concern and social relations are largely "frictional matters." A recurrent contract is defined as a repeated exchange between parties with moderate transaction specificity, relatively short duration and few but non-zero terms left to future resolution. In recurrent contracts, parties can experiment with safeguards as the relationship evolves. A relational contract is one with long term investment and repeated bargaining over output and property rights transfers where assets are highly specific and trading is subject to substantial future hazard [117]. Relational contracts specify mechanisms for dispute resolution rather than damage compensation. They are designed to promote equity and efficiency in a stable and enduring relationship.

Trust is essential to sustaining networks because it permits partners to choose high risk and reward actions; confidence in a partner's trustworthiness reduces risk. Trust depends on shared and inviolable goals, culture, responsibility, and vision [100, 117]. Loyalty, a key benefit of trust, implies that the relationship per se is valued, that the relationship counts as a decision factor, and that partners will invest considerable effort in maintaining it. Trust and commitment afford the added benefit of "functional

${ }^{20}$ From Ring and Van de Ven [117 p. 490]. 


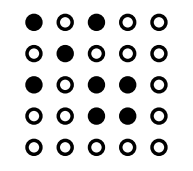

Assistance

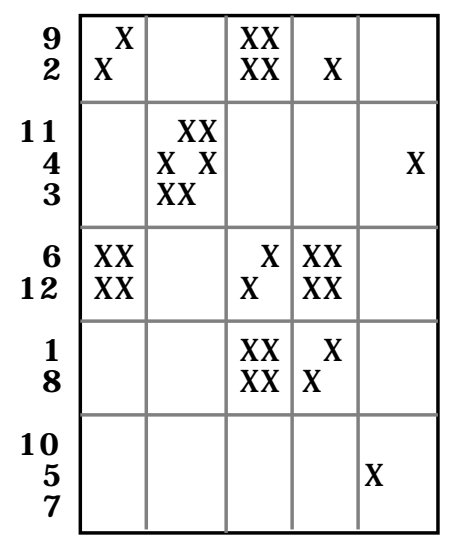

Figure 6 -- Three different types of tie are aggregated to show blocks and zeroblocks within a population of twelve researchers. The researchers are grouped into five teams. conflict;" given expectations of an enduring relationship, partners raise disagreements with the intention of innovating a mutually beneficial or win/win solution. This creates a mechanism for change and for finding new sources of value. Without trust, conflict is dysfunctional, often leading to network dissolution [100].

\section{E. Roles \& Ties}

While the concept of network organization presupposes that members are linked or tied together, the precise nature of ties and their influence on network structure are rarely specified in nonsociological models. If ties vary in strength and can also influence the formation of other ties, they can affect patterns of information flow [19, 49, 141]. Let tie strength be a function of importance, frequency of contact, or (in the case of individuals) emotional intensity. Then the presence of a strong tie from agent $\mathrm{A}$ to $\mathrm{B}$ and from $\mathrm{B}$ to $\mathrm{C}$ may justify assuming the presence of at least a weak tie from $A$ to $C$ [49]. Based on independent probabilities, if $\mathrm{A}$ spends half her time with $\mathrm{B}$, and $\mathrm{B}$ spends half her time with $\mathrm{C}$, then $\mathrm{A}$ spends one quarter of her time with $\mathrm{C}$ together with B. Any affinity relationship or positive correlation boosts this probability.

If a "bridge" is defined as the sole pathway between agents or groups of agents, then these assumptions imply that strong ties can not serve as bridges between any agents having other strong ties. The reason is that any strong tie other than the bridge tie implies the existence of another tie and thus an alternate pathway. In most large or practical networks, bridges will consist predominantly of weak ties [49]. For network analysis, there are at least three significant implications. First, agents with many weak ties (liaisons) may be the best positioned agents for diffusing innovations because they are likely to act as bridges. Second, blocks of agents with many tight ties and few weak ties are more likely to hold encapsulated or autochthonous information since their information flows circulate mostly within the group. Third, although fellow agents within a block of strong ties may be more forthcoming with information, agents at the end of weak ties may have more useful, less redundant information. These properties are not governed by the weakness of the ties but rather the structural holes between blocks that only weak ties are likely to bridge [19]. Information travels with higher velocity within blocks of strong ties than it between blocks bridged by weak ties.

A theory of ties also forms the basis for more considered social network analysis including precise definitions of such concepts as role, position, and boundary which can be used in defining network organizations. In addition to strength, ties may vary according to agent attributes or formal differentiation including, for example, geography, influence, and status [10, 141]. Agent clusters within a population of $\mathrm{N}$ agents can be represented as a blockmodel, a set of $\mathrm{N} \times \mathrm{N}$ matrices each of a given type of tie in which rows and columns have been permuted to bring structurally equivalent agents close together [123, 141]. Deterministic algorithms and statistical tools 
exist for partitioning agents into blocks as suggested by the hypothetical example of ties in a community of researchers ${ }^{21}$ appearing in Figure 6.

The row of images across the top depicts coarser interpretations of blocks and zeroblocks. Thresholded blocks are rectangular submatrices reporting on the presence of densely knit ties of homogeneous type. Zeroblocks report on the absence of ties. Blockmodels have the property of easily representing levels of granularity with more aggregate images. One possible interpretation of these data is that Block 2 is a dominant block, competing with and influencing other blocks without necessarily being influenced by members of any other single block. A possibly dysfunctional Block 5 exhibits ties in which members influence one another but do not provide each other with assistance. Blocks 1 and 3 collaborate, as do Blocks 3 and 4 . Typical patterns emerging from blockmodels include those in Figure 7.

\section{Reflexive Ties

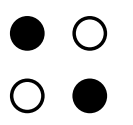

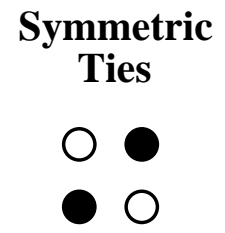

Jointly Held Perception

Deference

Figure 7 -- These are four possible $\mathrm{O}$
four possible
from sixteen interpretations drawn from
possible patterns.

A role may now be defined as a pair of vectors from a blockmodel, i.e. the array of ties from one agent to others (a row) and the array of ties from others to the agent (a column). Positions are blocks or submatrices into which populations are partitioned by given types of tie. These definitions accord well with a general interpretation of role as a collectively held expectation defining appropriate behavior and position as a location in a set of social relations [141]. For network organizations, boundaries appear as the edges of various blocks with different types of tie illustrating potentially ragged edges. Integration may therefore depend on the type of tie used to conceive a boundary. In Figure 6 above, blocks 1, 3, and 4 might form a network organization but to be consistent with earlier definitions, they require that networked blocks at least share purpose and control. Based on Figure 7, a blockmodel represents these as separate blocks with symmetric and reflexive images for these two types of tie. If additional matrix images demonstrated commonality of purpose and mutual control over resources, they would distinguish a network organization from, for example, a funding

${ }^{21}$ Loosely based on an example appearing in [141]. dependency (e.g., assistance) or an opinion leader (e.g., influence).

\section{F. Organizational Learning}

The importance of information assets to network organizations [33, 71, 112] raises important questions about managing information resources. Theories of organizational learning provide a framework by breaking information management into acquisition, distribution, interpretation and memory [68]. The first two describe the processes of obtaining and sharing information respectively. Sharing is important not only for completeness of access but also for generating new information. Interpretation is the process by which shared information acquires meaning and becomes translated into shared maps, frames, or schema. Organizational memory describes the storage of information for ready access and future use.

More learning may then be said to occur when information is shared more broadly, when more numerous and varied interpretations are developed, when different organizational members comprehend each other's interpretations -- even if their own interpretations differ, and when latent information is recognized as potentially useful and stored. More learning more does not necessarily imply a larger organizational action set, however, since this can add constraints to behavior as well as new options. In monitoring itself, an organization can also engage in single-loop learning by successively comparing itself to its governing policies and adjusting for mismatches, or it can engage in double-loop learning by examining and changing its governing values [7].

The flexibility of network organization in adding and discharging members creates several organizational learning problems. One is the problem of diffusing existing information and interpretation to joining members. Another is the problem of maintaining organizational history and experience in-house when members leave [71]. In highly unstable environments, members may welcome newly shared information but may have little incentive to relinquish their private sources of value. Yet, in fastchanging and competitive environments, organizations may have few alternatives to finding and sharing with partners. Vicarious learning and mimicry can mean entering an occupied niche while learning through experience can mean waiting longer than the opportunity lasts [68]. Rather, organizations can network or increase their store of knowledge by grafting on experts. As the need for and rate of knowledge assimilation increases, grafting becomes an attractive means of organizational learning [33, 68]. It can be both "faster than acquisition through experience and more complete than acquisition 


\section{NETWORK ORGANIZATIONS AS SOCIETIES}

\begin{tabular}{|c|c|c|c|c|c|}
\hline \multicolumn{2}{|r|}{$\begin{array}{c}\text { View of Network } \\
\text { Organization Feature }\end{array}$} & $\begin{array}{l}\text { Potential } \\
\text { Benefits }\end{array}$ & $\begin{array}{l}\text { Potential } \\
\text { Concerns }\end{array}$ & $\begin{array}{c}\text { Useful Analytical } \\
\text { Perspectives }\end{array}$ & $\begin{array}{c}\text { Useful } \\
\text { References }\end{array}$ \\
\hline 产 & $\begin{array}{l}\text { Form a goal oriented social } \\
\text { system for directing } \\
\text { collective action; forge a } \\
\text { common identity. }\end{array}$ & $\begin{array}{ll} & \text { Effect control within and outside } \\
\text { the organization. } \\
\text { Norms understood and guide } \\
\text { action. } \\
\text { Foster learning, innovation \& } \\
\text { participation. } \\
\text { - Promotes adaptation / flexibility. } \\
\text { Match internal structures to } \\
\text { environmental factors. }\end{array}$ & $\begin{array}{ll}\text { - } & \text { Requires significant investments } \\
\text { in social processes. } \\
\text { - } & \text { Slower consensus decisions. } \\
\text { - } & \text { Increased political influence } \\
\text { - } & \text { costs. } \\
\text { - } & \text { Mocal suboptimization. } \\
& \text { require morex integration / } \\
& \text { collaboration. } \\
\text { - } \quad \text { Large scale change is difficult . }\end{array}$ & $\begin{array}{l}\text { Theories of ties / innovation. } \\
\text { - Theories of organizational } \\
\text { learning. } \\
\text { Theories of human / technology } \\
\text { interaction. } \\
\text { - } \quad \text { Population Ecology. } \\
\text { - General systems theory. } \\
\text { - } \quad \text { Contingency theory. } \\
\text { Theories of groups. }\end{array}$ & $\begin{array}{c}{[2,10,13} \\
19,79,107 \\
111,112 \\
121,138- \\
140]\end{array}$ \\
\hline 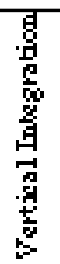 & Environments & $\begin{array}{l}\text { - } \\
\text { Recognizes networks as open } \\
\text { - Matchs. } \\
\text { external complexity. } \\
\text { Flatter management can be more } \\
\text { adaptable in changing } \\
\text { environments. }\end{array}$ & $\begin{array}{l}\text { Employee expectation of status as } \\
\text { reward. } \\
\text { More complex environments } \\
\text { require more integration / } \\
\text { collaboration. }\end{array}$ & $\begin{array}{l}\text { - } \quad \text { Contingency theory. } \\
\text { - } \quad \text { Population ecology. } \\
\text { - } \quad \text { Poneral systems theory. } \\
\text { power shift resistance. }\end{array}$ & $\begin{array}{c}57,79,81 \\
99,111]\end{array}$ \\
\hline 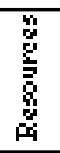 & $\begin{array}{l}\text { Consensus, Rank, Politics \& } \\
\text { Power }\end{array}$ & $\begin{array}{l}\text { Expertise as a critical resource can } \\
\text { elevate rank, promote } \\
\text { investments in information } \\
\text { gathering. }\end{array}$ & $\begin{array}{l}\text { More open to second guessing } \\
\text { than status. }\end{array}$ & $\begin{array}{l}\quad \text { Theories of power. } \\
\text { Theories of organizational } \\
\text { learning. }\end{array}$ & $\begin{array}{c}{[37,67,73} \\
74,79,94 \\
112,135]\end{array}$ \\
\hline 焉 & Organizational Learning & $\begin{array}{l}\text { Know-how harder to duplicate. } \\
\text { - } \quad \text { Recognizes people contribution. } \\
\text { Organizational memory becomes } \\
\text { key resource. } \\
\text { Knowledge resources can be } \\
\text { general or highly specific. }\end{array}$ & $\begin{array}{l}\text { - Possible loss with loss of partners } \\
\text { / people. } \\
\text { Decentralization can limit } \\
\text { learning. }\end{array}$ & $\begin{array}{l}\text { Theories of organizational } \\
\text { learning. } \\
\text { Theories of human / technology } \\
\text { interaction. }\end{array}$ & $\begin{array}{c}{[33,34,67} \\
68,112,115 \\
135]\end{array}$ \\
\hline 疍 & Identities, Groups \& Boundaries & $\begin{array}{l}\text { Norms such as loyalty help } \\
\text { explain commitment behavior. } \\
\text { Common "law and language" help } \\
\text { simplify interaction. }\end{array}$ & $\begin{array}{l}\text { Difficult to interpret behaviors } \\
\text { outside the group. }\end{array}$ & $\begin{array}{ll} & \text { Commitment-trust theory. } \\
\text { - } & \text { Structuration theory. } \\
\text { - } & \text { Identity and control theories. }\end{array}$ & $\begin{array}{c}{[13,56,107} \\
112,121 \\
139]\end{array}$ \\
\hline 䓪 & Trust \& Loyalty & $\begin{array}{l}\text { Mutual commitment permits new } \\
\text { governance structures. } \\
\text { Increased access to resources, } \\
\text { mutual knowledge transfer. } \\
\text { - } \quad \text { Shared risk. } \\
\text { Permits conflict to be functional / } \\
\text { healthy. } \\
\text { Increased economies of } \\
\text { collaboration / synergy. } \\
\text { Change is easier with strong trust } \\
\text { / friendship ties. }\end{array}$ & 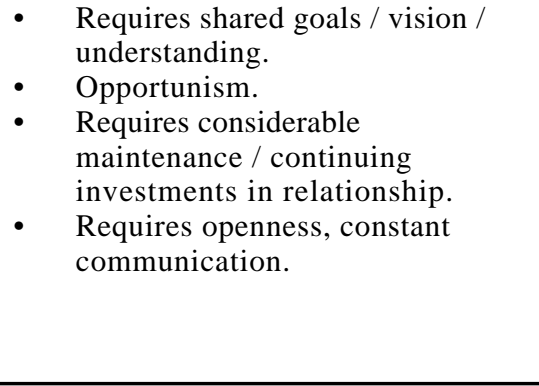 & $\begin{array}{l}\text { Commitment-trust theory. } \\
\text { Group \& identity theories as they } \\
\text { relates to the establishment of } \\
\text { loyalty and cohesion. }\end{array}$ & $\begin{array}{l}{[13,32,78} \\
100,107 \\
112,117 \\
121]\end{array}$ \\
\hline
\end{tabular}




\begin{tabular}{|c|c|c|c|c|c|}
\hline 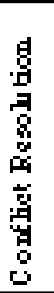 & Trust \& Loyalty & $\begin{array}{l}\text { Permits new governance } \\
\text { structures, relational \& recurrent } \\
\text { contracts. } \\
\text { Faster response to unanticipated } \\
\text { - } \quad \text { Rents. } \\
\text { - } \\
\text { Fewered risk. } \\
\text { negotiation and enforcement. }\end{array}$ & $\begin{array}{ll} & \text { Requires significant maintenance } \\
& \text { activity. } \\
\text { - } & \text { Opportunism from partners. } \\
\text { Fosters dependency. }\end{array}$ & - $\quad$ Commitment-trust theory. & {$[100,117]$} \\
\hline 䒿 & Granularity & $\begin{array}{l}\text { - } \begin{array}{l}\text { Networks appear at multiple levels } \\
\text { of interaction, particularly above } \\
\text { transactions level. } \\
\text { - Structure can alter individual } \\
\text { perceptions / power. }\end{array} \\
\end{array}$ & $\begin{array}{ll} & \text { Variables of interest change. } \\
\text { Boundaries may differ at different } \\
\text { levels. }\end{array}$ & $\begin{array}{ll}- & \text { Theories of loose coupling. } \\
& \text { Group theories (and many others) }\end{array}$ & $\begin{array}{l}{[14,80,92} \\
112,123 \\
128,137]\end{array}$ \\
\hline 受 & Identities, Groups \& Boundaries & $\begin{array}{ll} & \text { Shared identity / vision defines } \\
\text { core groups. } \\
\text { Norms understood without having } \\
\text { to inquire; clear expectations. } \\
\text { - } \quad \text { Group affinity and cohesion. } \\
\text { Groups benefit individuals with } \\
\text { resources and support. } \\
\text { Individuals benefit groups with } \\
\text { learning and specialization. }\end{array}$ & $\begin{array}{ll}- & \text { Requires group identity } \\
\text { maintenance activity. } \\
\text { - } \\
\text { Integration across boundaries } \\
\text { more difficult as group size } \\
\text { increases. } \\
\text { - Changing group identity is } \\
\text { extremely difficult. }\end{array}$ & $\begin{array}{ll}- & \text { Group theories. } \\
\text { - } & \text { Identity \& control theories. } \\
\text { - } & \text { Structuration theory. } \\
& \text { Theories of loose coupling. }\end{array}$ & $\begin{array}{l}{[2,10,13} \\
42,48,52 \\
56,74,97 \\
112,120 \\
121,136 \\
139]\end{array}$ \\
\hline 䇾 & Roles \& Ties & $\begin{array}{l}\text { Easier to define internal blocks } \\
\text { and external ties. } \\
\text { Weak ties help identify diffusion } \\
\text { links and information } \\
\text { encapsulation. } \\
\text { Loose coupling permits local } \\
\text { sensing mechanisms and } \\
\text { adaptation. } \\
\text { - Weak ties isolate failures. } \\
\text { - Ties can be a form of control } \\
\text { Jobs can lose formal definition; } \\
\text { more interchangeable. }\end{array}$ & $\begin{array}{ll}\text { - } & \text { Large scale change is difficult in } \\
\text { systems with numerous weak ties. } \\
\text { - } \\
\text { Independence may interfere with } \\
\text { coordination between groups. } \\
\text { - } \quad \text { Assistance remote or delayed. } \\
\text { Ties require significant } \\
\text { maintenance activity, need to } \\
\text { choose which to maintain. } \\
\text { Links require consent of both } \\
\text { participants. } \\
\text { Ambiguity can reduce } \\
\text { accountability. }\end{array}$ & $\begin{array}{ll} & \text { Theories of loose coupling. } \\
\text { - } & \text { Theories of ties and structural } \\
\text { holes. } \\
\text { - } \quad \text { Contingency theory. } \\
\text { - Structuration theory. }\end{array}$ & $\begin{array}{c}{[10,19,37} \\
48,49,52 \\
79,123,137 \\
139-141]\end{array}$ \\
\hline 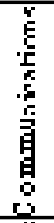 & $\begin{array}{l}\text { Consensus, Rank, Politics \& } \\
\text { Power }\end{array}$ & $\begin{array}{l}\text { - Technology attenuates status cues. } \\
\text { Lateral consultation more than } \\
\text { vertical command. }\end{array}$ & $\begin{array}{ll}\text { - } & \text { Status counts less; requires more } \\
\text { persuasion. } \\
\text { Essential communication can be } \\
\text { reduced during high activity } \\
\text { periods due to sender } \\
\text { unavailability. } \\
\end{array}$ & $\begin{array}{l}\text { - Theories of human / technology } \\
\text { interaction and communication. } \\
\text { - Theories of power / empowerment. } \\
\text { - Theories of communication. }\end{array}$ & $\begin{array}{l}{[25,26,42} \\
79,94,110 \\
124]\end{array}$ \\
\hline 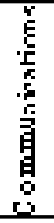 & Organizational Learning & $\begin{array}{l}\text { - } \quad \text { Shared information can generate } \\
\text { more information. } \\
\text { - Shared information increases } \\
\text { shared interpretations of events. } \\
\text { - Shared information improves } \\
\text { decisions. }\end{array}$ & $\begin{array}{l}\text { - Shared information can be costly } \\
\text { in political battles. }\end{array}$ & $\begin{array}{l}\text { Theories of organizational } \\
\text { learning. }\end{array}$ & {$[67,68,135]$} \\
\hline
\end{tabular}




\begin{tabular}{|c|c|c|c|c|c|}
\hline 窎 & Identities, Groups \& Boundaries & $\begin{array}{l}\text { Recognizes existence of motives } \\
\text { other than price-seeking. }\end{array}$ & $\begin{array}{ll}\text { - } & \text { Hard to characterize. } \\
\text { Motives often contingent. }\end{array}$ & $\begin{array}{l}\text { Identity and control theories. } \\
\text { - } \quad \text { Structuration theory. }\end{array}$ & $\begin{array}{l}{[10,13,48,} \\
52,112,139, \\
141]\end{array}$ \\
\hline 筫 & $\begin{array}{l}\text { Consensus, Rank, Politics \& } \\
\text { Power }\end{array}$ & $\begin{array}{l}\text { Flatter organization and } \\
\text { consultation increase buy-in. }\end{array}$ & - $\quad$ Political influence costs. & $\begin{array}{l}\text { - Human response to consultation } \\
\text { and participation. } \\
\text { - } \quad \text { Political influence theories. } \\
\text { - Theories of power. }\end{array}$ & $\begin{array}{l}{[6,13,37} \\
73,74,91 \\
110,112 \\
120]\end{array}$ \\
\hline 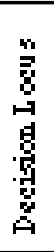 & $\begin{array}{l}\text { Consensus, Rank, Politics \& } \\
\text { Power }\end{array}$ & $\begin{array}{ll} & \text { Increased buy-in. } \\
\text { - } & \text { Decentralization encourages } \\
\text { innovation. } \\
\text { - } & \text { Better informed decisions. } \\
\text { - } & \text { Reduction in status barriers. } \\
\text { strategic direction. }\end{array}$ & $\begin{array}{ll}\text { - } & \text { Slower consensus decisions. } \\
\text { - } & \text { Changing management leaves } \\
\text { roles and responsibilities unclear. } & \text { Increased political influence } \\
\text { - } & \text { costs. } \\
\text { - } & \text { Resistance to radical change. } \\
\text { Local suboptimization. }\end{array}$ & $\begin{array}{ll}\text { - Human response to consultation } \\
\text { and participation. } \\
\text { Theories of power. } \\
\text { - } \quad \text { Political influence models. }\end{array}$ & $\begin{array}{l}{[6,66,73} \\
74,91,97 \\
109,110 \\
112,120 \\
128]\end{array}$ \\
\hline 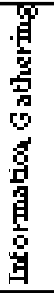 & Roles \& Ties & $\begin{array}{l}\text { Weak ties \& structural holes } \\
\text { identify possible diffusion links, } \\
\text { possibly greater innovation. } \\
\text { Information travels with high } \\
\text { velocity within strong tie blocks. } \\
\text { Multiple types of tie recognize } \\
\text { different levels of information } \\
\text { gathering. }\end{array}$ & $\begin{array}{l}\text { Encapsulated blocks may not } \\
\text { share information. } \\
\text { Ties require significant } \\
\text { maintenance activity, need to } \\
\text { choose which to maintain. }\end{array}$ & $\begin{array}{l}\text { Theories of ties / innovation. } \\
\text { Theories of organizational } \\
\text { learning. } \\
\text { Theories of human / technology } \\
\text { interaction. }\end{array}$ & $\begin{array}{l}{[10,19,49,} \\
112]\end{array}$ \\
\hline 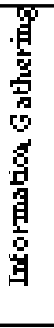 & Organizational Learning & $\begin{array}{l}\text { Grafting is an extremely effective } \\
\text { way to gain knowledge resources. } \\
\text { Knowledge acquisition generally } \\
\text { higher in decentralized systems. } \\
\text { Networks share information more } \\
\text { broadly. } \\
\text { Shared information can create } \\
\text { more information and foster } \\
\text { innovation. }\end{array}$ & $\begin{array}{l}\text { Danger of losing grafts and also } \\
\text { losing knowledge. } \\
\text { Memory can be fragmented in } \\
\text { decentralized systems. }\end{array}$ & $\begin{array}{l}\text { Theories of organizational } \\
\text { learning. }\end{array}$ & $\begin{array}{l}{[7,33,67} \\
68,71,72, \\
97,109,112 \\
113]\end{array}$ \\
\hline 究 & $\begin{array}{l}\text { Consensus, Rank, Politics \& } \\
\text { Power }\end{array}$ & $\begin{array}{l}\text { - } \\
\text { - } \text { Incre expertise based decisions. } \\
\text { Tools and decisions support can } \\
\text { raise individual expertise. } \\
\text { - Authority can be based on network } \\
\text { centrality. } \\
\text { Change easier with strong trust / } \\
\text { friendship ties. }\end{array}$ & 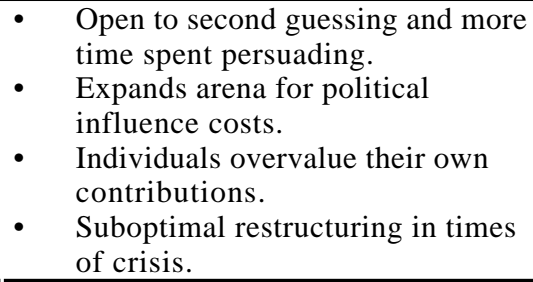 & $\begin{array}{l}\text { - } \quad \text { Political influence models. } \\
\text { Theories of power. }\end{array}$ & $\begin{array}{l}{[6,14,37} \\
43,74,78- \\
80,94,110 \\
120,128 \\
144]\end{array}$ \\
\hline
\end{tabular}

Table 5-- The social view of network organizations highlights issues such as trust, social structure, power, roles, and ties which can influence human behaviors. Note references may relate to theory or network organization attributes and may appear in multiple frameworks. 
through imitation." [68, p. 97]. There is fairly strong evidence, for example, that biotechnology firms learn by networking [113]. Sociological theories on organizational learning thus offer a fourth possible explanation for the emergence of network organization in addition to the two and the oneoffered under the computer and the economy metaphors respectively. Volatile environments increase the value of learning by grafting.

\section{G. Environments}

Network organizations must function within and respond to their environments. The principle of requisite variety, from general systems theory, contends that an organization's internal regulatory mechanisms must be as diverse as the environmental complexity with which it must contend [99, 126]. A mismatch between internal and external complexity is problematic in either case. Excess internal complexity unnecessarily raises costs. On the other hand, insufficient internal complexity leads the organization to process dissimilar cases in a similar manner. Given the long-standing assertion that the pace of change is quickening [81], the ability of networks to reconfigure themselves may be interpreted as a response to the principle of requisite variety. In contrast, hierarchies have stronger but fewer ties. They can sometimes respond more quickly but lack the requisite variety to respond appropriately. Network flexibility is captured in another of Sabel's elegantly succinct phrasings: the "meta-corporation" is an organization which is "designed to be redesigned." Similarly, "the network form is designed to handle tasks and environment that demand flexibility and adaptability" [10 p. 397]. And again, "it has become increasingly clear that the organizational form associated with flexible specialization is the network, although we have not always used that term" [111 p. 431].

It is not necessarily sufficient, however, to maintain a high degree of complexity in a complex environment; the parts must also match. Given a contingency theory view, there is no one best organizational form and firms must map structural elements of the organization, for example technology, culture, strategy, and management style, to structural variables of the environment. Contingency theory seeks to "understand and explain how organizations function under different conditions" [79 p. 186]. Different market conditions require different kinds of organizations along the dimensions of differentiation and integration. The more specialized ordifferentiated is an operation or cognitive orientation (e.g. research versus production outlook), the more embedded or integrated into supporting structure it must become. In particular, businesses functioning in turbulent environments require a higher degree of differentiation among units as the focus of attention for any unit narrows due to increased complexity of its tasks. This in turn requires a higher degree of collaborative integration as outputs and process must still be linked [79].

Whether organizations can survive to achieve an appropriate goodness of fit is the subject of population ecology. Analogous to organizational Darwinian selection, population ecology holds that "if one adopts an evolutionary epistemology, then over time one expects that entities develop a more exquisite fit with their ecological niches" [136 p. 20]. Structural inertia constrains managerial choice, preventing organizations from adapting and surviving in all contexts. Resource constraints, poor information, political realities, culture, funds, and contracts limit executives' abilities to force change and evolve their organizations [57]. An organizational failure perspective, for example, suggests that rigid wage structures may prevent large hierarchical firms from paying entrepreneurs the value of their contribution while also causing them to overpay for basic support, a final argument favoring network organizations over hierarchies. As noted by Baker, Piore, Sabel, and others, network organizations seem particularly well suited to continuous adaptation since they are more adept at defeating inertia and reorganizing their internal structures.

In Table 5, a summary of the network organization as society shows key structural elements to concern trust, social norms, identities, groups, roles, ranks, and ties among others. Processes can include, for example, how agents gather and share information, how they act within and reinforce social structure, and how they adapt to changed environments. The major element of purpose is to direct collective action toward common goals.

\section{CONTRASTS AND COMMON THEMES}

Each discipline contributes a unique perspective to its analysis of network forms yet common themes also emerge. Differences center on fundamental assumptions made within each metaphor. In the computer metaphor, for example, agents tend to lack self-interest and guile, while in the economic metaphor agents show little or no awareness of the appropriateness of their actions in social situations.

The benefit of a computer metaphor is its precision. Although computer models may make simplifying assumptions, the process of building them makes their propositions, tools, and definitions unusually 
concrete. They typically create unambiguous constructs, for example, variable encapsulation as a measure of modularity, and amount of information as a measure of complexity. They also clearly articulate tradeoffs: Adding processors increases throughput at the cost of additional coordination. Broadening skill sets, i.e., generalization, tends to increase workload as more task types match the expanded sets. Centralization reduces total processor costs but risks greater vulnerability. Modularity improves resilience and coping ability but makes global change more difficult.

The computer metaphor, however, implicitly assumes that structure follows from strategy -- that organizational architecture is a matter of strategic choice. The danger of this assumption lies in treating the firm as a mechanistic entity that responds in predictable ways. "Organizational determinism" presupposes that organizations are sufficiently plastic to allow organizational architects to reshape them almost at will. Yet, culture and social structure can limit the effects of change and this view underestimates the ability of territorial interests to subvert the strategist's best laid plans [92].

The benefit of an economy metaphor is that network organizations can be explored in light of rational selfinterest, general welfare properties, and incentives. It makes original contributions, for example, in its prescriptions for product customization, efficient mechanism design, and tradeoffs between private and public good. In many cases, the economy metaphor also permits the use of strong optimality and stability criteria to show, for example, why information asymmetry leads to inefficiency and why partners might not defect from cooperation under repeated interaction.

One network attribute which the economy metaphor inaccurately characterizes is informal pliable boundaries. "Firms are normally regarded as complete entities" [70 p. 32], associating edges with asset ownership. Defining boundaries becomes particularly troublesome when firms are viewed as open systems with imperfect group membership and ties that are weak as well as strong. As with the computer metaphor, this framework also suffers from organizational determinism. Its assumptions regarding mechanism design do not permit culture or context to thwart implementation. Social settings consist of myriad unarticulated rules that can both promote and proscribe actions in ways that bear little relation to price-seeking behavior.

Network organizations as societies are burdened with identity maintenance activity, relationship building, power seeking, and political influence activity. They constantly engage in attempts at control, the social construction of boundaries, and at the same time in integration mechanisms to penetrate these boundaries. They are open systems that respond to environmental flux and exhibit multiple levels of granularity. Members can exhibit in-group bias reflecting both homogeneity preferences and conservation of effort, and differences in tie strength can alter the movement of information throughout the network. Ineffable constructs such as power, status, role, identity, and group affiliation are difficult to quantify in either economic or computational terminology. Sociological explanations differ from those in computer science and economics, and studies tend to remain close to empirical particulars, often eschewing abstract reasoning away from data 22 . This metaphor highlights social aspects of people's actions in organizational settings where the focus is not optimality or efficiency but understanding.

While the level of interpretation, understanding, and explanation are greatly improved, results from applying sociological tools are highly contingent. They impart fewer prescriptive answers. Social structures in one organization may be quite different from social structures in others. Organizational configurations are not necessarily predicted to outperform alternatives across contexts. Consensus management, for example, may benefit an organization by encouraging ideas and participation in times of growth but may hinder requisite changes in times of retrenchment. Observations stemming from the society metaphor frequently do not permit evaluation along efficiency criteria such as speed, accuracy, or allocation of risk. The value of this metaphor, as with any of the three frameworks, is therefore likely to increase when used in conjunction with a complementary perspective.

Despite these differences, similarities in themes recur across metaphors, which suggest foundation principles for motivating network organizations. Bridging the attributes proposed in the introduction, five principal themes cover: the need to balance stability against flexibility, the need to balance specialization against generalization, the need to balance centralization against decentralization, synergy of complementary practices, and the supporting role of newer information technologies.

\section{A. Flexibility Balances Stability}

There is usually a tradeoff between stability and flexibility. Stability, established practice, and

${ }^{22}$ I am indebted to Steve Freeman for this observation. 
standardization promote efficiency and consistency of expectations. Flexibility and adaptation, on the other hand, promote survival in changing environments and the chance to pursue fleeting opportunities outside the scope of normal operations. Firms may need to enter into, reposition within, and exit from niche markets [58]. If stability ensures efficiency and short term cost effectiveness, flexibility ensures renewal and long term cost effectiveness. Networks typically are more stable than markets and more flexible than hierarchies. Although a tradeoff can be expected, this is generally true only along a given technological frontier. With vastly better technology, one firm can exercise both greater flexibility and efficiency than another [85].

In volatile environments, flexibility benefits organizations by reducing opportunity costs and vulnerability and by promoting adaptation [90, 103]. On the other hand, if there were no new problems to solve and economic and social conditions were to remain unwaveringly static, there would be no reason for structural change, no need to handle exceptions, no impetus for adaptation, no cause for altering worker roles, and no concern for exacting ever greater efficiency from established practice. Stability concerns would dominate.

In computing terms, network structures enhance flexibility by facilitating resource substitution, improving adaptation, and relaxing operating constraints. Modular design, loose coupling, and parallelism, permit local adaptation which does not disrupt global activity. Large scale adaptation is also possible by completely replacing one or more modules and restructuring lateral linkages [24, 44, 126, 137]. Virtual resources relax binding resource constraints by providing on-demand access [20, 28]. Even if virtual resources are sluggish or unresponsive, they may be very cost effective relative to outright acquisition or development. Extending the computer metaphor, rigid hierarchy and flexible networks parallel hardware and software respectively; each performs similar functions but has advantages in different contexts; "hardware and software are logically equivalent. ... The decision to put certain functions in hardware and others in software is made on the basis of such factors as cost, speed, ... reliability, and frequency of expected changes [130 p. 10]“23 From a decision throughput perspective, organizational flexibility concerns tools for managing modularity and coupling, task interdependence, task diversity, as well as cost, speed, reliability, and frequency of expected changes.

\footnotetext{
${ }^{23}$ Emphasis added.
}

In economic terms, a capacity for marginal substitution helps measure organizational flexibility. This is the ease with which companies can swap one internal operation or input for another [103]. Figure 8 shows graphically ${ }^{24}$ how substitution might occur. Market demand XY initially makes both production techniques $\alpha$ and $\beta$ efficient but a shift to demand $\mathrm{X}^{\prime} \mathrm{Y}^{\prime}$ leaves only technique $\alpha$ efficient.

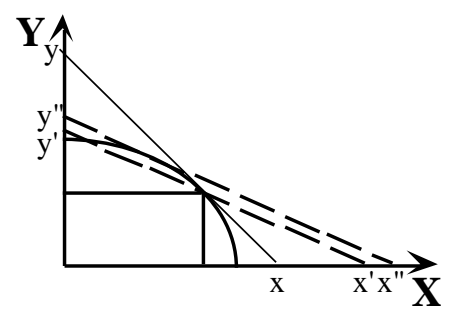

Figure 8 -- Production technology $\alpha$ is more flexible than $\beta$ after a shift in demand from $\mathrm{XY}$ to $\mathrm{X}^{\prime} \mathrm{Y}^{\prime}$.

Since $\alpha$ permits greater leeway to substitute input $\mathrm{Y}$ for input $\mathrm{X}$, a company using $\alpha$ will shift production to levels meeting demand $X^{\prime \prime} Y^{\prime \prime}$ since $X^{\prime} Y^{\prime}$ is not on its efficient frontier. In economic terms, the principal tools used to measure flexibility are marginal substitutability and environmental uncertainty or risk. Networks permit greater substitution through modifying their links to resources. Flexibility reduces risk, on the cost side by improving liquidity and asset reallocation, and on the revenue side by promoting product customization.

At least three principles address flexibility issues in social systems. The first is the principle of requisite variety from general systems theory in which internal structures must exhibit sufficient variety to cope with structures in the environment [99, 126]. Population ecology also supports this first point, arguing that organizations must fit their environmental niches but their inertia must not prevent them from adapting [57]. The second principle is that flexibility requires trust between network partners [100, 112, 117]. Environmental uncertainty leaves organizations exposed to opportunistic behavior from their partners. They need to trust that disputes will be resolved fairly and efficiently, ensuring more operating latitude and thus flexibility. Several articles note that higher levels of trust distinguish networks from markets and hierarchies. People vary in their risk tolerance and their affinities so that strong friendship ties can increase their willingness to change [78]. Depending on the organization, constant change may leave

\footnotetext{
${ }^{24}$ Based on [103 Figure $1 \mathrm{p}$ 1821.]
} 
members alienated and fearful of their continuing roles within the group. A third point is that the ability to effectively cope with uncertainty increases one's power within an organization [110]. Tools to consider from organizational literature include commitment and trust theories, theories of power, general systems theory, and population ecology.

\section{B. Generalization Balances Specialization}

Network literature shows a widespread concern for the tradeoffs between specialization and generalization [1, 10, 33, 37, 79, 111, 121].

Specialization offers deeper knowledge and focused expertise, economies of scale, and cost efficiency for tailored units. Generalization offers broader knowledge and cross-functional expertise, economies of scope, and efficiency of greater resource utilization. As in the case of "flexible specialization," much effort has been invested in trying to capture the best of both.

Coordinated problem solvers who optimize decision throughput must balance higher cost specialized resources, higher throughput rates, and lower utilization against greater numbers of lower cost generic resources, lower throughput rates and higher utilization rates. In an organizational decision process, the choice of an appropriate number of processors or managers cannot be made independent of the decision to off-load exception events to specialized co-processors. In a hierarchy, exception events travel vertically to a vested decision authority (a specialized adaptation) but a network may handle them locally (a generalized adaptation). As a rule, highly variable decision inputs render specialized processors unattractive due to overhead in processing exceptions. Increasing the general capabilities of any autonomous agent, however, tends to increase the complexity of the agent [126]. In networks, generalization can be effected by increasing the lateral linkages, i.e. the computational processing power of the system. These issues benefit from an analysis using queuing theory, complexity theory, and principles of modularity and distributed processing.

From an economic perspective, firms may specialize by developing core competencies and trading for skills and resources that other firms own in greater abundance or produce with greater skill [70]. Firms may protect themselves against hold-up costs arising from specialization by owning the production chain from mine to market but they sacrifice flexibility. Ownership tends to trade lower fixed and higher variable costs for higher fixed and lower variable costs. Potential owners must then determine the expected length of production runs over which they can amortize their high fixed costs. Problems of asset specificity and hold-up are addressed in transaction cost economics. Principal-agency, game theory, and the rule of comparative advantage can also apply.

From an organizational theory perspective, specializing concerns tradeoffs among communication, skills, adaptability and authority. Specialization permits a more focused language, as in the case of accounting terminology, which improves in-group communication at the expense of out-group clarity. Deeply specialized roles may also drive authority relationships by creating fiefdoms of expertise, unassailable by and inaccessible to others without comparable skills [140]. Generalized knowledge and multi-skilling tend to minimize these fiefdoms enhancing pluralism and consensus management. But generalization tends to reduce accountability. This may accompany loss of control at the top and unclear task responsibility when multiple people are candidates for task completion [37]. It also muddies roles when people move from superior to subordinate and back across projects. Generalists can reduce costs by reducing team size and cutting high fees to specialists and outside consultants [10]. Moreover, generalists integrate an organization through larger connecting networks. But, specialization permits a narrower focus and with it the development of greater proficiency at a given task. By specializing, individual processes such as labor become more embedded in a support network of ancillary processes which co-specialize. Specialization therefore creates dependency and efficiency, while generalization createsindependence and flexibility [111]. It also strengthens in-group ties at the expense of out-group ties. At the environmental level, network organizations need capabilities that are general enough to be optimal over multiple configurations [57]. Supporting analytical tools include general systems theory, contingency theory, and population ecology.

\section{Decentralization Balances Centralization}

Whether to concentrate resources and control or to distribute them has drawn considerable attention from network literature $[4,6,10,73,90,92,98,103$, $114,116,119,122,126]$. In an information processing context this is similar to serial versus parallel design. To the extent that tasks may be decoupled, they will run to completion more quickly if executed in parallel than in series. Parallelism offers potential increases in speed, potential use of greater numbers of less expensive processors, and potential flexibility as processors can be collectively reallocated. Built-in redundancy also simplifies fault recovery. Parallelism, or equivalently decentralization, however, introduces rapidly growing coordination and communication costs. A serial 
process may be preferred if tasks do not decouple easily, if coordination costs of managing interdependency are too high, or if processors are too expensive. A computer processing metaphor for the firm might consider tools for task decomposition, coordination theory to manage interdependencies, synchronous and asynchronous communication protocols, and parallel versus serial design and computation.

Decentralizing the firm in economic terms largely concerns scale, ownership, decision authority, and transaction costs. Resource decentralization can improve service quality for local agents but it costs in terms of redundancy, coordination, and missed economies of scale [54]. Decentralizing ownership in a principal-agent model also implies that the principal or owner sells the firm or project to the agent. This transaction gives the agent full claim to all residual profits; ownership improves his/her incentives and is likely to be preferred when there is high information asymmetry favoring the agent and low monitoring or enforcement potential. If projects require agents with great skill, agents' intangible assets cannot be purchased, i.e. vertically integrated; their outside opportunities and hence reservation wages are high, and effort monitoring is likely to be low. If the benefits of combining complementary assets and indispensable agents outweigh the increased governance costs of joint control, decentralized ownership creates more value.

Using property rights theory, it can be shown that decentralized information ownership should accompany decentralized incentives $[4,16]$. Also, if the necessary information is local or decentralized, then decision authority should be decentralized [63] Centralizing decision authority is preferred when it is easier to move local information to a central office than to distribute decision rights to local offices [95]. If knowledge of local conditions is skill based or fast changing, then difficulty transferring it favors decentralization. A self-interest model of autonomous agents, however, requires that incentives be distributed along with decision rights so that agents consider the interests of the group in addition to their private welfare. Incentives, however, can sometimes reduce total output since reward systems do not always provide each agent with his or her marginal productivity. Costs other than labor must also be recovered.

Lastly, if a market's transactions costs are too high relative to a firm's production costs, activities will be vertically integrated or centralized. If the reverse is true, activities will be decentralized. Economic models of decentralization thus involve transaction cost economics, principal-agency, property rights theories, and theories on the collocation of information and decision authority.

Organizational learning theories suggest that there are hidden costs to decentralization. With decentralization comes a learning penalty and the chance to avoid mistakes of the past [71]. Particularly when knowledge and know-how become the key trading stock, organizations risk losing a wealth of information as partnerships shift. Network firms must therefore gear their internal systems for rapid information collection and transfer to some common location, in order to keep information assets within the network $[28,71]$.

Ironically, and in contrast to the principle that environmental changes require flexibility, organizational theories of power predict that harsh environments, such as those undergoing rapid change, lead to centralized control: “... at the very time the organization faces a crisis which may have resulted from inattention to the demands of the environment or from failures of policy, psychological dynamics are set in motion which reduce contact with the external environment, place a premium on loyalty and commitment to already chosen policies, and define as treasonous any kind of deviation from the adopted line" [110 p. 325]. Studies have found that in times of crisis or increased competition, procedures become more formalized, decisions are specified more in advance and are more likely to be written [110]. A shortened time horizon increases task filtration, reduces coordination, and shifts control towards formal patterns of vertical control and leader directed activity [124]. Crisis induced by rapid change fosters a siege mentality, promoting hardened positions and polarized beliefs along existing lines of authority. Theories of power present a remarkable psychological insight in that even self-induced hardship can be used by persons in power to justify coopting resources from competing projects under the theory that their plans were sound, they just need more resources. Network organizations decentralize control incurring a cost of increased political activity [37, 120] consistent with theories of power [110].

As networks decentralize control, however, they encourage greater participation. Political and empowerment models show that employees generally appreciate greater autonomy, information, and resource control $[73,110]$ and they are more satisfied when participating in decisions [80]. Decentralization, however, may increase workload and stress due to excessive coordination costs. Too much task overlap unnecessarily increases workload, confusion, and competition for resources while too little leaves no margin for error. Partial overlap appears to achieve the best tradeoff between 


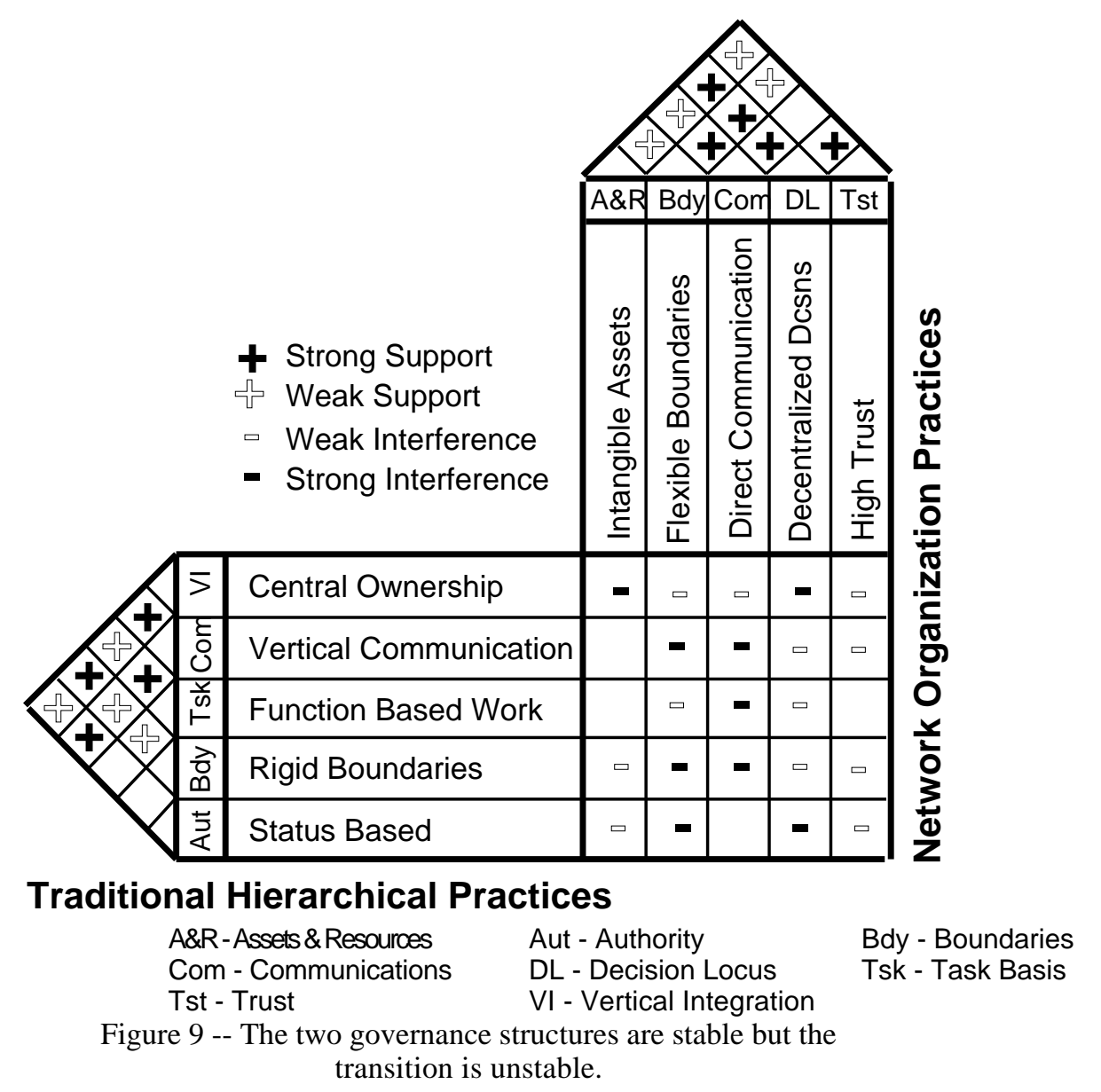

performance and workload [124]. A sociological perspective therefore highlights non-economic benefits of decentralization which extend to loyalty, satisfaction, power, and stress.

\section{In Search of Synergy \& Synthesis}

Creating synergy is an essential feature of cooperation $[1,18,28,45,58,70,72,77,85,96,112,118$, 138]. Organizations attempt to find the right combination of behaviors which, if successful, will generate increasing returns. "The first major component of post-industrial strategy is to seek that combination of businesses, array of internal services, and the structure for organizing them that promotes synergies -- a whole that multiplies the value of its parts" [73 p. 7].

Among cooperative problem solvers, distributing portions of complex tasks allows the group to solve larger and more complex problems in less time than might be possible for individuals [45, 125]. Single agents face bounded rationality and finite resource constraints that are relaxed through cooperation. The field of distributed artificial intelligence and many aspects of computation, of parallelism, and of modular design address this issue $[45,64,77,82$, 102, 125]. In economic settings, cooperative gains typically imply joint profit or surplus. Increasing returns may take several forms including economies of scale, economies of scope, strategic complements [70], and network externalities [40, 138]. The purpose of cooperation is largely to create and, if possible, capture these gains. From a sociological perspective, coming together under a goal directed activity involves the creation of identity, norms, and processes for inter-agent association and control incorporating whatever congenital organizational processes and resources agents bring with them. An organization, as distinct from a simple aggregation, collection, or "bag of beans" [139] requires a common law, language, and manner of thinking. It creates an identity and a social structure in which actions reinforce certain norms and norms reinforce certain actions. Group theories, structuration theories, and theories of identity and control address these issues .

Although organizational design might be simpler if it were possible to aggregate eclectic "best practices" across multiple disciplines, organizations cannot 
blindly mix practices without concern for complements among them [18, 69, 96, 105]. Creating a self-reinforcing organization can depend not only on which practices are adopted but also on the order in which they are adopted since this can put organizations on different forward trajectories [23, 92]. Structures that appear sound in isolation may be unsound if they are taken out of context or if they oppose one another. Vertical hierarchy, for example, minimizes transaction costs [143] but it discourages the reintegration of conception and execution, even if this improves flexibility $[111,121]$. The two forces oppose one another but both can add value.

Given the importance of identifying complementary organizational design variables, it is helpful to judge particular architectures for their stability, coherence, and synergy. A tool adapted from product design [62] shows graphically how design variables might complement or interfere with one another [18]. For example, within a hierarchy, vertical integration, functional work groups, narrow job descriptions, and centralization of key decisions can be mutually reinforcing. Analogous network organization practices include decentralized decisions, project teams, broader job descriptions, and trust which are also mutually reinforcing. Network and hierarchical practices, however, typically compete. Adopting any single network practice in conjunction with a dominant cluster of hierarchical practices may lead to friction and possible rejection of the adopted practice. Interactions drawn from the design variables in Table 1 appear in Figure 9.

Plus signs indicate synergy or complementary practices and minus signs indicate interference or competing practices. A matrix of densely reinforcing practices is coherent and stable while one of densely interfering practices is inconsistent or unstable [18]. The matrix helps emphasize the importance of synergy in the collective set of processes adopted by a network organization. Reflecting the stability versus flexibility tradeoff, it also graphically illustrates how flexible structures must nevertheless be stable in terms of coherence and consistency.

This bears directly on the process of adopting network organizational forms. Change management is difficult and business process reengineering (BPR) efforts tend to have extremely high failure rates $[12$, 55]. If BPR endeavors to move organizations from hierarchies to networks, an inattentiveness to complements might explain this difficulty.

\section{E. Supporting Role of Information and Information Technology}

Emerging information technology (IT) has played a major role in network organizational development
$[28,34,46,88,109,112,128]$, indeed a number of authors have written of the IT-enabled network organization $[6,55,71,105,120]$. More of a phenomenon than a set of principles, IT relates to several of the attributes in the three metaphor framework. The arrival of information technology has affected network organizations, for example, in computing terms by rerouting communications, in economic terms by reducing information asymmetry, and in sociological terms by changing roles and ranks of members.

Under a computational metaphor, IT has established more rapid point-to-point communications with more numerous channels and significant reductions in information delay $[6,109,120]$. More channels contribute to the likelihood that more nodes contribute data. Thus it contributes to information overload at specific bottlenecks as it also enhances distributed sensing. Then as more agents contribute data, and computation aids processing, improvements in accuracy, retention, and timeliness can lead to better decisions [67], more coordinated problem solving $[21,85]$ and greater handling of complexity [5].

In order for the output of autonomous agents to cohere, however, they must integrate their various activities. An IT backbone provides the means for data sharing and integration [120]. Group decision support systems further enhance coherence [27] while individual decision support and relational databases reduce managerial reliance on subordinates [6, 67]. IT's ability to rapidly add and detach system nodes also facilitates the virtual organization [71, 83].

The economic effects of IT are equally profound. Ubiquitous connectivity allows the best firms to locate one another in global markets and to form elite partnerships [3]. The versatility of information technology also affords organizations the option of mass customization [71], helping firms create and capture consumer value. A resource view of IT suggests that it can be used to gather and capture information providing a distinctive and inimitable advantage [71, 108]. IT also reduces vertical integration by lowering coordination costs, digesting complex market information, and enabling just-intime delivery systems that also lower inventory buffers [90]. By promulgating standard market interfaces between firms, IT can also reduce asset specificity and opportunism risk further lowering the costs of ownership from a transaction cost perspective [22]. On balance, there is evidence of a "move to the middle" implying that firms have outsourced more value to markets due to IT $[17,22]$ but that they use fewer suppliers. Competition to improve quality has required relationship specific investments which are 
important from an incomplete contracts perspective [11]. To motivate their ex ante investments in quality, suppliers need to capture a share of the ex post surplus which they can only do if they are not competing in large numbers with other suppliers for dividing gains. Thus IT would seem to have affected the market structure in favor of networked structured firms.

Through monitoring, IT can reduce information asymmetry and it allows managers to minister to low levels of detail. One advantage is that this can improve performance based compensation $[6,71]$ and alleviate problems dividing team surplus by measuring contribution. But, highlighting the desirability of working with multiple frameworks, IT can also lead to unattractive levels of surveillance and loss of personal control [71, 144]. In principalagency problems, perfect monitoring leads to more efficient, often "first-best" solutions, the standard by which other economic alternatives are judged. If actions are entirely predetermined, automation through IT may offer the best solution. If, however, actions require difficult well-informed choices or specialized expertise, strict compliance monitoring of network partners in a principal-agency sense may be counterproductive since the effort applying knowledge is not open to inspection and partners may resent the intrusion.

Placing partners under an IT microscope limits freedom of action, changes power in the relationship, and robs them of dignity. Zuboff [144] has likened this to an information "panopticon," a type of penal system in which the slightest actions are observable, eliminating all autonomy, self-expression, and discretion. Agents are likely to resist attempts at control from outside their function [140]. In this case, a political or interactionist model is useful. Those suffering reduced autonomy due to IT will seek ways to subvert the system, for example, through sabotage, disuse, delay, use of alternative procedures, supplying inaccurate data, or sticking to the letter but disregarding the intent of a system [91].

As an alternative to external control, IT can help integrate the network organization [10]. It can commingle distinct internal structures through lateral communication just as it can intermingle network and external structure through tighter coupling [120]. Tighter cross-functional ties and stronger buyer / supplier relations can lead to the interpenetration of boundaries. Strong links can potentially flatten organizational hierarchy first by enabling a redistribution of resources, decision rights, power and control $[6,83,120,144]$ and second by attenuating status distinctions. Cues marking age, race, gender, and dress might not accompany non-verbal communication $[25,26,42]$. IT also permits workers to perform new tasks, reducing the skill requirements for integrated work $[55,59]$.

With decentralization and the removal of status distinctions, expertise becomes increasingly important as a source of power in network organizations. Power and influence might no longer derive from rank but from convincing others to accept a particular interpretation of the data [73]. As expertise becomes critical resources then flow not to hierarchical posts but to obvious centers of competence [67]. Whether network members actually gain or lose power can also be affected by design. Evidence suggests that existing power centers may discourage the adoption of IT systems that reduce their authority and, ceteris paribus, new IT systems tend to reinforce preexisting cultural norms and control structures $[8,24,91,110]$. IT makes the enforcement of rules both easier and less necessary due to the immediacy of feedback [24, 110].

IT can broadly distribute information, supplanting revelation on a need-to-know basis, and it can promote organizational learning by rapidly diffusing ideas $[42,67,129]$. Increased sharing might form the basis of better decisions and learning curve effects [22]; it might also amplify knowledge generation by focusing additional sources of expertise on important issues [68, 71] within the network. Distribution, however, is only one element of organizational learning supported by IT. It can simplify the process of knowledge acquisition by tapping sources of competitive intelligence and by simplifying the process of network member grafting [21, 68]. Since the potential loss of network partners leads to a potential loss of learning, a technology based organizational memory may lessen the effect and greatly improve management of intellectual capital [21, 28, 33, 67, 68, 71]. IT provides a significant complement to network organizational structure and learning $[6,10,28,71,83,105,120]$.

\section{CONCLUSIONS}

This article has surveyed the network organization literature to explain its multiple design variables using ideas from computer science, economics, and sociology. In particular, network organizations are defined by highly cospecialized assets, an integrative joint control, and common purpose. Network organizations tend to perform well under conditions which require both efficiency and flexibility. Much of the literature also emphasizes that information and know-how represent important network organization assets -- an observation that supports the concept of network organization in several ways. Knowledge 
complements can be combined to create value, the inalienability of know-how implies that the experts themselves need to exercise control, and information links increase the ability to handle complexity. According to all three metaphors, synergy helps motivate agents to work together. Jointly pursuing group opportunities then requires agents to balance several needs: flexibility and stability, generalization and specialization, and decentralization and centralization. These factors are also widely influenced by information technology.

Each of the main metaphors for network organization also contributes a somewhat different perspective on network organization etiology. One interpretation suggests that information technology improves agents' information processing capabilities so that flatter structures can handle similar loads. A second alternative suggests that dramatic reductions in coordination costs makes coordinating activities through markets relatively cheaper and coordinating problem solvers relatively easier. A third, more economic, possibility is that increasing use of complementary intangible resources requires that indispensable agents retain ownership to induce efficient effort and investment. Collaboration dominates when collective gains exceed governance costs. From an organizational learning perspective, a fourth possibility is that organizations prefer to learn by grafting new members in volatile environments. Learning by doing is too slow; learning by following cedes the spoils of leading to the leader. A final interpretation, an organizational failures perspective, suggests that rigid bureaucratic structures, endemic in hierarchies, have difficulty changing policies and shifting resources that are optimal for one set of environmental conditions.

The variety of features characterizing network organization makes it unlikely that any single argument can explain all of its various forms. But if there is any one explanation which integrates all three perspectives it is this: change may cause agents to address rising complexity as cooperative problem solvers. Complementary knowledge sources are important to solving large scale integrative problems but agents are indispensable to their expertise -implying that agents may only gain by working in groups. To function as a group, they need to establish mutually agreeable goals, a coherent group identity, and norms for action and reciprocity that enable and disable group and non-group actions respectively.

A literature survey offers a more detailed conclusion. Rising competition and change cause organizations to respond more swiftly as cooperative problem solvers to their increasingly complex environments [45, 79].
Together, competition and change increase problem complexity by increasing the number of dynamic variables that managers must consider while more rapid change decreases acceptable response time [79, 126]. The need for haste and locally applied expertise justifies the movement of conception to points of execution [121] -- separation can lead to miscommunication and delay. Since the ability to interpret equivocal circumstances is largely inalienable and human-specific [135], know-how cannot be easily transferred to or centralized within a single decision maker as it is needed. Barring the ability to integrate conception and execution by centralization, conception and certain decision rights are decentralized to executors instead. Decentralized ownership, however, needs to follow decentralized decision rights to alleviate agency costs arising from information asymmetry and to align ex ante investment incentives [4, 16, 95]. Completely decentralized ownership may be limited to the extent that two or more skills form the minimum complement necessary to seize an opportunity. If skills are strategic complements they may require indispensable experts to collaborate in order to realize project returns. Joint ownership of project returns can thus create co-dependency and co-dependency may require trust $[100,112,117]$. As change creates complexity it also creates risk. Intervening in the environment to control various exigencies can prove both ineffective and costly if partners forego their commitments. Without trust or concern for the welfare of one's partners, pursuing the highest risk and reward options over time becomes infeasible. Integrating these arguments is also consistent with the interpretation of network organizations as purposive integrated systems with cospecialized assets and joint control.

Casting the network organization into three metaphorical frameworks has engaged analytical tools as diverse as queuing theory, complexity theory, property rights theory, and structuration theory, among others. Ideally, inter-disciplinary tools provide a more complete view of the attributes that describe, the contexts that favor, and the principles that govern network organizations. As understanding improves and environments continue to change, they might also represent points of departure for continuing study.

\section{BIBLIOGRAPHY}

1. Alchian, A.A. and H. Demsetz, Production, Information Costs, and Economic Organization. American Economic Review, 1972. 62(5): p. 777-795.

2. Aldrich, H.E. and P. Marsden, Environments and Organizations, in Handbook of 
Sociology, N.J. Smelser, Editor. 1988, Sage: Beverly Hills. p. 361-392.

3. Alstyne, M.V. and E. Brynjolfsson. Communication Networks and the Rise of an Information Elite -- Do Computers Help the Rich get Richer? in International Conference on Information Systems. 1995. Amsterdam:

4. Alstyne, M.V., E. Brynjolfsson, and S. Madnick, Why Not One Big Database? Principles for Data Ownership. Decision Support Systems, 1995. 15(4): p. 267-284.

5. Andrews, M.R., J. DeVries, D. Durfee, R. Rubinstein, Analysis of Networked Corporations as Complex Systems1996, MIT: (unpublished manuscript)

6. Applegate, L.M., J.I. Cash, and D.Q. Mills, Information Technology and Tomorrow's Manager. Harvard Business Review, 1988. : p. 128-136.

7. Argyris, C. and D.A. Schon, Organizational Learning: A Theory of Action Perspective. 1978, Reading, MA: Addison-Wesley.

8. Attewell, P. and J. Rule, Computing and Organizations: What We Know and What We Don't Know. Communications of the ACM, 1984. 27: p. 1184-1192.

9. Axelrod, R., The Evolution of Cooperation. 1984, New York: Basic Books.

10. Baker, W.E., The Network Organization in Theory and Practice, in Networks and Organizations, N. Nohria and R.G. Eccles, Editors. 1993, Harvard Business School Press: Boston, MA. p. 397-429.

11. Bakos, Y. and E. Brynjolfsson, From Vendors to Partners: Information Technology and Incomplete Contracts in Buyer-Supplier Relationships. Journal of Organizational Computing, 1993. 3(3): p. 301-328.

12. Bashein, B.J., M.L. Markus, and P. Riley, Preconditions for BPR Success. Information Systems Management, 1994. 11(2): p. 713.

13. Biggart, N.W. and G.G. Hamilton, On the Limits of a Firm-Based Theory to Explain Business Networks: The Western Bias of Neoclassical Economics, in Networks and Organizations, N. Nohria and R.G. Eccles, Editors. 1993, Harvard Business School Press: Boston, MA. p. 471-491.

14. Brass, D.J. and M.E. Burkhardt, Centrality and Power in Organizations, in Networks and Organizations, N. Nohria and R.G. Eccles, Editors. 1993, Harvard Business School Press: Boston, MA. p. 191-215.

15. Brynjolfsson, E., Information Technology and the 'New Managerial Work'1990, Center for Coordination Science, MIT Sloan School: March, 3563-93

16. Brynjolfsson, E., Information Assets, Technology and Organization. Management Science, 1995. (forthcoming).

17. Brynjolfsson, E., et al., Does Information Technology Lead to Smaller Firms. Management Science, 1994. 40(12).

18. Brynjolfsson, E., A.A. Renshaw, and M. Van Alstyne, The Matrix of Change:Sloan Management Review, (forthcoming) 1997.

19. Burt, R., The Social Structure of Competition, in Networks and Organizations, N. Nohria and R.G. Eccles, Editors. 1993, Harvard Business School Press: Boston, MA. p. 57-91.

20. Byrne, J.A., R. Brandt, and O. Port, The Virtual Corporation, in Business Week1993, p. 98-103.

21. Ching, C., C.W. Holsapple, and A.B. Whinston, Modeling Network Organizations: A Basis for Exploring Computer Support Coordination Possibilities. Journal of Organizational computing, 1993. 3(3): p. 279-300.

22. Clemons, E.K., S.P. Reddi, and M.C. Row, The Impact of Information Technology on the Organization of Economic Activity: The "Move to the Middle" Hypothesis. Journal of Management Information Systems, 1993. 10 (2): p. 9-35.

23. Croson, D., Towards a Set of InformationEconomy Management Principles1995, Wharton School of Management:

24. Crowston, K. and T. Malone, Information Technology and Work Organization, in Handbook of Human-Computer Interaction, M. Helander, Editor. 1988, Elsevier: p. 1051-1069.

25. Daft, R.L. and R.H. Lengel, Organizational Information Requirements, Media Richness and Structural Design. Management Science, 1986. 32(5): p. 554-571.

26. Daft, R.L., R.H. Lengel, and L.K. Trevino, Message Equivocality, Media Selection, and Manager Performance: Implications for Information Systems. MIS Quarterly, 1987. : p. 355-366.

27. Datta, A. Cooperative Problem Solving in Distributed Decision Making Contexts. in Systems, Man, and Cybernetics. 1991. IEEE.

28. Davidow, W.H. and M.S. Malone, The Virtual Corporation. 1992, New York: HarperCollins. 294.

29. Davis, R. and R.G. Smith, Negotiation as a Metaphor for Distributed Problem Solving. 
Artificial Intelligence, 1983. 20(1): p. 63109.

30. Deitel, H.M., An Introduction to Operating Systems. 1983, Reading, MA: AddisonWesley. 673.

31. Dertouzos, M.L., R.K. Lester, and R.M. Solow, Made in America -- Regaining the Productive Edge. 1989, Cambridge: MIT Press. 344.

32. Doz, Y.L. and C.K. Prahalad, Managing DMNCs: A Search for a New Paradigm. Strategic Management Journal, 1991. 12: p. 145-164.

33. Drucker, P., The Coming of the New Organization. Harvard Business Review, 1988. January-February: p. 45-53.

34. Drucker, P., The New Society of Organizations. 1992. (September-October): p. pp. 95-104.

35. Durfee, E.H. and V.R. Lesser. Using Partial Global Plans to Coordinate Distributed Problem Solvers. in International Joint Conference on Artificial Intelligence. 1987.

36. Eccles, R.G., Control with Fairness in Transfer Pricing. Harvard Business Review, 1983. November-December: p. 149-161.

37. Eccles, R.G. and D.B. Crane, Managing Through Networks in Investment Banking. California Management Review, 1987. 30(1): p. 176-195.

38. Eisenhardt, K., Agency Theory: An Assessment and Review. Academy of Management Review, 1989. 14(1): p. 5774.

39. Erman, L.D., et al., The Hearsay II Speech Understanding System: Integrating Knowledge to Resolve Uncertainty. Computing Surveys, 1980. 12(2): p. 213253.

40. Farrell, J. and G. Saloner, Standardization, Compatibility and Innovation. Rand Journal of Economics, 1985. 16(1): p. 70-83.

41. Filman, R.E. and D.P. Friedman, Coordinated Computing. 1984, New York: McGraw Hill.

42. Finholt, T. and L.S. Sproull, Electronic Groups at Work. Organizational Science, 1990. 1(1): p. 41-64.

43. Freeman, L.C., Centrality in Social Networks: Conceptual Clarification. Social Networks, 1979. 1: p. 215-239.

44. Galbraith, J.R., Organizational Design: An Information Processing View. Interfaces, 1974. 4(3): p. 28-36.

45. Gasser, L. and R.W. Hill, Coordinated Problem Solvers. Annual Review of Computer Science, 1990. 4: p. 203-253.
46. George, V.P., Technological Intensity and Interfirm Cooperation: An Industry Level Study of Alliance Networks of US Public Firms, 1985-19901994, MIT Sloan School: March, ICRMOT 102-94, Sloan 3663-94

47. Gerlach, M., Alliance Capitalism: The Social Organization of Japanese Business. 1992, Berkeley, CA: University of California Press.

48. Giddens, A., The Constitution of Society. Outlines of the Theory of Structuration. 1984, Cambridge: Polity Press.

49. Granovetter, M., The Strength of Weak Ties. American Journal of Sociology, 1973. 78(6): p. 1360-1380.

50. Granovetter, M., Problems of Explanation in Economic Sociology, in Networks and Organizations, N. Nohria and R.G. Eccles, Editors. 1993, Harvard Business School Press: Boston, MA. p. 471-491.

51. Grossman, S.J. and O.D. Hart, The Costs and Benefits of Ownership: A Theory of Vertical and Lateral Integration. Journal of Political Economy, 1986. 94(4): p. 691719.

52. Haines, V., Social Network Analysis, Structuration Theory and the HolismIndividualism Debate. Social Networks, 1988. 10: p. 157-182.

53. Hamel, G., Y.L. Doz, and C.K. Prahalad, Collaborate with Your Competitors -- and Win. Harvard Business Review, 1989. 67(1): p. 133-139.

54. Hammer, M., Reengineering Work: Don't Automate, Obliterate. Harvard Business Review, 1990. July-August: p. 104-112.

55. Hammer, M. and J. Champy, Reengineering the Corporation. 1993, New York: HarperCollins. 233.

56. Handy, C., Balancing Corporate Power: A New Federalist Paper. Harvard Business Review, 1992. (November-December): p. 59-73.

57. Hannan, M.T. and J. Freeman, The Population Ecology of Organizations. American Journal of Sociology, 1977. 82(5): p. 929-962.

58. Harrigan, K.R., Joint Ventures and Competitive Strategy. Strategic Management Journal, 1988. 9(2): p. 141158.

59. Harrison, J.M. and C.H. Loch, Operations Management and Reengineering1995, Stanford Business School: December,

60. Hart, O., An Economist's Perspective on the Theory of the Firm. Columbia Law Review, 1989. 89(7): p. 1757-1774. 
61. Hart, O. and J. Moore, Property Rights and the Nature of the Firm. Journal of Political Economy, 1990. 98(6): p. 1119-1157.

62. Hauser, J. and D. Clausing, The House of Quality. Harvard Business Review, 1988. 66(3): p. 63-73.

63. Hayek, F.A., The Use of Knowledge in Society. American Economic Review, 1945. 35(4): p. 3-17.

64. Hayes-Roth, B., A Blackboard Architecture for Control. Artificial Intelligence Journal, 1985. 26: p. 251-321.

65. Hewitt, C., Viewing Control Structures as Patterns of Message Passing. Journal of Artificial Intelligence, 1977. 8(3): p. 323364.

66. Howard, R., The CEO as Organizational Architect: An Interview with Xerox's Paul Allaire. Harvard Business Review, 1992. September-October: p. 107-121.

67. Huber, G.P., A Theory of the Effects of Advanced Information Technologies on Organizational Design, Intelligence, and Decision Making. Academy of Management Review, 1990. 15(1): p. 47-71.

68. Huber, G.P., Organizational Learning: The Contributing Processes and the Literatures. Organizational Science, 1991. 2(1): p. 88114.

69. Jaikumar, R., Postindustrial Manufacturing. Harvard Business Review, 1986. : p. 69-76.

70. Jarillo, C., On Strategic Networks. Strategic Management Journal, 1988. 9: p. 31-41.

71. Jarvenpaa, S.L. and B. Ives, The Global Network Organization of the Future: Information Management Opportunities and Challenges. Journal of Management Information Systems, 1994. 10(4): p. 2557.

72. Johnston, R. and P.R. Lawrence, Beyond Vertical Integration -- The Rise of the ValueAdding Partnership. Harvard Business Review, 1988. 66(4): p. 94-101.

73. Kanter, R.M., The Future of Bureaucracy and Hierarchy in Organizational Theory: A Report from the Field1989, Harvard Business School: April,

74. Kanter, R.M., The New Managerial Work. Harvard Business Review, 1989. November-December: p. 85-92.

75. Katz, M.L. and C. Shapiro, Network Externalities, Competition and Compatibility. American Economic Review, 1985. Vol. 75: p. pp. 70-83.

76. Kogut, B., Joint Ventures: Theoretical and Empirical Perspectives. Strategic Management Journal, 1988. 9: p. 319-332.
77. Kornfeld, W.A. and C. Hewitt, The Scientific Community Metaphor. IEEE Transactions on Systems, Man, and Cybernetics, 1981. 11(1): p. 24-33.

78. Krackhardt, D., The Strength of Strong Ties: The Importance of Philos in Organizations, in Networks and Organizations, N. Nohria and R.G. Eccles, Editors. 1993, Harvard Business School Press: Boston, MA. p. 216-239.

79. Lawrence, P.R. and J.w. Lorsch, Organization and Environment. 1967, Boston: Harvard University Press.

80. Leavitt, H.J., Unhuman Organizations. Harvard Business Review, 1962. : p. 90-98.

81. Leavitt, H.J. and T.L. Whisler, Management in the 1980s. Harvard Business Review, 1958. : p. 41-53.

82. Lesser, V.R. and D.D. Corkill, Functionally-Accurate, Cooperative Distributed Systems. IEEE Transactions on Systems, Man, and Cybernetics, 1981. 11(1): p. 81-96.

83. Lucas, H.C. and j. Baroudi, The Role of Information Technology in Organizational Design. Journal of Management Information Systems, 1994. 10(4): p. 9-23.

84. Malone, T.W., Modeling Coordination in Organizations and Markets. Management Science, 1987. 33(10): p. 1317-1332.

85. Malone, T.W., Organizing Information Processing Systems: Parallels Between Human Organizations and Computer Systems, in Cognition, Computation, and Cooperation, W. Zachary, S. Robertson, andJ. Black, Editors. 1989, Ablex Publishing: Norwood, NJ. p. 56-83.

86. Malone, T.W. and K. Crowston, The Interdisciplinary Study of Coordination1992, Center for Coordination Science: December,

87. Malone, T.W., K.L. Crowston, and B. Pentland, Tools for Inventing Organizations: Toward a Handbook of Organizational Processes.1992, MIT Center for Coordination Science:

88. Malone, T.W. and J.F. Rockart, Computers, Networks and the Corporation. Scientific American, 1991. 265(3): p. 128-136.

89. Malone, T.W. and S.A. Smith, Modeling the Performance of Organizational Structures. Operations Research, 1988. 36(3): p. 421-436.

90. Malone, T.W., J. Yates, and R.I. Benjamin, Electronic Markets and Electronic Hierarchies. Communications of the ACM, 1987. 30(6): p. 484-497. 
91. Markus, M.L., Power, Politics, and MIS Implementation. Communications of the ACM, 1983. 26(6): p. 430-444.

92. Markus, M.L. and D. Robey, Information Technology and Organizational Change: Causal Structure in Theory and Research. Management Science, 1988. 34(5): p. 583598.

93. Marschak, J. and R. Radner, Economic Theory of Teams. 1972, New Haven: Yale University Press.

94. Marsden, P., Restricted Access in Networks and Models of Power. American Journal of Sociology, 1983. 88: p. 686-717.

95. Meckling, W.H. and M.C. Jensen. Knowledge, Control and Organizational Structure. in Seminar on Analysis and Ideology. 1984. Interlaken, Switzerland:

96. Milgrom, P. and J. Roberts, Complementarities and Fit: Strategy, Structure, and Organizational Change in Manufacturing. Journal of Accounting and Economics, 1993. 19(2-3): p. 179.

97. Mills, D.Q., Rebirth of the Corporation. 1991, New York: John Wiley \& Sons. 320.

98. Minsky, M., The Society of Mind. 1985, New York: Simon and Schuster. 339.

99. Morgan, G., Images of Organization. 1986, Newbury Park, CA: Sage. 421.

100. Morgan, R.M. and S.D. Hunt, The Commitment-Trust Theory of Relationship Marketing. Journal of Marketing, 1994. 58: p. 20-38.

101. Nagel, R. and R. Dove, 21st Century Manufacturing Strategy -- An Industry Led View1992, Iacocca Institute, Lehigh University: March,

102. Nii, H.P., Blackboard Systems. AI Magazine, 1986. 7(3): p. 82-106.

103. Niman, N.B., Modeling Coordination in Organizations and Markets. Management Science, 1992. 38(12): p. 1819-1826.

104. Nohria, N. and R.G. Eccles, ed. Networks andOrganizations. 1993, Harvard Business School Press: Boston, MA. 544.

105. Nolan, R. and D. Croson, Creative Destruction. 1995, Boston: Harvard University Press. 259.

106. Nolan, R.L., A.J. Pollock, and J.P. Ware, Creating the 21st Century Organization. Stage by Stage, 1988. 8(4): p. 1-11.

107. Perrow, C., Small Firm Networks, in Networks and Organizations, N. Nohria and R.G. Eccles, Editors. 1993, Harvard Business School Press: Boston, MA. p. 445-470.

108. Peteraf, M., The Cornerstones of Competitive Advantage: A Resource-Based
View. Strategic Management Journal, 1993. 14: p. 179-191.

109. Peters, T., Liberation Management: Necessary Disorganization for the Nanosecond Nineties. 1992, New York: Alfred A. Knopf Inc. 834.

110. Pfeffer, J., Power in Organizations. 1981, HarperBusiness. 391.

111. Piore, M.J., Fragments of a Cognitive Theory of Technological Change and Organizational Structure, in Networks and Organizations, N. Nohria and R.G. Eccles, Editors. 1993, Harvard Business School Press: Boston, MA. p. 430-444.

112. Powell, W.W., Neither Market Nor Hierarchy: Network Forms of Organization. Research in Organizational Behavior, 1990. 12: p. 295-336.

113. Powell, W.W. and P. Brantley, Competitive Cooperation in Biotechnology: Learning through Networks?, in Networks and Organizations, N. Nohria and R.G. Eccles, Editors. 1993, Harvard Business School Press: Boston, MA. p. 366-394.

114. Quinn, J., H. Mintzberg, and R. James, The Strategy Process. 1988, Englewood Cliffs, NJ: Prentice Hall. 998.

115. Quinn, J.B., Intelligent Enterprise. 1992, New York: Free Press. 473.

116. Radner, R., Hierarchy: The Economics of Managing. Journal of Economic Literature, 1992. XXX: p. 1382-1415.

117. Ring, P.S. and A.H. Van de Ven, Structuring Cooperative Relationships Between Organizations. Strategic Management Journal, 1992. 13: p. 483-498.

118. Roberts, E., New Ventures for Corporate Growth. Harvard Business Review, 1980. 58(4): p. 134-132.

119. Rockart, J.F., C.V. Bullen, and J.S. Leventer, Centralization vs. Decentralization of Information Systems1977, Center for Information Systems Research, MIT Sloan School: April, (Unpublished Manuscript)

120. Rockart, J. and J. Short, The Networked Organization and the Management of Interdependence, in The Corporations of the 1990s, M.S. Morton, Ed. 1991, p. 189-216.

121. Sabel, C., Moebius-Strip Organizations and Open Labor Markets: Some Consequences of the Reintegration of Conception and Execution in a Volatile Economy, in Social Theory for a Changing Society, P. Bairdieu and J.S. Coleman, Editors. 1991, Westview Press: Boulder, CO. p. 23-61.

122. Sah, R. and J. Stiglitz, The Architecture of Economic Systems: Hierarchies and 
Polyarchies. American Economic Review, 1986. 76(4): p. 716-727.

123. Sailer, L.D., Structural Equivalence: Meaning and Definition, Computation and Application. Social Networks, 1978. 1(1): p. 73-90.

124. Serfaty, D. and D.L. Kleinman. Adaptation Processes in Team Decision Making and Coordination. in IEEE Symposium on Systems, Man, and Cybernetics. 1990.

125. Simon, H., Administrative Behavior. 3rd. ed. 1976, New York: Free Press.

126. Simon, H., The Sciences of the Artificial. 2 ed. 1992, Cambridge, MA: MIT Press. 247.

127. Smith, A., The Wealth of Nations. 1976, Chicago: University of Chicago Press. 568.

128. Snow, C.C., R.E. Miles, and H.J. Coleman, Managing 21st Century Network Organizations. Organizational Dynamics, 1992. 20(3): p. 5-20.

129. Sproull, L. and S. Kiesler, Reducing Social Context Cues: Electronic Mail in Organizational Communication. Management Science, 1986. 32(11): p. 1492-1512.

130. Tanenbaum, A., Structured Computer Organization. 1976, Englewood Cliffs, NJ: Prentice-Hall. 443.

131. Tully, S., The Modular Corporation, in Fortune1993, p. 106-114.

132. Van de Ven, A.H. and G. Walker, The Dynamics of Interorganizational Coordination. Administrative Science Quarterly, 1984. 29: p. 598-621.

133. Varian, H., Microeconomic Analysis. 3rd ed. 1992, New York: W. W. Norton \& Company.

134. von Hippel, E., The Sources of Innovation. 1988, New York: Oxford University Press. 218.

135. Weick, K., Technology as Equivoque, in Technology and Organizations, P. Goodman, Sproull, L. S., and Associates, Editor. 1990, Jossey-Bass: San Francisco. p. 1-44.

136. Weick, K.E., Educational Organizations as Loosely Coupled Systems. Administrative Science Quarterly, 1976. 21: p. 1-19.

137. Weick, K.E., Management of Organizational Change Among Loosely Coupled Elements, in Change in Organizations, G. Associates, Editor. 1982, Jossey-Bass: San Francisco. p. 375-408.

138. Whetten, D.A., Interorganizational Relations: A Review of the Field. Journal of Higher Education, 1981. 52(1): p. 1-28.

139. White, H., Identity and Control. 1992, Princeton, NJ: Princeton University Press.
140. White, H., Agency as Control in Formal Networks, in Networks and Organizations, N. Nohria and R.G. Eccles, Editors. 1993, Harvard Business School Press: Boston, MA. p. 92-117.

141. White, H.C., S.A. Boorman, and R.L. Breiger, Social Structure from Multiple Networks I -- Blockmodels of Roles and Positions. American Journal of Sociology, 1976. 81(4): p. 730-780.

142. Williamson, O.E., Markets and Hierarchies. 1975, New York: North-Holland.

143. Williamson, O.E., Transaction Cost Economics, in Handbook of Industrial Organization, R. Schmalensee and R.D. Willig, Editors. 1989, North-Holland: New York. p. 136-181.

144. Zuboff, S., In The Age of the Smart Machine. 1988, New York: Basic Books, Inc. 


\section{APPENDIX A -- ILLUSTRATION OF A SOLUTION TO THE PUBLIC GOODS PROBLEM}

The following describes in mathematical terms the Groves-Clarke mechanism that appears to have emerged in the financial community. ${ }^{25}$ Team members get to claim the full value of a project for his or her department if they win a contract and costs are shared equiproportionally among team mates. In addition, each person receives a bonus at the end of the year which may approach five to ten times base salary. Among other factors, these bonuses are distinguished by their decoupling from "seniority or formal hierarchical position" [37 p. 188] and by their heavy reliance on cross-evaluation surveys in which bankers rate one another. Projects are won or lost depending on total effort and successful bids may qualify a bank for future projects with the same client. Putting these data into variable form, the total value, $\mathrm{V}_{\mathrm{i}}$, of a project to an individual is his reservation value for this and future projects, $\mathrm{R}_{\mathrm{i}}$, net of his share, S, of costs, C, and his level of effort, $\mathrm{E}_{\mathrm{i}}$. More concisely

$$
\mathrm{V}_{\mathrm{i}}=\mathrm{R}_{\mathrm{i}}-\mathrm{E}_{\mathrm{i}}-\mathrm{SC}
$$

It only makes sense to undertake a project if the sum of participants' values, net of costs, results in a surplus or $\sum V_{i}=\sum\left(R_{i}-E_{i}-S C\right)>0$. Although this sum is efficient for purposes of undertaking a project, the question is whether individuals have an incentive to freeload on the group, i.e. declare something less than $\mathrm{V}_{\mathrm{i}}$, or to exaggerate, i.e. declare something greater than $\mathrm{V}_{\mathrm{i}}$. The cross-evaluation forms and the multiple counting of project wins allow team members to credit one another with the value of their contribution at the time of bonus determination. Letting the bonus determination be $\mathrm{B}_{\mathrm{i}}$, and assuming that projects are won if the sum of private values (net of effort, etc.) is sufficiently high, then the form of Groves-Clarke mechanism effectively used by investment banks appears to be:

$$
\text { payoff to } \mathrm{i}=\left\{\begin{array}{ll}
\mathrm{V}_{\mathrm{i}}+\sum_{\mathrm{j} \neq \mathrm{i}} \mathrm{B}_{\mathrm{j}} & \text { if } \mathrm{B}_{\mathrm{i}}+\sum_{\mathrm{j} \neq \mathrm{i}} \mathrm{B}_{\mathrm{j}} \geq 0 \\
0 & \text { if } \mathrm{B}_{\mathrm{i}}+\sum_{\mathrm{j} \neq \mathrm{i}} \mathrm{B}_{\mathrm{j}}<0
\end{array}\right\}
$$

If one supposes that $\mathrm{V}_{\mathrm{i}}+\sum_{\mathrm{j} \neq \mathrm{i}} \mathrm{B}_{\mathrm{j}} \geq 0$, then it makes sense for an individual to honestly declare $V_{i}$ as his

\footnotetext{
${ }^{25}$ More sophisticated versions of the Groves-Clarke mechanism requiring no outside subsidy are possible but still not budget balancing [133].
}

appropriate value for winning the project and that this value be used in setting bonuses for others. In contrast, if $\mathrm{V}_{\mathrm{i}}+\sum_{\mathrm{j} \neq \mathrm{i}_{\mathrm{j}}}<0$, then an individual still has an incentive to honestly declare $\mathrm{V}_{\mathrm{i}}$ because the project is privately too costly. No one has an incentive to work harder than their reservation level of effort because there are no increasing returns to effort. Once the contract is won, each receives its total value net of equiproportional costs. Likewise, there is no incentive to underperform or "free ride" since reduced effort almost certainly eliminates the possibility of winning the contract and any bonus derived therefrom. 